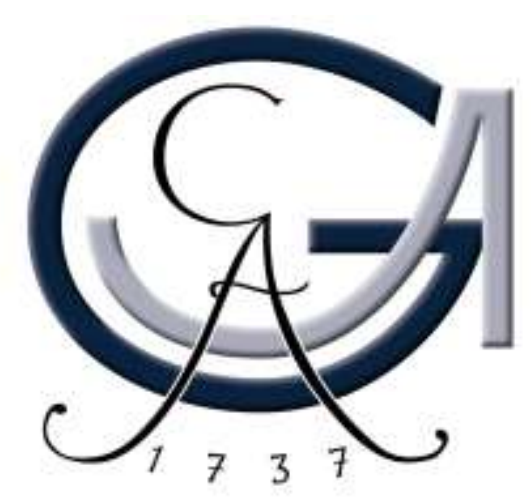

\title{
Epigenetic Modulation in Alzheimer's disease: Function of Hippocampal microRNAs
}

\author{
Dissertation \\ for the award of the degree \\ "Doctor rerum naturalium" \\ of the Georg-August-Universität Göttingen
}

within the doctoral program Molecular Physiology of the Brain

of the Georg-August University School of Science (GAUSS)

\author{
Submitted by: \\ Maryam Boroomandi \\ Born in Marvdasht, Iran
}

Göttingen

2015 
For Mahbanoo 


\section{PhD Thesis Committee:}

- Prof. Dr. Mikael Simons: Max Planck Institute for experimental medicine, University Medical Center, Göttingen (Referent)

- Prof. Dr. André Fischer: Deutsches Zentrum für Neurodegenerative Erkrankungen (DZNE), University Medical Center, Göttingen (Co-referent)

- Prof. Dr. Anja Schneider: Deutsches Zentrum für Neurodegenerative Erkrankungen (DZNE), University Medical Center, Göttingen

\section{Examination Committee:}

Members of the $\mathrm{PhD}$ thesis committee and:

- Prof. Dr. Michael Hörner: Johann Friedrich Blumenbach Institute for Zoology and Anthropology and Center for Molecular Physiology of the Brain (CMPB), GeorgAugust-Universität, Göttingen

- Prof. Dr. Gregor Eichele: Max Planck Institute for Biophysical Chemistry Deptartment of Genes and Behaviour, Göttingen

- Prof. Dr. Tiago Fleming Outeiro: University Medical Center Göttingen Deptartment of NeuroDegeneration and Restaurative Research, Göttingen

Date of oral examination: 21.7.15 


\section{Declaration}

I herewith declare that I have prepared the dissertation 'Epigenetic modulation in Alzheimer's disease: function of hippocampal microRNAs' entirely by myself with no other aids or sources than quoted.

29.5.2015, Göttingen

Maryam Boroomandi 


\section{Table of contents}

List of figures

\section{Introduction}

1.1 Memory deterioration with aging and Alzheimer's disease

1.1.1 Brain and memory organization 2

1.1.2 Memory storage regions in the brain 3

1.1.3 Biological and molecular basis of memory 4

1.1.4 Genetic basis of memory formation 4

1.1.5 Impact of aging on brain gene expression 4

1.1.6 Epigenetic mechanisms in Alzheimer's disease $\quad 5$

1.1.7 Non-coding RNAs 6

1.1.8 MicroRNA 7

1.1.9 Biogenesis of the miRNA

1.1.10 MiRNAs in the central nervous system

1.1.11 MiRNA potential as biomarker 10

1.1.12 MiRNA detection and profiling approaches 11

1.2 MiRNAs as therapeutic targets in Alzheimer's disease $\quad 12$

1.2.1 Exosomes 12

1.2.2 Biogenesis of the exosomes 13

1.2.3 Composition of the exosomes 14

1.2.4 Function of the exosomes 14

1.2.5 Exosomes as delivery vehicles 14

1.3 Project objectives 17

\section{Materials and Methods}

2.1 Materials 19

2.1.1 Animals 19

2.1.2 Antibodies 19

2.1.3 Plasmids 19

2.1.4 Buffers and solutions $\quad 20$

2.1.5 Media and Sera 21

2.1.6 Commercial kits 21

2.2. Methods 22

2.2.1 RNA Isolation 22

2.2.2 RNA quantity and quality 22

2.2.3 Library preparation 23

2.2.4 Bioinformatics and statistical analysis 23

2.2.5 Statistical analysis of next-generation sequencing data 23

2.2.6 Cell culture and exosomes 24

2.2.7 Freezing of cells 24

2.2.8 Thawing of cells 24

2.2.9 Growth and maintenance of cells

2.2.10 Transformation of E. coli 25

2.2.11 Plasmid DNA isolation from E. coli 25

2.2.12 DNA concentration measurement 26

2.2.13 Transfection of plasmids 26

2.2.14 Exosome collection and preparation $\quad 26$

2.2.15 Determination of the exosome protein concentration 27

2.2.16 Electroporation 27

2.2.17 Luminometer analysis $\quad 27$

2.2.18 Western blot analysis 


\section{Results}

3.1 Molecular changes in brain aging 31

3.1.1 Small RNAome of memory subregions in adult mouse brain 31

3.1.2 MiRNA profile of memory subregions differs in young and old mice

3.1.3 Blood small RNAome changes along aging 46

3.1.4 Other small RNAs in brain and blood 55

3.2 MiRNAs as therapeutic targets in Alzheimer's disease

3.2.1 Measles virus glycoproteins can be sorted in the exosomes

3.2.2 Modification of the exosomes with the measles virus glycoproteins did not change $\quad 60$ efficiency of the cargo delivery

\section{Discussion}

4.1 Impact of aging on the brain

4.1.1 Small RNA expression in memory subregions changes with aging 63

4.1.2 MiRNAome changes along aging in memory subregions distinctly

4.1.3 Aging-associated inflammatory and immune system activation pathways 65

4.1.4 MiRNA as a predictive biomarker $\quad 65$

4.1.5 Choice of biofluid for biomarker studies $\quad 66$

4.1.6 Blood indicates changes in the aging brain 66

4.2 MiRNA as therapeutic target $\quad 68$

4.2.1 Neuronal targeting of the exosomes 68

4.2.2 Loading the exosomes with desired cargo

\section{Conclusion}

5.1 Aging-associated changes in miRNA expression profile $\quad 71$

5.2 Exosomal delivery of miRNA inhibitory molecules

6. Summary

$\begin{array}{ll}\text { 7. References } & 75\end{array}$

8. Acknowledgements 90

9. Appendices $\quad 92$ 


\section{List of figures}

\begin{tabular}{|c|c|c|}
\hline Fig. 1.1.1 & Canonical pathway of biogenesis of microRNA. & 8 \\
\hline Fig. 1.2.1 & Formation of MVE and release of exosomes in extracellular milieu. & 13 \\
\hline Fig. 3.1.1 & Distribution frequency of mapped small RNA class reads. & 31 \\
\hline Fig. 3.1.2 & Number of expressed miRNAs in different brain subregions of young mice. & 33 \\
\hline Fig. 3.1.3 & $\begin{array}{l}\text { Correlation (Pearson) matrix of miRNAome expression patterns between different } \\
\text { brain subregions in young mice. }\end{array}$ & 34 \\
\hline Fig.3.1.4 & Morris water maze experiment. & 35 \\
\hline Fig. 3.1.5 & Distribution frequency of mapped small RNA class reads in aged mice. & 36 \\
\hline Fig. 3.1.6 & Number of expressed miRNAs in different brain subregions of old mice. & 37 \\
\hline Fig. 3.1.7 & $\begin{array}{l}\text { Heat maps show the Euclidean distances between the differentially expressed } \\
\text { miRNAs in brain subregions of old over young animals. }\end{array}$ & $\begin{array}{l}39- \\
40\end{array}$ \\
\hline Fig. 3.1.8 & Number of the differentially expressed miRNAs in the brain subregions. & 41 \\
\hline Fig. 3.1.9 & $\begin{array}{l}\text { Correlation (Pearson) matrix of miRNAome expression patterns between different } \\
\text { brain subregions in aged mice. }\end{array}$ & 41 \\
\hline Fig. 3.1.10 & $\begin{array}{l}\text { Venn diagram shows commonly upregulated miRNAs in brain subregions upon } \\
\text { aging }\end{array}$ & 43 \\
\hline Fig. 3.1.11 & $\begin{array}{l}\text { Venn diagram shows the commonly downregulated miRNAs in all brain subregions } \\
\text { upon aging. }\end{array}$ & 44 \\
\hline Fig. 3.1.12 & $\begin{array}{l}\text { The bar graph shows that miRNA are the most abundant class of small RNAs in } \\
\text { blood of young and aged mice. }\end{array}$ & 46 \\
\hline Fig. 3.1.13 & $\begin{array}{l}\text { Blood miRNA population by frequency of uniquely mapped reads in young and in } \\
\text { old mice. }\end{array}$ & 47 \\
\hline Fig. 3.1.14 & $\begin{array}{l}\text { Heat map shows the correlation between miRNAs in the brain and blood in both } \\
\text { young and old group. }\end{array}$ & 48 \\
\hline Fig. 3.1.15 & Heat map shows the differential miRNA expression changes in blood of old mice. & 49 \\
\hline Fig. 3.1.16 & $\begin{array}{l}\text { Venn diagrams show the number of unique and overlapping upregulated miRNAs } \\
\text { between the separate brain regions and blood in the old mice. }\end{array}$ & 50 \\
\hline Fig. 3.1.17 & $\begin{array}{l}\text { Venn diagrams show the number of unique and overlapping downregulated miRNAs } \\
\text { between the separate brain regions and blood in the old mice. }\end{array}$ & 51 \\
\hline Fig. 3.1.18 & $\begin{array}{l}\text { Venn diagrams show the number of unique and overlapping upregulated and down } \\
\text { regulated miRNAs between the whole brain subregions and blood in the old mice. }\end{array}$ & 53 \\
\hline Fig. 3.1.19 & $\begin{array}{l}\text { Top } 10 \text { canonical pathways that are linked to commonly downregulated and } \\
\text { commonly upregulated miRNAs in brain regions and blood. }\end{array}$ & 54 \\
\hline Fig. 3.1.20 & $\begin{array}{l}\text { Heat map shows the Euclidean distances between the differentially expressed } \\
\text { snoRNAs in ACC, DG, CA1 and CA } 3 \text { from old over young animals. }\end{array}$ & $\begin{array}{l}56- \\
57\end{array}$ \\
\hline Fig. 3.1.21 & $\begin{array}{l}\text { PiwiRNA population by frequency of uniquely mapped reads in blood samples from } \\
\text { young and old mice. }\end{array}$ & 58 \\
\hline Fig. 3.2.1 & $\begin{array}{l}\text { Exemplary picture of the western blot analysis of the protein preparations from the } \\
\text { exosomes from the cell culture medium and } \mathrm{N} 2 \mathrm{a} \text { cell lysates. }\end{array}$ & 60 \\
\hline Fig. 3.2.2 & Results of the luminometer analyses of exosomal delivery of $3 \mu \mathrm{g}$ GL3 siRNA. & 61 \\
\hline Fig. 3.2.3 & Results of the luminometer analyses of exosomal delivery of $10 \mu \mathrm{g}$ GL3 siRNA. & 61 \\
\hline
\end{tabular}




\section{List of tables}

\begin{tabular}{lll}
\hline Table 1.1 & Studies, which used exosomes as delivery vehicles. & 15 \\
\hline Table 2.1 & Primary antibodies & 19 \\
\hline Table 2.2 & Plasmids obtained from other laboratories & 19 \\
\hline Table 2.3 & Phosphate buffered saline (PBS) & 20 \\
\hline Table 2.4 & CHAPS lysis buffer (The pH was adjusted to 8). & 20 \\
\hline Table 2.5 & Components of 400 $\mu$ 1 Electroporation buffer & 20 \\
\hline Table 2.6 & Protein loading buffer (The pH was adjusted to 6.8) & 21 \\
\hline Table 2.7 & Commercially available media, sera, and additives & 21 \\
\hline Table 2.8 & Commercial kits used in this study & 22 \\
\hline Table 2.9 & The exact volume of each solution for RNA isolation per brain tissue & 28 \\
\hline Table 2.10 & Stacking gel used for electrophoresis & 29 \\
\hline Table 2.11 & Resolving gel (10 or 12 \%) & 45 \\
\hline Table 3.1 & List of miRNAs that are upregulated and downregulated along aging specifically in & 45 \\
& each memory subregion & \\
\hline
\end{tabular}




\section{List of abbreviations}

\begin{tabular}{|c|c|}
\hline 3' UTR & 3' untranslated region \\
\hline A-beta & Amyloid beta \\
\hline $\mathrm{ACC}$ & Anterior cingulate cortex \\
\hline $\mathrm{AD}$ & Alzheimer's disease \\
\hline Ago2 & Argonaute \\
\hline ApoE4 & Apolipoprotein E4 \\
\hline APP & Amyloid precursor proteins \\
\hline APS & Ammonium persulfate \\
\hline CA & Cornu ammonis \\
\hline cAMP & Cyclic adenosine monophosphate \\
\hline CHAPS & 3-[(3-cholamidopropyl) dimethylammonio]-1-propanesulfonate \\
\hline CREB & cAMP response element-binding protein \\
\hline $\mathrm{CSF}$ & Cerebrospianl fluid \\
\hline DG & Dentate gyrus \\
\hline DGCR8 & DiGeorge Syndrome Critical Region 8 \\
\hline DMEM & Dulbecco's Modified Eagle Medium \\
\hline EDTA & Ethylenediaminetetraacetic acid \\
\hline ESCRT & Endosomal sorting complex required for transport \\
\hline EV & Extracellular vesicles \\
\hline $\mathrm{F}$ & Fusion protein \\
\hline $\mathrm{FCS}$ & Fetal Calf Serum \\
\hline FD & Frontotemporal Dementia \\
\hline FGFR1 & Fibroblast growth factor receptor 1 \\
\hline FTLD-17 & Frontotemporal Lobar Dementia linked to chromosome 17 \\
\hline G418 & Geneticin \\
\hline GTP & Guanosine-5'-triphosphate \\
\hline $\mathrm{H}$ & Hemagglutinin protein \\
\hline HM & Henry Molaison \\
\hline HRP & Horseradish peroxidase conjugated antibodies \\
\hline HT1080-Luc & Human fibrosarcoma cell line with luciferase activity \\
\hline IEG & Immediate early genes \\
\hline long-ncRNA & long non-coding RNAs \\
\hline MAPK & Mitogen activated protein kinase \\
\hline miRNA & Micro RNAs \\
\hline miscRNA & miscellaneous RNAs \\
\hline mRNA & Messenger RNA \\
\hline MVBs & Multivesicular bodies \\
\hline MVG & Measles virus glycoprotein \\
\hline $\mathrm{N} 2 \mathrm{a}$ & Mouse neuroblastoma cell line \\
\hline NFkB & nuclear factor kappa-light-chain-enhancer of activated B cells \\
\hline ncRNA & Non-coding RNAs \\
\hline NGS & Next Generation Sequencing \\
\hline NSC & Neural stem cells \\
\hline PBMC & Peripheral blood mononuclear cells \\
\hline PBS & Phosphate buffered saline \\
\hline PCA & Principal component analyses \\
\hline $\mathrm{PD}$ & Parkinson's Disease \\
\hline Pen/Strep & Penicillin/Streptomycin \\
\hline piwiRNA & Piwi-interacting RNA \\
\hline precursor-miRNA & Pre-miRNA \\
\hline pri-miRNA & Primary miRNA \\
\hline PSEN & presenilin gene \\
\hline qRT-PCR & Quantitative real time polymerase chain reaction \\
\hline
\end{tabular}




\begin{tabular}{|ll|}
\hline Ran & RAs-related Nuclear protein \\
RISC & RNA-induced silencing complex \\
RNAi & RNA interference \\
rRNA & Ribosomal RNA \\
RVG & Rabid virus glycoproteins \\
SDS & Sodium dodecyl sulphaste \\
siRNA & Small interfering RNAs \\
snoRNA & Small nucleolar RNA \\
snRNA & Small nuclear ribonucleic RNA \\
TEMED & N'N'N'-tetramethylethylene diamine \\
TOD & Tangle-only Dementia \\
tPA & Tissue plasminogen activator \\
TRBP & RNA-binding protein \\
tRNA & Transfer RNA \\
Zif268 & Zinc-finger protein \\
\hline
\end{tabular}




\section{Introduction}




\subsection{Memory deterioration with aging and Alzheimer's disease}

Aging is a complex biological mechanism, which can be defined as the accumulation of processes that decline many physiological functions and simultaneously increase chance of mortality in animals as well as humans. Along with many other functions of the body, aging massively declines the ability to learn and remember. Neurodegeneration is the process of neuronal cell damage, which accelerate dramatically with aging and could lead to Alzheimer's disease (AD). Loss of neurons and disease manifestation are rather late events in the progression of $\mathrm{AD}$ when therapeutic interventions are no longer effective.

Diagnosis of $\mathrm{AD}$ in its asymptomatic phases provides the possibility of adequate therapeutic interventions. Hence, the needs for finding new and non-invasive methods for diagnosis of the pathology of $\mathrm{AD}$ are urgent. The following sections summarize the current knowledge about the molecular changes that occur in the brain and in biofluids during aging, with a focus on identifying novel and non-invasive diagnostic and therapeutic candidates.

\subsubsection{Brain and memory organization}

Learning and memory are two unique functions of the brain enabling the organism to acquire and retrieve an imagination of itself and its world. Learning can be described as encoding of the data while memory is the process of recalling the data. According to the time span that it can be stored, memory is subdivided into two major subtypes: short-term and long-term. 1) Short-term memory is the kind of memory that stores information temporarily, which can be recalled shortly thereafter. 2) Long-term memory requires retrieval of information from the past. This information could be from a few minutes ago or along time ago. Long-term memory itself can be divided into implicit and explicit memory. Explicit memory is dependent on consciousness for storage of information such as memory of an event or specific names. In contrast, implicit memory does not need consciousness and is present in non-mammalian vertebrates and even invertebrates. Implicit memory is also called non-declarative memory and refers to remembering skills such as walking or swimming. Explicit or declarative memory itself is divided into episodic and semantic memory (Tulvig, 1983). Episodic memory is about events, such as of places and time while semantic memory refers to the stored information about the world (Squire et al., 1993). 


\subsubsection{Memory storage regions in the brain}

The hippocampus is a neuroanatomical structure that is part of the limbic system and is present in all mammals. It is perhaps the most studied part of the brain and it has been widley established that the hippocampus is responsible for memory, learning and spatial navigation functions. A large body of our knowledge about hippocampus and its significant role in short-term and long-term memory comes from Brenda Milner's pioneering studies on the patient Henry Molaison (known as HM, died at 2008) that suffered from severe epilepsy so that his medial temporal lobe was removed via surgery. Following surgery HM's brain was unable to convert short-term memory to new long-term memory, while he could remember older events that had occurred before the surgery very well. Milner has studied this patient for almost thirty years and thanks to her reports now we have a comprehensive knowledge about different types of memories and the role of hippocampus in memory (Scoville and Milner, 1957).

Hippocampus or hippocampal formation has subregions called dentate gyrus (DG) and cornu ammonis (CA). CA itself is divided into three subdivisions CA1, CA2, CA3. Among these subdivisions CA1 and CA3 have distinct functions. There are three important connectional pathways in the hippocampus namely the Schaffer-collateral pathway, the perforant pathway and the mossy fiber pathway. The Schaffer-collateral pathway refers to the path between CA1 and CA3. Axons of the perforant path convey sensory information from neurons in entorhinal cortex to the DG. Mossy fiber pathway refers to the DG unmyelinated axons that project to CA3. These pathways create hippocampal trisynaptic loop (Amarel et al., 2006).

The anterior cingulate cortex (ACC) is part of the limbic system and in humans is involved in attention that regulates emotion and cognition (Bush et al., 2000). One example for this function is error detection, which was first, described by the American psychologist John Ridley Stroop and subsequently is called Stroop effect (Stroop, 1935). The stroop effect is referred to a conflict-urging stimulus by reading color names, which are denoted in corresponding versus not corresponding colors. However it has been shown that ACC along with posterior cingulate cortex go under profound laminar loss in AD (Scheff and Price, 2001).

In rodents ACC plays an important role in long-term memory formation (Weible et al., 2012). 


\subsubsection{Biological and molecular basis of memory}

Pioneering studies performed by Eric Kandel and his colleagues on Aplysia paved the way to have a clear understanding of memory formation and consolidation at the molecular level. These studies showed that short-term memory is formed upon the increase in the concentration of cyclic adenosine monophosphate (cAMP) in the sensory neurons, which initiates by a stimulus and neurotransmitter secretion. All these processes finally lead to increased concentration of glutamate receptor in the synaptic cleft (Brunelli et al., 1976). Also from vast amount of studies on long-term memory consolidation it came out that the formation of long-term memory requires new protein synthesis and subsequently new gene expression. An important protein expression, which is expressed and activated during longterm memory consolidation, is cAMP response element-binding protein (CREB). CREB activation occurs after persistent elevation in the amount of cAMP and mitogen activated protein kinase (MAPK) levels (Bacskai et al., 1993).

\subsubsection{Genetic basis of memory formation}

As mentioned above, long-term memory formation needs de novo protein synthesis: hence, immediate early genes (IEG) come into play. These genes get activated in response to the stimuli with cellular basis and start the transcription process for new protein synthesis. The majority of IEGs are transcription factors like c-Fos, c-Myc, c-Jun, Egr1 and zinc-finger protein Zif268 (Guzowski et al., 2002) Zif268 has a crucial role in consolidation and reconsolidation of different forms of explicit memories (Veyrac et al., 2014). There are also non-transcription factor genes like Arc and a tissue plasminogen activator (tPA) that get activated during long-term memory formation (Qian et al., 1993).

\subsubsection{Impact of aging on brain gene expression}

Aging is the process of getting older over time. Different biological changes are happening in an organism during aging, e.g. reduced ability to regenerate the damages or coping with stress, and consequently increased risk of diseases. The risk for cognitive diseases also drastically increases because brain tissue goes under the process of aging as well. Since the hippocampus has a significant role in memory consolidation, it is one of the first regions that will suffer in memory-associated diseases such as AD. However the major 
changes happening in the hippocampus are not on the morphological level but at the gene expression level leading to some functional modifications, like changes in the synaptic properties of hippocampal cells (Burger, 2010).

\subsubsection{Epigenetic mechanisms in Alzheimer's disease}

The term 'epigenetic' was introduced to biology by Conrad Waddington. Nowadays epigenetic is defined as mitotically and meiotically heritable changes in gene expression without a change in the DNA sequence. DNA methylation, histone acetylation and RNAmediated gene silencing are considered as major epigenetic modulations in eukaryotic cells. They play important roles in development and gene regulation. These mechanisms can also underlie cancer and neurodegeneration mechanisms (Klose and Bird, 2006; Jones and Baylin, 2002; Baylin and Ohm, 2006; Qureshi and Mehler, 2013).

Neurodegeneration in $\mathrm{AD}$ is associated with two abnormal protein aggregations: neurofibrillary tangles and the amyloid-beta (A-bet) plaques. Neurofibrillary tangles or insoluble aggregates of tau protein are one of the crucial hallmarks of $\mathrm{AD}$ and other neurodegenerative diseases grouped as taupathies, diseases like Niemann Pick disease (Auer et al., 1995), Frontotemporal Lobar Dementia linked to chromosome 17 (FTLD-17) (Mackenzie and Rademakers, 2007) and Tangle-only Dementia (TOD) (Yamada, 2003).

These amyloid plaques are the result of the $\beta$ and $\gamma$ secretases enzymatic action on amyloid precursor proteins (APP).

Besides aging, a combination of genetic and environmental factors have been considered as risk factors for sporadic form of AD. From genetic point of view, the disease can be caused by autosomal dominant mutations in the amyloid precursor protein (APP) or presenilin gene (PSEN). However these familiar forms account for only approximately $5 \%$ of the disease and the majority of $\mathrm{AD}$ patients suffer from the sporadic form with Apolipoprotein $\mathrm{E}$ (ApoE4) genotype. As previously mentioned another crucial risk factor for this disease etiology is the environment. Epigenetic mechanisms in combination with environmental factors regulate gene expression at the systems level. Epigenetic modifications are manifested at different levels of the gene expression machinery: modifications of histone proteins and DNA methylation exert a direct effect at gene-transcription levels while miRNAs influence posttranscriptional mechanisms. Aside from that, non-coding RNAs (ncRNA) play important 
roles in hereditary changes of DNA-methylation in response to environmental factors. These molecules might contribute to the increased risk of sporadic AD that is reported among first grade relatives of AD patients (Malecova and Morris, 2010).

\subsubsection{Non-coding RNAs}

Non-coding RNAs are functional RNAs that are transcribed from DNA and as their name suggests do not encode proteins. Instead they have regulatory roles in gene expression. Non-coding RNAs include long and small non-coding RNAs. Long non-coding RNAs have over 200 nucleotides while small non-coding RNAs have usually less than 200 nucleotides. Long non-coding RNAs (long-ncRNA) have epigenetic regulatory roles in transcription, splicing and imprinting (Mercer et al. 2009). One well-known small non-coding RNAs is transfer RNA (tRNA), which is involved in protein synthesis by mediating amino acid transfer (Phizicky and Hopper 2010). Another small non-coding RNA is ribosomal RNA (rRNA) found in the ribosome and is involved in protein translation (Stults et al., 2008). Another small non-coding RNAs are small nucleolar RNA (snoRNA) which acts in the processing and modifications of other non-coding RNAs like rRNA (Holley and Topkara, 2011), small nuclear RNA (snRNA) which is involved in splicing, (Valadkhan, 2005), small interfering RNAs (siRNA) has a significant role in RNA interfering pathway and can splice mRNA in site-specific manner (Kawaji and Hayashizaki, 2008), Piwi-interacting RNA (piwiRNA) is so named because of its interaction with Piwi proteins and have posttranscriptional roles specially in germ line cells (Lin, 2007), and microRNAs (miRNA) which are very well known because of their important role in posttranscriptional gene expression modification in different organism life time, like development, growth and even diseases (Bartel 2004). In the present study the main concentration was on the miRNA profiling and expression, so the next parts deal with miRNA properties and biosynthesis. 


\subsubsection{MicroRNA}

MicroRNA (miRNA) constitutes a class of endogenous non-coding small RNAs, which is single-stranded in its mature form and consists of 18-25 nucleotides and regulates gene expression. MiRNAs are found abundantly in plant and animal cells and hence they are well conserved through the evolution, it can be claimed that miRNAs are crucial components of the gene regulation system (Chen and Rajewsky, 2007). The function of miRNAs as gene expression regulators was described in early 2000 (Reinhart et al., 2000; Lagos-Quintana, 2001) although they were discovered few years earlier in C. elegans (Lee et al., 1993). Up to now, over 1800 different miRNAs have been identified in humans. The largest and most distinct number of all presently identified miRNAs is expressed in the brain, where they have been implicated in neuronal differentiation, development and synaptic function (Bartel, 2004, Motti et al., 2012). Interestingly one miRNA can regulate several different downstream targets, in line with that dysregulation of the neuronal miRNAs could have a deleterious effect on neuronal function and survival. Also many studies have shown that some miRNAs in AD brain are deregulated including miRNAs that target the expression of APP or APP processing secretases (Satoh, 2010, Cogswell et al., 2008; Herbert et al. 2008; Schonrock et al., 2010; Shioya et al., 2010; Smith et al., 2011).

\subsubsection{Biogenesis of the miRNA}

The canonical process of miRNA biogenesis is pictured in Fig. 1.1.1. However, there are also many miRNAs that are generated via alternative mechanisms (Miyoshi et al., 2010). MiRNAs are either derived from intronic sequences, intergenic regions or encoded by clusters like a polycistronic transcript (Lagos-Quintana, 2001). MiRNA genes are transcribed by either RNA polymerase II or RNA polymerase III into primary miRNA transcripts (Lee et al., 2004; Cai et al., 2004; Borchert et al., 2006) primary miRNA (pri-miRNA), which is a hairpin structure, goes under nuclear processing. Nuclear processing depends on the function of the nuclear protein known as DiGeorge Syndrome Critical Region 8 (DGCR8). DGCR8 associates with the enzyme Drosha, a protein that cuts RNA to form the "Microprocessor" complex. In this complex, DGCR8 orients the catalytic RNase III domain of Drosha to liberate hairpins from pri-miRNAs by cleaving RNA about eleven nucleotides from the hairpin base (two helical RNA turns into the stem). The resulting product has a 3' hydroxyl and $5^{\prime}$ phosphate with a two-nucleotide overhang at its 3 ' end and is often termed as a precursor-miRNA (pre-miRNA). Pre-miRNAs, which still have the hairpin structure, are exported from the nucleus in a process involving the nucleocytoplasmic shuttler Exportin-5. 
This protein recognizes a two-nucleotide overhang left by the RNase III enzyme Drosha at the 3' end of the pre-miRNA hairpin. Exportin-5-mediated transport to the cytoplasm is an energy-dependent process; therefore, it is associated with Guanosine-5'-triphosphate (GTP) and RAs-related Nuclear protein (Ran). In the cytoplasm, the pre-miRNA hairpin is cleaved to its mature size by Dicer (an RNase III enzyme). Dicer acts in association with the doublestranded RNA-binding protein (TRBP). The functional mature miRNA is then loaded along with Argonaute (Ago2) proteins into the RNA-induced silencing complex (RISC) and then it guides RISC to silence target mRNAs by mRNA cleavage, deadenylation and translational inhibiton.

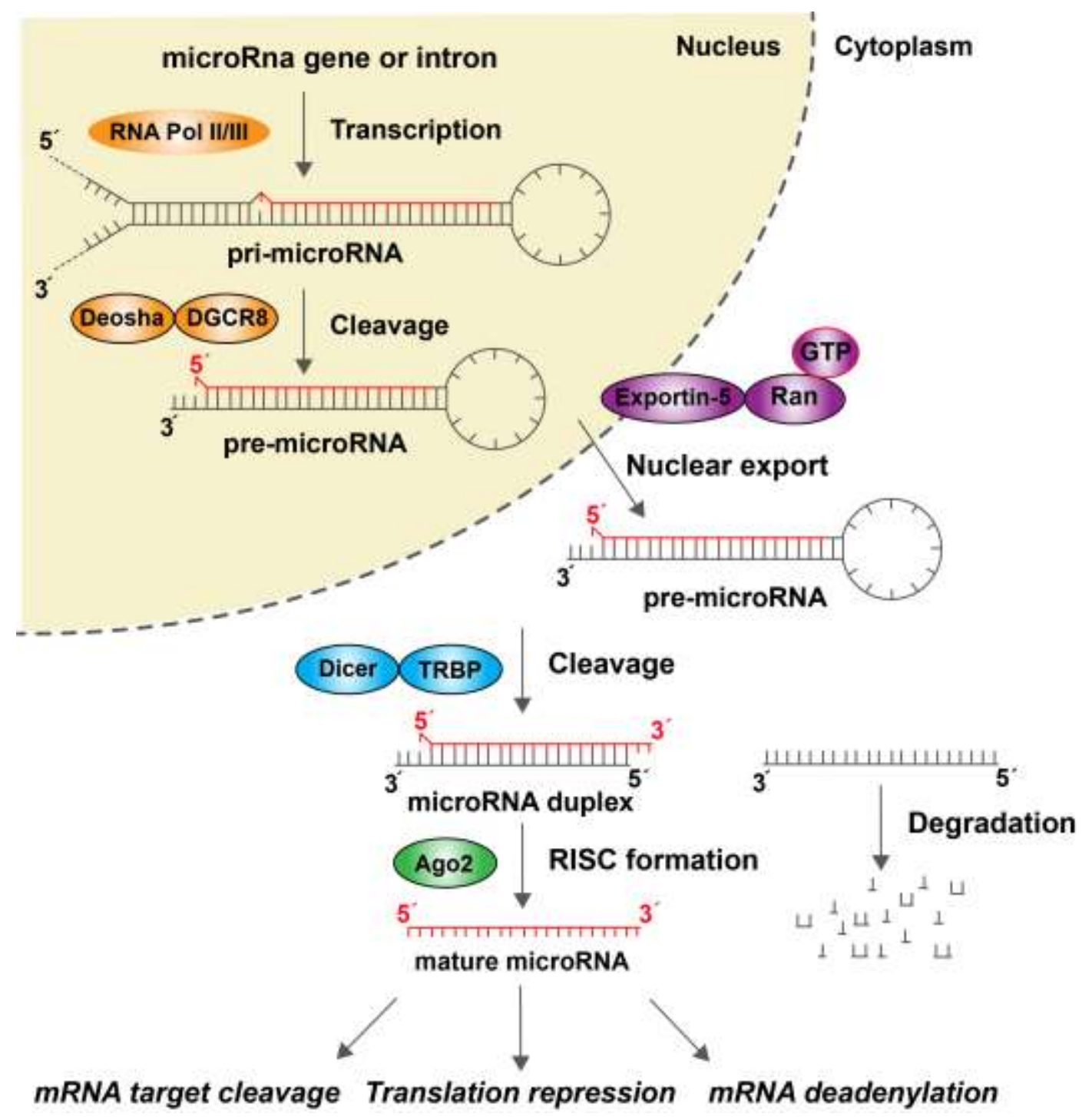

Fig. 1.1.1 Canonical pathway of biogenesis of microRNA. (adapted from: Winter et al., 2009: 229). 


\subsubsection{MiRNAs in the central nervous system}

MiRNAs are key regulators of the posttranscriptional control of the gene. Since discovery of the miRNAs the role of the miRNAs in the central nervous system has been studied massively. Interestingly, the enrichment of miRNAs in different parts of adult brain shows distinct expression patterns, e.g. miR127, miR128, miR9 and let-7 members are highly expressed in the brain (Bak et al., 2008). It has also been revealed that different miRNAs are expressed in different neuronal stages like development, proliferation, differentiation and synaptogenesis. The role of miRNAs in neuronal development has been shown by Dicer ablation (Andersson et al., 2010). As Dicer is a key enzyme in the miRNA maturation process, targeting this enzyme can reveal the role of miRNAs at different stages of the neuronal development (Kawase-Koga et al., 2009). Besides neuronal development, neuronal proliferation and differentiation of the neural stem cells to adult neurons is regulated by miRNAs. The miRNAs studied so far include MiR9, miR124, miR134, miR137 and miR184 are examples of some studied miRNAs in this area (Zhao et al., 2009; Lagos-Quintana et al., 2002; Szulwach et al., 2010; Liu et al., 2010). Of note, miR137 and miR184 expression is controlled by epigenetic regulation linked to DNA methylation.

Synaptogenesis and neurite outgrowth are two critical processes that are crucial to memory formation and consolidation. The epigenetic role of two non-coding RNAs including miRNA 124 and piRNA-F has been already reported in the long-term memory consolidation (Landry et al., 2013). It has also been revealed that miR 132 and miR212 play an important role in dendrite outgrowth and neurogenesis in the granule cells of DG in the adult hippocampus (Magill et al., 2010).

MiRNAs have also significant roles in dysfunction of the neuronal cells and neurodegeneration. MiRNAs mostly exert their role in neurodegenerative diseases by dysregulating the disease-related proteins. MiR9 is downregulated in $\mathrm{AD}$ and targets three important proteins namely Fibroblast growth factor receptor 1 (FGFR1), nuclear factor kappalight-chain-enhancer of activated B cells (NFkB) and Sirtunin1 (SIRT1) (Femminella et al., 2015). Down regulation of miR107 and miR29a/b leads to the increase at BACE1 level in AD patients (Wang et al., 2008; Hebert et al., 2008). MiR298 and miR328 show their effect by repressing BACE1 expression and A-beta accumulation (Boissonneault et al., 2009). MiR101 regulated repression of APP expression, which itself leads to A-beta accumulation (Vilardo et al., 2010). It has been shown that miR34c is expressed at high level in the hippocampus of the $\mathrm{AD}$ patients and $\mathrm{AD}$ mouse models (Zovoilis et al., 2011) the upregulation of miR34c in $\mathrm{AD}$ 
is associated with SIRT1. Besides Amyloid beta expression regulations, miRNAs role in tauassociated mechanisms in $\mathrm{AD}$ has been studied. MiR146a is an example for this case upregulation of miR-146a has been reported in AD patients (Lukiw et al., 2008). MiRNAs are also involved in other neurodegenerative diseases like Frontotemporal Dementia (FD) and Parkinson's disease (PD) (Arrant and Roberson, 2014; Doxakis 2010).

\subsubsection{MiRNA potential as biomarker}

Biomarkers (abbreviation for biological markers) are usually defined as a measurable indicator of the pathophysiological or healthy state of an organism or pharmacological response to a treatment. Biomarkers or surrogate markers have been used to diagnose or prognose a disease, blood pressure, high temperature, antibodies, electrolyte levels and blood cell counts are known examples of biomarkers. These biomarkers are used to monitor and predict health states in individuals so that appropriate therapeutic intervention can be planned. Moreover a cell or a molecule can serve as a biomarker. In this study a biomolecule, hippocampal and peripheral blood mononuclear cells (PBMC) miRNA, is used, to explore biomarker for aging and consequently AD simply because aging is one of the highly important risk factors for sporadic form of AD. Referring to studies, miRNA deregulations, deficiencies or excesses have been associated with a variety of diseases including cancer, $A D$, metabolic diseases, and many others (Wiemer, 2007; Nelson and Keller, 2007; Krutzfeldt and Stoffel, 2006; Calin et al., 2002).

In different mechanisms such as mRNA degradation or protein synthesis inhibition miRNA molecules target mostly the 3'UTR (Barbato et al., 2009). The interesting fact is that the polymorphisms in the 3'UTR of the binding sites of the miRNAs can change the affinity of these molecules to the target (Wang et al., 2008). So downregulation of the genes occurs upon the upregulation of the miRNAs. There is an inverse correlation between miRNA and mRNA and protein. MiRNA abnormal expression has been shown in the pathways involved in the mechanisms of neurodegenerative diseases. On the other hand the complementarity between the miRNA and its target site on the mRNA is imperfect, so it is possible for each miRNA to regulate hundreds of potential targets (De Felice, 2014).

In line with this a reliable biomarker should have some criteria; miRNAs are to a high extent specific to each organ and diseased organ, so they have an optimal pathological sensitivity. Furthermore miRNA detection is rapid, robust, accurate and inexpensive. They are also 
present in body fluids and that makes them a non-invasive or minimally invasive biomarker for pathological situations (Etheridge et al., 2011). Although the majority of miRNAs are found intracellular, remarkable number of miRNAs has been isolated from a variety of human body fluids, including plasma, urine, cerebrospinal fluid and blood serum (Weber et al., 2010; Turchinovich et al., 2011). There are ribonuclases in extracellular space and body fluids, which can degrade freely circulating RNAs, amazingly there are remarkable amount of RNAs in plasma, cerebrospinal fluid (CSF) and other extracellular space fluids so it seems that miRNAs are protected against RNase digestion. Interestingly, a certain subset of total circulating miRNAs was found to be exclusively transported within nanovesicles like exosomes while a distinct proportion of miRNAs was only present in the not-encapsulated Ago2-bound form (Arroyo et al., 2011). Aside from Ago2, existence of other RNA binding protein has been also confirmed (Wang et al., 2010). Another study also showed the existence of miRNA protein chaperones that could selectively protect miRNAs in the extracellular environment (Kosaka et al., 2010). In the present study the main focus was on isolation of small RNAs from solid tissue (brain) and PBMC (peripheral blood mononuclear cell), so the concerns about ribonuclases are not the case.

\subsubsection{MiRNA detection and profiling approaches}

Since miRNA discovery and revealing its role in gene expression regulation, techniques and methods, for miRNA detection and profiling, are progressing. Choosing the method for miRNA profiling depends highly on the aim of the project and also cost affords limitations. One of the major methods to detect miRNAs is quantitative real time polymerase chain reaction (qRT-PCR), which is an established method and has an acceptable sensitivity; miRNA microarray method is also a highly applied miRNA detection method with relatively lower costs in comparison to qRT-PCR but its specificity is not as good as qRT-PCR. Both methods have the disadvantage that they cannot identify novel miRNAs. Novel RNA sequencing methods like high-throughput next-generation sequencing (NGS) function highly sensitive and specific and these methods can detect novel miRNAs (Pitchard et al., 2012). This special advantage of NGS makes it a reliable method for biomarker discovery. However NGS needs bioinformatics experts to analyze the raw data from sequencer. Beside all the benefits, which NGS provides for miRNA profiling studies it has also some shortcomings for example it cannot be used for absolute quantification and its dependency on computational data analysis makes it very costly. 


\subsection{MiRNAs as therapeutic targets in Alzheimer's disease}

Altered expression of certain miRNAs is reported in development of the neurodegenerative diseases. It has been shown that differentially expressed miRNAs like miR-29a/29b-1 and miR-9 target BACE1 mRNA in AD (Hebert et al., 2008 and Shioya et al., 2010). MiRNA 34c has been shown to be upregulated in the hippocampus of AD patients. In the corresponding mouse models (Zovoilis et al., 2011) this miRNA reduces Sirtuin 1 protein level. Depletion of upregulated miRNA, which underlies the disease or pathological processes, could be a proper way to influence the disease progression. One important obstacle in targeting miRNAs is delivery of the therapeutics to the target cells. A pioneering study confirmed that exosomes contain different types of small RNAs (Valadi et al., 2007). Based on this study, experiments that focused to load the exosomes with siRNAs were initiated by Alvarez-Erviti et al. (2011). In this study to circumvent the immunogenicity, exosomes were purified from dendritic cells of the same animal and to target neural cells specifically rabid virus glycoproteins (RVG) were sorted in the exosomes. In the present study a system, which is based on sorting the measles virus glycoprotein (MVG) in the exosomes, was applied in order to pseudotype exosomes for neuronal cells. The following sections deal with the exosome biology and its properties for siRNA delivery.

\subsubsection{Exosomes}

Intercellular communication is a crucial hallmark of the eukaryotic cells. This communication can be either direct cell-cell communication or mediated by extracellular vesicles $(\mathrm{EV})$. According to their biogenesis and function these vesicles can be divided into different groups, e.g. ectosomes, shedding vesicles, microparticles and microvesicles (Hess et al., 1999; Holme et al., 1994; György et al., 2011; Cocucci et al., 2009).

The term exosome also refers to a group of extracellular nanovesicles in eukaryotic cells. Pan and Johnstone described Exosomes for the first time as a means to dispose of unwanted material during reticulocyte maturation (Pan and Johnstone, 1983). Electron microscopic images of these nanovesicles show a distinct saucer-shape with the size of 30 to $100 \mathrm{~nm}$ (van Niel et al., 2006). However this saucer-shape like appearance was later reported to be a consequence of sample preparation for electron microscopy (Raposo et al., 1996). Exosomes in reality have a completely rounded shape, which can be demonstrated by cryo-electron microscopy analysis, because preparation process for this kind of microscopy does not deform the original shape of the exosome (Conde-Vancells, 2008). 


\subsubsection{Biogenesis of the exosomes}

Numerous studies have confirmed that exosomes originate from multivesicular bodies (MVBs). Exosomes get released into the extracellular milieu as a consequence of fusion of the MVB limiting membrane with the cell membrane (Fig.1.2.1). This distinguishes exosomes from ectosomes, which are produced by direct budding of the cell membrane (Valssov et al., 2012). Based on its protein composition an MVB can have two fates: it can either end up in the lysosome for degradation or merge with the cell membrane to release exosomes (Thery et al., 2006). The synthesis of the exosomes and sorting of cargo requires the function of endosomal sorting complex required for transport (ESCRT); this machinery is also needed for lysosome synthesis. The ESCRT is composed of four main protein complexes: ESCRT0, ESCRT1, ESCRT2, and ESCRT3 (Williams and Urbe, 2007; Hurley, 2008). ESCRT0, ESCRT1, ESCRT2 have important function in recognition and sorting the ubiquitinylated proteins for secretion via exosomes, while ESCRT3 is important in invagination of the cell membrane (Raiborg and Stenmark, 2009).

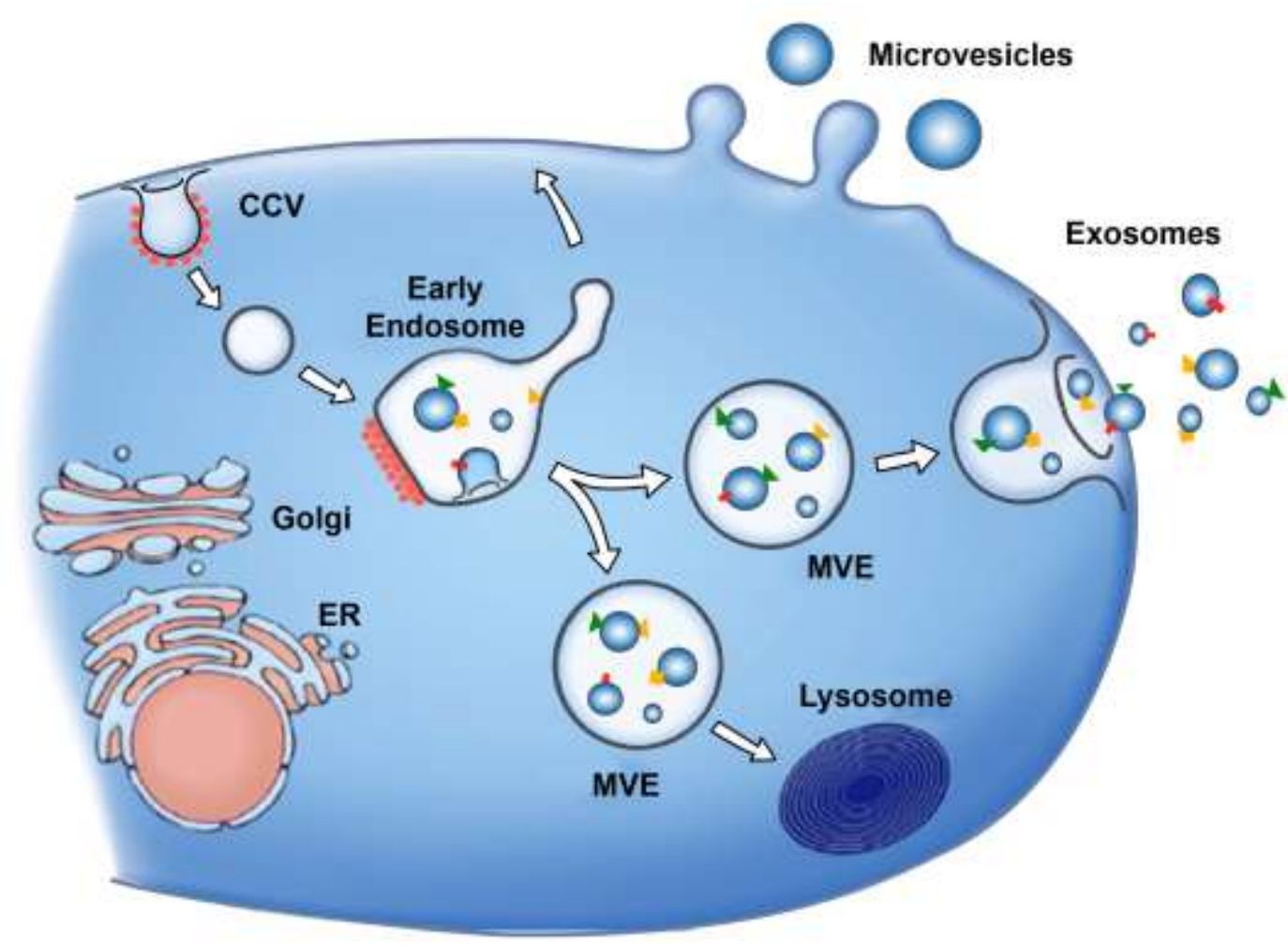

Fig. 1.2.1 Formation of MVE and release of exosomes in extracellular milieu (adapted from: Raposo and Stoorvogel, 2013: 375). 


\subsubsection{Composition of the exosomes}

Beside the unique shape of the exosomes, their protein and lipid composition can also be regarded as exclusive properties. Proteins with MVB origins like Alix and Flotillin, heat shock proteins like hsc70 and hsc90, as well as integrins and tetraspanins e.g. CD63, CD9, CD81 and CD82 have been found in exosomes. Since exosomes have an endosomal origin another group of proteins that can be detected in them are fusion and membrane transport proteins e.g. Annexin and Flotillin. (Simons and Raposo, 2009).

The lipid compartment of the exosomes is similar to the plasma membrane of cells of their origin (Subra et al., 2007). A large proportion of the exosomal lipids are raft-lipids like ceramide, sphingolipids and glycerophospholipids (Subra et al., 2007; Trajkovic et al., 2008). The involvement of ceramide in biogenesis of exosomes has been confirmed since an ESCRT-independent pathway requires it (Trajkovic et al., 2008).

\subsubsection{Function of the exosomes}

Early studies, which led to the discovery of exosomes, described these vesicles as a carrier to dispose the superfluous cellular material from reticulocytes (Pan and Johnstone, 1983). Other roles have been proposed for exosomes in further studies e.g., Raposo et al. (1996) surveyed the role of exosomes in antigen presentation in pioneering studies. In this study they proved that exosomes work as MHCII presenters to T cells. In the nervous system as well, some functions for exosomes have been revealed, Bakhti et al. (2011) reported exosomal function in myelin formation. In this project the role of exosomes in material transportation between the cells was of paramount interest, hence the next sections deal with the function of exosomes in delivering the desired cargo.

\subsubsection{Exosomes as delivery vehicles}

Another feature of exosomes, which is highly compelling, is their role in intracellular communication. This intracellular transmission can include the transfer of pathogenic nervous system proteins like amyloid beta peptide (Rajendran et al., 2006) and alpha-synuclein (Emmanouilidou et al., 2010). These bioactive nanovesicles also transfer mRNA and miRNA between cells (Valadi et al., 2007). This special property of exosomes in mediating the cell contents has great benefits for biomarker research. Exosome-derived miRNAs and proteins has been studied as diagnostic biomarkers for prostate cancer, lung cancer and kidney injuries (Duijvesz et al., 2013; Yamashita et al., 2013; Zhou et al., 2006). 
This function of exosomes is particularly useful because it can be exploited to deliver desirable cargoes to target cells. One interesting cargo could be a therapeutic agent. Many studies put their efforts to load exosomes with their desired cargo. Table 1.1 shows a list of these studies, which loaded various kinds of cargo into the exosomes, and specifies the method used for loading. The main trials have been done with electroporation and transfection methods. In electroporation an external electric field is applied to make the biological membrane permeable then a desired cargo, which could be a drug or a genetic piece like DNA or siRNA can be loaded to the cell. Transfection as word is a combination of trans and infection. Different genetic material can be entered to the cell with this method; siRNA constructs are among these different materials. It should be taken into account that in animal cells most of the time transfection involves transient pores in the cell membrane in order to uptake of the transfection material. Different methods are used for transfection: cell squeezing, calcium phosphate, electroporation, or most recently by mixing a cationic lipid with the material to produce liposomes, which fuse with the cell membrane and deliver their cargo inside.

Table 1.1 Recently published studies, which used exosomes as delivery vehicles.

\begin{tabular}{|lll|}
\hline Study & Cargo & Method \\
\hline Alvarez-Erviti et al. (2011) & siRNA & Electroporation \\
Shtam et al. (2013) & siRNA & Electroporation \\
Wahlgren et al. (2012) & siRNA & Electroporation \\
Pan et al. (2012) & shRNA & Transfection of exosome producing cells \\
Chen et al. (2014) & miRNA & Transfection of exosome producing cells \\
Bryniarski et al. (2013 & miRNA & Incubation of exosome with cargo \\
Zhang et al. (2010) & miRNA & Transfection of exosome producing cells \\
Katakowski et al. (2010) & miRNA & Transfection of exosome producing cells \\
Kosaka et al. (2012) & miRNA & Transfection of exosome producing cells \\
Pan et al. (2012) & miRNA & Transfection of exosome producing cells \\
Xin et al. (2012) & miRNA & Cell activation \\
Ohno et al. (2012) & miRNA & Transfection of exosome producing cells \\
Munoz et al. (2013) & miRNA & Transfection of exosome producing cells \\
\hline
\end{tabular}


In all the studies listed in the above table, interfering RNAs are adopted as a therapeutic agent. Some other studies have applied exosomes for other therapeutic cargoes, e.g. doxorubicin as chemotherapeutic in cancer treatment research (Tian et al., 2013; Jang et al., 2013) and curcumin as an anti-inflammatory mediator (Zhuang et al., 2011; Sun et al., 2010).

In the present study in order to use exosomes as reliable drug delivery vehicle for neuronal cells, the main concentration is to develop a method to produce exosomes, which can target neurons specifically. Pseudotyping of exosomes with rabid virus glycoproteins (RVG) was performed before by Alvarez-Erviti et al. (2011) to target glia and neurons. Anliker et al. (2010) introduced a method, which apply pseudotyped lentiviral vectors for specific gene transfer to different cell types, including neurons. This method is based on single chain antibodies, which recognize cell surface antigens. The process of pseudotyping is accomplished by using measles virus glycoproteins (MVG). This virus provides a promising strategy for specific cell entry by retargetable envelope MVG namely hemagglutinin protein $(\mathrm{H})$, which is responsible for receptor recognition, and fusion protein (F) (Funke et al., 2008). Interestingly variants of the hemagglutinin protein $(\mathrm{H})$ and the measles virus fusion protein (F) truncated at their cytoplasmic tails have shown efficient incorporation into lentiviral particles (Funke et al., 2009). In this project MVG $\mathrm{H}$ and $\mathrm{F}$ are used for exosome pseudotyping. 


\subsection{Project objectives}

$\mathrm{AD}$ is the most frequent cause of dementia in elderly people. Due to increased life expectancies the number of people afflicted with this disease is believed to double in the near furture. Despite intensive research there is no effective therapy for AD. Clinical trials targeted towards amyloid pathology have all failed. It is believed that this is at least in part due to the fact that diagnosis is made too late, when causative treatments are ineffective. Hence, there is great need to identify biomarker for early diagnostic methods and therapeutic intervention. A central hypothesis of this thesis is that microRNAs provide a novel avenue to develop biomarker and therapeutic approaches for AD. Thus, this thesis had two central aims:

1. Detection of the circulating miRNAs as implications for age-related cognitive impairments and $\mathrm{AD}$ in body fluids like blood from aged versus young mice as a noninvasive method to search for miRNA signatures of aging and AD.

2. Since miRNAs can interfere at posttranscriptional level we sought to establish a therapeutic method which is based on RNA interfering. To conquer the blood brain barrier the exosomes were planned as delivery vehicles. To end up with a high efficiency method, in this project experiments were concentrated on neuronal targeting of the exosomes. 
Materials and Methods 


\subsection{Materials}

\subsubsection{Animals}

Four-month-old adult and eighteen-month-old adult male C57BL/6 wild-type mice were purchased from Janvier Rodent research models and associated service. All animals were housed in the animal facility of the European Neuroscience Institute, Göttingen with standard temperature and humidity and dark/light condition. They were fed and watered ad libitum with a standard laboratory mouse diet and cages were changed every ten days. All animal care and testing protocols were approved by the Veterinary Institute of the Lower Saxony State Office for Consumer Protection and Food Safety.

\subsubsection{Antibodies}

Primary antibodies, which were used, are listed in Table 2.1. Secondary horseradish peroxidase (HRP)-conjugated antibodies were purchased from Dianova (1: 2,000; Hamburg, Germany) and for western blot analysis, which were performed in Paul Ehrlich Institute, Langen the secondary antibodies conjugated with horseradish peroxidase were obtained from DakoCytomation (1:2,000; Hamburg, Germany).

Table 2.1 Primary antibodies used for western blot

\begin{tabular}{llll}
\hline Target & Host species & Application & Reference \\
\hline Flotillin-2 & Mouse & WB (1:1000) & BD Biosciences, Heidelberg, Germany \\
F (F431) & Rabbit & WB (1:1000) & $\begin{array}{l}\text { Buchholz CJ, Laboratory, Paul Ehrlich } \\
\text { Institute, Langen, Germany }\end{array}$ \\
H (606) & Rabbit & WB (1:2000) & $\begin{array}{l}\text { Buchholz CJ, Laboratory, Paul Ehrlich } \\
\text { Institute, Langen, Germany }\end{array}$
\end{tabular}

\subsubsection{Plasmids}

Table 2.2 Plasmids donated from other laboratories

\begin{tabular}{ll}
\hline Plasmid & Reference \\
\hline pCG_Hwt & Buchholz CJ, Paul Ehrlich Institute, Langen, Germany \\
pCG_Fwt & Buchholz CJ, Paul Ehrlich Institute, Langen, Germany \\
pCG_Hcd18 & Buchholz CJ, Paul Ehrlich Institute, Langen, Germany \\
pCG_Fcd30 & Buchholz CJ, Paul Ehrlich Institute, Langen, Germany \\
pCG_Hcd14 & Buchholz CJ, Paul Ehrlich Institute, Langen, Germany \\
pCG_Fcd24 & Buchholz CJ, Paul Ehrlich Institute, Langen, Germany
\end{tabular}

The plasmid cards are attached in appendice1-4. 


\subsubsection{Buffers and solutions}

Table 2.3 Phosphate buffered saline (PBS) (for preparation of 1 Liter of 10x PBS).

\begin{tabular}{ll}
\hline Ingredient & Percent/concentration \\
\hline $\mathrm{NaCl}$ & $80.0 \mathrm{~g}$ \\
$\mathrm{KCl}$ & $2.0 \mathrm{~g}$ \\
$\mathrm{Na}_{2} \mathrm{HPO}_{4}\left(\right.$ or $\left.18.05 \mathrm{~g} \mathrm{Na}_{2} \mathrm{HPO}_{4}{ }_{-}{ }_{2} \mathrm{H}_{2} \mathrm{O}\right)$ & $14.4 \mathrm{~g}$ \\
$\mathrm{KH}_{2} \mathrm{PO} 4$ & $2.4 \mathrm{~g}$
\end{tabular}

Table 2.4 CHAPS lysis buffer (The $\mathrm{pH}$ was adjusted to 8) (For preparation of 1 Liter 1x Lysis buffer).

\begin{tabular}{ll}
\hline Ingredient & Percent/concentration \\
\hline $\begin{array}{l}\text { 3-[(3-cholamidopropyl) dimethylammonio]-1- } \\
\text { propanesulfonate (CHAPS), }(\wedge=1 \%)\end{array}$ & $10 \mathrm{~g}$ \\
Tris (hydroxymethyl) aminomethane (Tris), $(\wedge=50$ & $6.1 \mathrm{~g}$ \\
$\mathrm{mM})$ & \\
$\begin{array}{l}\text { Ethylenediaminetetraacetic acid (EDTA) } \\
(\wedge=5 \mathrm{mM})\end{array}$ & $1.5 \mathrm{~g}$
\end{tabular}

Table 2.5 Components of $400 \mu 1$ Electroporation buffer (The $\mathrm{pH}$ was adjusted to 7.2).

\begin{tabular}{ll}
\hline Ingredient & Percent/concentration \\
\hline Potassium phosphate & $1,15 \mathrm{mM}$ \\
Potassium chloride & $1,25 \mathrm{mM}$ \\
Optiprep & $21 \%$
\end{tabular}

Table 2.6 Protein loading buffer (The $\mathrm{pH}$ was adjusted to 6.8) Loading buffer $4 \mathrm{x}$

\begin{tabular}{ll}
\hline Ingredient & Percent/concentration \\
\hline Glycerol & $10 \%$ \\
Tris-HCl & $50 \mathrm{mM}$ \\
EDTA & $2 \mathrm{mM}$ \\
SDS & $2 \%$ \\
$\beta$ mercaptoethanol & $144 \mathrm{mM}$ \\
Bromophenol blue & $0.05 \%$
\end{tabular}




\subsubsection{Media and Sera}

Table 2.7 Commercially available media, sera and additives.

\begin{tabular}{ll}
\hline Medium name & Reference \\
\hline Dulbecco's Modified Eagle Medium (DMEM) & PAA Laboratories, Pasching, Austria \\
Fetal Calf Serum (FCS) & PAA Laboratories, Pasching, Austria \\
GlutaMAX'TM-I supplement & Invitrogen, Darmstadt, Germany \\
LB medium + LB agar plate & AppliChem (Darmstadt, Germany) \\
Opti-MEM + GlutaMAX ${ }^{\mathbf{M}}$-I & Invitrogen, Darmstadt, Germany \\
Phosphate Buffered Saline (PBS) PAA & Laboratories, Pasching, Austria \\
Penicillin/Streptomycin (Pen/Strep) 100x & Invitrogen, Darmstadt, Germany \\
Geneticin (G418) & Sigma-Aldrich, Taufkirchen, Germany \\
Optiprep (Density Gradient Medium) & Axis-schield, Oslo, Norway
\end{tabular}

\subsubsection{Commercial kits}

Table 2.8 Commercial kits used in this study.

\begin{tabular}{lll}
\hline Kit & Application & Origin \\
\hline Bardford protein assay & $\begin{array}{l}\text { Exosome protein concentration } \\
\text { measurement } \\
\text { Xtra Midi Kit }\end{array}$ & BioRad \\
& Luciferase activity measurement & $\begin{array}{l}\text { Machery-Nagel, Dueren, } \\
\text { Germany }\end{array}$ \\
Luc-Screen ${ }^{\circledR}$ System & & Bedford, MA, USA \\
& & \\
$\begin{array}{l}\text { RNeasy Protect animal Blood kit } \\
\text { TruSeq small RNA sample } \\
\text { preparation kit }\end{array}$ & $\begin{array}{l}\text { RNA extraction from mice blood } \\
\text { Small RNA library preparation }\end{array}$ & $\begin{array}{l}\text { Qiagen, Germany } \\
\text { Illumina, San Diego, CA, }\end{array}$ \\
& & USA
\end{tabular}




\subsection{Methods}

\subsubsection{RNA Isolation}

Mice were anesthetized with ketamine/xylazin diluted in PBS (per mouse $18 \mu 1$ Ketamin, 8,6 $\mu$ 1 Xylazin diluted in 173,4 $\mu 1$ PBS). 500 $\mu 1$ Blood was taken from heart using an Insulin syringe 1ml/ 40 I.U. and 12 gauge x $40 \mathrm{~mm}$ needle (BBraun, Meslungen, Germany) quickly and transferred to blood collection tubes from kit to avoid coagulation. RNA isolation from blood was performed with RNeasy Protect Animal kit (see table 2.8) according to the manufacturer protocol. For RNA isolation from brain regions first the brain was dissected. The dissection of ACC, DG, CA1 and CA3 regions was performed under a stereomicroscope (Motic) as described before (Hagihara et al., 2009). The RNA isolation from each region was done using TRI Reagent (Sigma-Aldrich Chemie GmbH, Munich, Germany). For RNA isolation the tissue was thoroughly homogenized in TRI Reagent. After that chloroform (AppliChem, Darmstadt, Germany) was added to the samples and was shaken vigorously and left at room temperature (RT) for $15 \mathrm{~min}$. Then the samples were centrifuged at $12000 \mathrm{xg}$, at $4^{\circ} \mathrm{C}$ for $15 \mathrm{~min}$ to acquire the three phases, the aqueous phase which is containing RNA was collected into a new $1.5 \mathrm{ml}$ tube, mixed with Isopropanol (AppliChem, Darmstadt, Germany) and kept at $-20^{\circ} \mathrm{C}$ for at least $14 \mathrm{~h}$. Afterwards the aqueous phase Isopropanol mixture was centrifuged for $30 \mathrm{~min}$ at $4 \mathrm{C}$ at $12000 \mathrm{xg}$ thereafter the supernatant was discarded and washed with $75 \%$ ethanol twice $(12000 x g$ for 5 minutes each wash step). Finally the pellet was dissolved in $15 \mu \mathrm{l}$ RNase free water. The exact amount of TRI reagent, chlorophorm, Isopropanol and ethanol per each tissue is listed in the table below:

Table 2.9 The exact volume of each solution for RNA isolation per brain tissue.

\begin{tabular}{lllll}
\hline Brain tissues & TRI reagent & Chlorophorm & Isopropanol & Ethanol \\
\hline ACC & $400 \mu 1$ & $80 \mu 1$ & $200 \mu 1$ & $500 \mu 1$ \\
DG & $400 \mu 1$ & $80 \mu 1$ & $200 \mu 1$ & $500 \mu 1$ \\
CA1 & $800 \mu 1$ & $160 \mu 1$ & $400 \mu 1$ & $500 \mu 1$ \\
CA3 & $800 \mu 1$ & $160 \mu 1$ & $400 \mu 1$ & $500 \mu 1$
\end{tabular}

\subsubsection{RNA quantity and quality}

RNA from blood and brain tissue was quantified using a NanoDrop spectrophotometer (Thermoscientific, Peqlab). The exact quantity and quality measurement of the blood and brain RNA was performed with a 2100 Agilent Bioanalyzer microfluidics platform according to the manufacturer's instructions. 


\subsubsection{Library preparation}

Small RNA libraries were prepared from total RNA using the TruSeq small RNA sample preparation kit (see table 2.8) according to the manufacturer's instructions. In all cases blood, ACC and hippocampal subregions $100 \mathrm{ng}$ of total RNA was used as starting material.

\subsubsection{Bioinformatics and statistical analysis}

Small RNA detection was performed using Oasis (Capece et al., 2015) web tool for analysis of small RNAseq libraries. The following steps were performed by the Oasis pipeline. The raw Illumina reads were preprocessed to filter out reads of length smaller than 15 nucleotides and greater than 32 nucleotides. The filtered reads were mapped to the reference genome using STAR (Dobin et al., 2013) in non splice-junction-aware mode. The counts of the samples were summarized by MiRBase release v20 for miRNAs, piRNAbank V.2 for piwiRNAs and Ensembl for snRNAs, snoRNAs and rRNAs. It then predicts the novel miRNAs using miRDeep2 (Friedländer et al., 2012). All NGS data are publicly available in GEO database.

\subsubsection{Statistical analysis of next-generation sequencing data}

In order to perform the subsequent bioinformatics and statistical data analysis, Python (version 2.7.6) and R (version 2.7.6) environment were used. We normalized the read counts using standard quantile normalization method. We filtered out samples with library size < 100,000 reads. A threshold of minimum of 100 reads was used to filter out low abundant reads and outliers were also filtered out that were obtained from pairwise correlation (Pearson correlation coefficients) matrix. We then used customized python scripts for description, summarization and visualization of the data. Differential expression analysis was performed using DESeq2 (Love et al., 2014) package. Heatmaps and venn diagrams were generated using python's plotting library matplotlib (v1.4.3). Clustering of the pairwise correlation matrix and the differentially expressed miRNAs was performed using hierarchical clustering (SciPY version 0.15.1). The Ingenuity Pathway Analysis ((IPA, Qiagen) was used to analyze the list selected miRNA targets. We selected only experimentally verified genes and removed duplicates in Ingenuity Pathway Analysis (IPA). 


\subsubsection{Cell culture and exosomes}

All cell culture work was performed according to security level S1 safety rules and was done under sterile conditions. Cell culture and exosome isolation work were performed in the laboratory of Prof. Anja Schneider, at the Max Planck Institute for Experimental Medicine, Göttingen. Murine Neuroblastoma cell line (N2a) was used for cell culture and exosome isolation and Human fibrosarcoma cell line with luciferase activity (HT1080Luc) was used as the reporter cell line. Freezing, thawing, growth and maintenance of N2a cell line are explained below:

\subsubsection{Freezing of cells}

For long-term storage of cell lines, N2a cells were frozen at $-160^{\circ} \mathrm{C}$ liquid Nitrogen. For freezing, as the first step the cells were detached or trypsinised with $2 \mathrm{ml}$ of $0.05 \%$ trypsin-EDTA (Gibco). The trypsinization reaction was then stopped with $10 \mathrm{ml}$ of Dubelco's Modified Eagle's Medium (DMEM) (see table 2.7) and cell suspension was centrifuged subsequently after centrifugation of the cell suspension for $5 \mathrm{~min}$ at $900 \mathrm{xg}$ the pellet was resuspended in $0.5 \mathrm{~mL}$ DMEM, $0.5 \mathrm{~mL}$ of $2 \mathrm{x}$ freezing medium (40 \% FCS, $20 \% \mathrm{DMSO}$ in DMEM) was added, the suspension was mixed gently and transferred into a Nalgene ${ }^{\circledR}$ Sterile Cryogenic Vial (Thermo Fisher Scientific, Roskilde, Denmark). Cell vials were transferred to a Nalgene ${ }^{\circledR}$ Cryo freezing container (Thermo Fisher Scientific, Roskilde, Denmark), which was filled with Isopropanol and allowed slow freezing at a temperature-dropping rate of $1 \mathrm{C} / \mathrm{min}$ in an $-80^{\circ} \mathrm{C}$ freezer. For permanent storage, cells were stored at $-160^{\circ} \mathrm{C}$ liquid nitrogen.

\subsubsection{Thawing of cells}

To thaw the cells, a cryogenic vial was removed from liquid nitrogen and immediately incubated in a $37^{\circ} \mathrm{C}$ water bath. Rapidly after the cell suspension became liquid, $10 \mathrm{~mL}$ of pre-warmed fresh growth medium was added and the suspension was centrifuged for 5 min at 900xg. The cell pellet was resuspended in fresh pre-warmed growth medium and plated on a $10 \mathrm{~cm}$ petri dish or a $75 \mathrm{~cm}$ cell culture flask.

\subsubsection{Growth and maintenance of cells}

Cells were grown at $37^{\circ} \mathrm{C}$ and $5 \% \mathrm{CO} 2$ in humidified incubators. Cells were grown in 
general growth medium. General growth medium is composed of: $1 \mathrm{~mL}$ Penicillin/Streptomycin, $5000 \mathrm{U} / 5000 \mu \mathrm{g}, 1 \mathrm{~mL}$ GlutaMAX ${ }^{\mathbf{T M}}$-I supplement, $200 \mathrm{mM}$ (see table 2.7) $10 \mathrm{~mL}$ Fetal Calf Serum (FCS, see table 2.7) in Dulbecco's Modified Eagle Medium (see table 2.7) with $4.5 \mathrm{~g} / \mathrm{L}$ glucose. HT1080Luc cell line was kindly donated from Paul Ehrlich Institute, Langen and was used as luciferase reporter cell line. The medium which was used for this cell line was the same as N2a cells but instead of Penicillin/Streptomycin antibiotic $1 \mathrm{mg} / \mathrm{mL}$ Gentecin (G418) (see table 2.7) antibiotic was added to the DMEM. G418 is commonly used in laboratory research to select genetically engineered cells. In this case it was used to select the marker gene, which is responsible for luciferase activity in HT1080Luc cells, which express luciferase activity. PBS was used for washing the cells; PBS was either purchased from PAA (see table 2.7) or prepared manually.

To obtain 1x PBS, 10xPBS was diluted 10 times with bi-distilled $\mathrm{H}_{2} \mathrm{O}$. The $\mathrm{pH}$ value was adjusted to 7.2-7.4 (see table 2.3)

\subsubsection{Transformation of E. coli}

pCGHwt and pCGFwt and their mutant variants plasmids were kindly donated from Prof. Christian Buchholz, Paul Ehrlich Institute, Langen, Germany (see table 2.2 and Plasmid maps in appendices 1-4) For amplification of plasmid DNA constructs in bacteria, the chemocompetent E. coli strand Subcloning Efficiency DH5alpha' (Invitrogen, Carlsbad, CA, USA) was used. For transformation, $50 \mu \mathrm{L}$ of competent cells were thawed on ice for $5 \mathrm{~min}$. thereafter, $0,5 \mu \mathrm{g}$ of the desired plasmid for example pCGHwt and pCGFwt or other variants were added to the cells, the suspension was mixed and incubated on ice for 20 min followed by heat-shock at $42^{\circ} \mathrm{C}$ for $42 \mathrm{sec}$. After recovery on ice for $2 \mathrm{~min}, 500 \mu \mathrm{L}$ of LB medium (25 $\mathrm{g} \mathrm{LB}$ in $1 \mathrm{~L} \mathrm{H} 2 \mathrm{O}$, autoclaved) was added and the cells were incubated for $1 \mathrm{~h}$ at $37 \mathrm{C}$ under shaking. For single transformants selection, the culture was spread on LB plates (LB-Agar 40 g per $1 \mathrm{~L} \mathrm{H} 20$, autoclaved) supplemented with the appropriate antibiotics $(100 \mu \mathrm{g} / \mathrm{ml}$ ampicillin) and incubated at $37 \mathrm{C}$ for $14-20 \mathrm{~h}$.

\subsubsection{Plasmid DNA isolation from E. coli}

To amplify plasmid DNA from transformed E. coli at a medium-scale, a single colony was picked from the LB plate using an autoclaved tip and transferred to $100 \mathrm{~mL}$ of antibiotic supplemented LB medium. Bacteria were incubated for $10-16 \mathrm{~h}$ at $37^{\circ} \mathrm{C}$ under constant shaking. Thereafter, cells were harvested by centrifugation for $10 \mathrm{~min}$ at $3,000 \mathrm{rpm}$ and $4{ }^{\circ} \mathrm{C}$ and plasmid DNA was isolated and purified with the NucleoBond Xtra Midi Kit (see table 
2.8) according to the manufacturer's instructions. Extracted DNA was dissolved in $350 \mu 1 \mathrm{TE}$ buffer from the kit.

\subsubsection{DNA concentration measurement}

DNA concentration was determined by measuring the optical density at $260 \mathrm{~nm}$ (A260), samples were measured on Nanodrop spectrophptometer (Thermoscientific, Peqlab).

\subsubsection{Transfection of plasmids}

Two Plasmid DNAs (see Plasmid maps in appendices 1-4) were cotransfected into murine N2a cell lines using Mirus Bio TransIT®-LT1 Transfection Reagent (Mirus Bio LLC, Madison, WI, USA). Before transfection, the N2a cells were grown to a confluence of $60 \%$ in a $10 \mathrm{~cm}$ dish culture. $27 \mu 1$ transfection reagent and $4,5 \mu \mathrm{g}$ of each plasmid DNA were added to $18 \mu 1$ Opti-MEM (see table 2.7), mixed gently and incubated at room temperature for 25-45 min. After incubation, the mixture was added to the cells in a drop-wise manner, the cell culture dish was shaken gently and the cells were incubated under culture conditions for 16$24 \mathrm{~h}$.

\subsubsection{Exosome collection and preparation}

Exosome collection was accomplished by changing from growth medium to collecting medium, which is free from FCS. Exosome isolation was performed according to a protocol based on Thery et al. (2006), which is considered as the golden standard method to isolate exosomes from cell culture medium.

The cell culture supernatant was subjected to serial centrifugation at $3500 \mathrm{xg}$ for 10 minutes, $4500 \mathrm{xg}$ for 10 minutes (two times) and 10,000xg for 30 minutes. Finally the supernatant was subjected to ultracentrifugation at $100,000 \mathrm{xg}$ to obtain the exosome pellet and the exosomefree supernatant. Exosome pellet was resuspended in electroporation buffer. To confirm the presence of expressed proteins in N2a cells, after cell culture supernatant collection these cells were harvested. For protein analysis, corresponding cells of a $10 \mathrm{~cm}$ petri dish were scraped in $400 \mu 1$ of CHAPS lysis buffer (see table 2.4) and centrifuged for $10 \mathrm{~min}$ at 45,00xg and $4^{\circ} \mathrm{C}$. Protein from cell lysates were resuspended in loading buffer (see table 2.6) and kept at $80^{\circ} \mathrm{C}$ to be subjected later to western blotting. 


\subsubsection{Determination of the exosome protein concentration}

The protein concentration of exosomes was determined using Bradford Protein Assay (BioRad, Germany) according to the manufacturer's instructions. This assay is based on the Coomassie blue dye binding to proteins i.e. the higher the protein concentration the darker is the color of the test sample. Coomassie absorption is at $595 \mathrm{~nm}$; protein concentration of the test samples is determined by comparing to that of a series of protein standards, which in this study was Bovine Serum Albumin (BSA). The absorbance of the reaction was measured at $595 \mathrm{~nm}$ using a 96-well plate reader (MRXTc Revelation, Dynex Technologies).

\subsubsection{Electroporation}

Two different amounts of exosomes and siRNA were used for the experiment. The first step was conducted with $3 \mu \mathrm{g}$ of exosomes (from transfected and not-transfected cells). These exosomes were electroporated with $3 \mu \mathrm{g}$ of GL3siRNA (Qiagen, Hilden, Germany). For the next step of the experiment $10 \mu \mathrm{g}$ of exosomes (from transfected and not-transfected cells) were electroporated with $10 \mu \mathrm{g}$ of GL3siRNA. In both steps for electroporation the resuspended exosomes in $100 \mu$ l electroporation buffer (see table 2.5) were electroporated in a $4 \mathrm{~mm}$ cuvette (Gene Pulser/MicroPulser, BioRad, Germany). The cuvettes were put in the shock pod cuvette chamber of Gene Pulser Xcel electroporation device (BioRad, Germany). For electroporation the Exponential program was used at $400 \mathrm{mV}$ and $125 \mu \mathrm{F}$ capacitance (pulse time 10-15 ms).

The electroporated exosomes were added drop wise to the HT1080Luc cells, which have been before cultivated in $24 \mathrm{well}$ plates and were incubated at $37^{\circ} \mathrm{C}$ for $48 \mathrm{~h}$. As the standard control for transfection efficiency, the GL3siRNA was mixed with OptiMEM (see table 2.7) and oligofectamine, the transfection reagent (Invitrogen, Carlsbad, CA, USA) according to the manufacturer transfection protocol and added to the cells. As negative control only oligofectamine was added to the cells.

\subsubsection{Luminometer analysis}

RNA interference (RNAi) responses of luciferase in luciferase-expressing cells were measured with Luc-Screen ${ }^{\circledR}$ System kit (see table 2.8) 48h after the HT1080 Luc cells were 
treated with GL3 siRNA electroprated exosomes. Buffer1 (contains buffered luciferase reaction and cell lysis reagents) and buffer2 (contains luciferin substrate) were equilibrated at room temperature and then $200 \mu 1$ of buffer 1 was added to $400 \mu 1$ medium from each well, buffer 2 was added in 5 minutes. The luminescence was measured on a luminometer. Data analyses for luminescence intensity were performed with Excel and Prism 6 softwares.

\subsubsection{Western blot analysis}

In the case that exosomes were intended to be subjected to western blotting the exosome pellet was resuspended in $20 \mu 1$ loading buffer (see table 2.6).

Exosome isolation was performed from non-transfected and transfected cells. For confirming the exosome isolation quality the western blot was performed. Flotillin-2 antibody was used as positive marker for exosomes.

\subsubsection{SDS-PAGE}

Sodium dodecyl sulfate ployacrylamide gel electrophoresis (SDS-PAGE) was performed using the Bio-Rad Mini-PROTEAN 3 electrophoresis system (Bio-Rad Laboratories $\mathrm{GmbH}$, Munich, Germany) for proteins separation based on the molecular weight after denaturation. Preparation of two-layered polyacrylamide gels was conducted in the Bio-Rad Mini-PROTEAN 3 casting system. Composition for the upper stacking gel $(2 \mathrm{ml})$ and the lower resolving gel $(5 \mathrm{ml})$ is listed below:

Table 2.10 Stacking gel used for electrophoresis

\begin{tabular}{ll}
\hline Ingredient & Percent/concentration \\
\hline Acrylamide/bis-acrylamide (29:1) solution & $4 \%$ \\
Tris-HCl pH 6.8 & $125 \mathrm{mM}$ \\
SDS & $0.1 \%$ \\
Ammonium persulfate (APS) & $0.05 \%$ \\
N'N'N'-tetramethylethylene & $0.005 \%(\mathrm{v} / \mathrm{v})$ \\
diamine (TEMED) &
\end{tabular}

For loading on the gel, exosome and cell lysate samples were prepared as follows: Exosome pellets were resuspended in $20 \mu 1$ of denaturing protein-loading buffer (see table 2.6). Before loading on the gel, the samples were boiled at $95^{\circ} \mathrm{C}$ for $5 \mathrm{~min}$. The gel was run in running trisglycine electrophoresis buffer (25 mM tris, $192 \mathrm{mM}$ glycine, $0.1 \% \mathrm{SDS}$ ) for $90 \mathrm{~min}$ at $100 \mathrm{~V}$. 
Loading of the marker PageRuler® Plus Prestained Protein Ladder (Fermentas, St. Leon-Rot, Germany) enabled estimation of molecular weights of the analyzed proteins.

Table 2.11 Resolving gel (10 or $12 \%$ ) used for electrophoresis

\begin{tabular}{ll}
\hline Ingredient & Percent/concentration \\
\hline Acrylamide/bis-acrylamide (29:1) solution & 10 or $12 \%$ \\
Tris-HCl pH 6.8 & $325 \mathrm{mM}$ \\
SDS & $0.1 \%$ \\
APS & $0.05 \%$ \\
TEMED & $0.005 \%(\mathrm{v} / \mathrm{v})$
\end{tabular}

\subsubsection{Western blotting}

After electrophoresis separation, proteins were subjected to Western blotting by using the Bio-Rad Mini-Protein System according to the manufacturer's instruction. In the procedure, proteins were transferred from SDS-polyacrylamide gels onto a Whatman ${ }^{\circledR}$ Protran Nitrocellulose Transfer Membrane (Whatman GmbH, Dassel, Germany) by application of $100 \mathrm{~V}$ for $55 \mathrm{~min}$ at room temperature in transfer buffer $(25 \mathrm{mM}$ Tris, $192 \mathrm{mM}$ glycine, $20 \%$ methanol).

Following transfer of proteins, the nitrocellulose membrane was incubated in $4 \%$ nonfat dried milk (Sigma-Aldrich Chemie, Munich, Germany) in PBS for $30 \mathrm{~min}$ at room temperature to avoid nonspecific binding of immunoglobulins. The membrane was then incubated with primary antibody in PBST (0.1\% Tween-20 in PBS) (dilutions according to Table 2.1) for at least $18 \mathrm{~h}$ at $4^{\circ} \mathrm{C}$ or $1 \mathrm{~h}$ at room temperature followed by 3 washing steps of $10 \mathrm{~min}$ in PBST at room temperature. Subsequently, the membrane was incubated with horseradish peroxidase(HRP) conjugated secondary antibody $(1: 1,000$ in PBST) for $1-2 \mathrm{~h}$ at room temperature and again washed 3x with PBST each washing step $10 \mathrm{~min}$.

HRP-antibody binding was visualized by chemiluminescence using Pierce ECL Western Blotting Substrate (Thermo Fisher Scientifc Inc., Rockford, IL, USA). The emitted light signal was captured on X-ray films (CL-XPosure ${ }^{\mathrm{TM}}$ Film, Thermo Fisher Scientific, Rockford, IL, USA), which were scanned with a conventional scanner. 
Results 


\subsection{Molecular changes in brain aging}

\subsubsection{Small RNAome of memory subregions in adult mouse brain}

In order to have an overview of the small RNAome of memory subregions in the adult brain, four subregions that are crucial in memory and cognitive function namely anterior cingulate cortex (ACC), dentate gyrus (DG), cornu ammonis (CA1) and (CA3) from 4-monthold mice ( $n=9$ ) were subjected to small RNA sequencing. As mentioned before ACC is responsible for long-term memory consolidation and formation in rodents (Weibele et al., 2012). Other three hippocampal subregions represent the short-term memory related areas. Our analysis revealed that microRNA (miRNA) is the biggest proportion of small RNAs in adult mice brain, small nucleolar RNAs (snoRNA) is the second abundant small RNAs and piwi-interacted RNA (piwiRNA) is the third most abundant small non-coding RNAs, read amounts of other small non-coding RNAs like ribosomal RNA (rRNA) and small nuclear RNA (snRNA) are extremely low (Fig. 3.1.1).

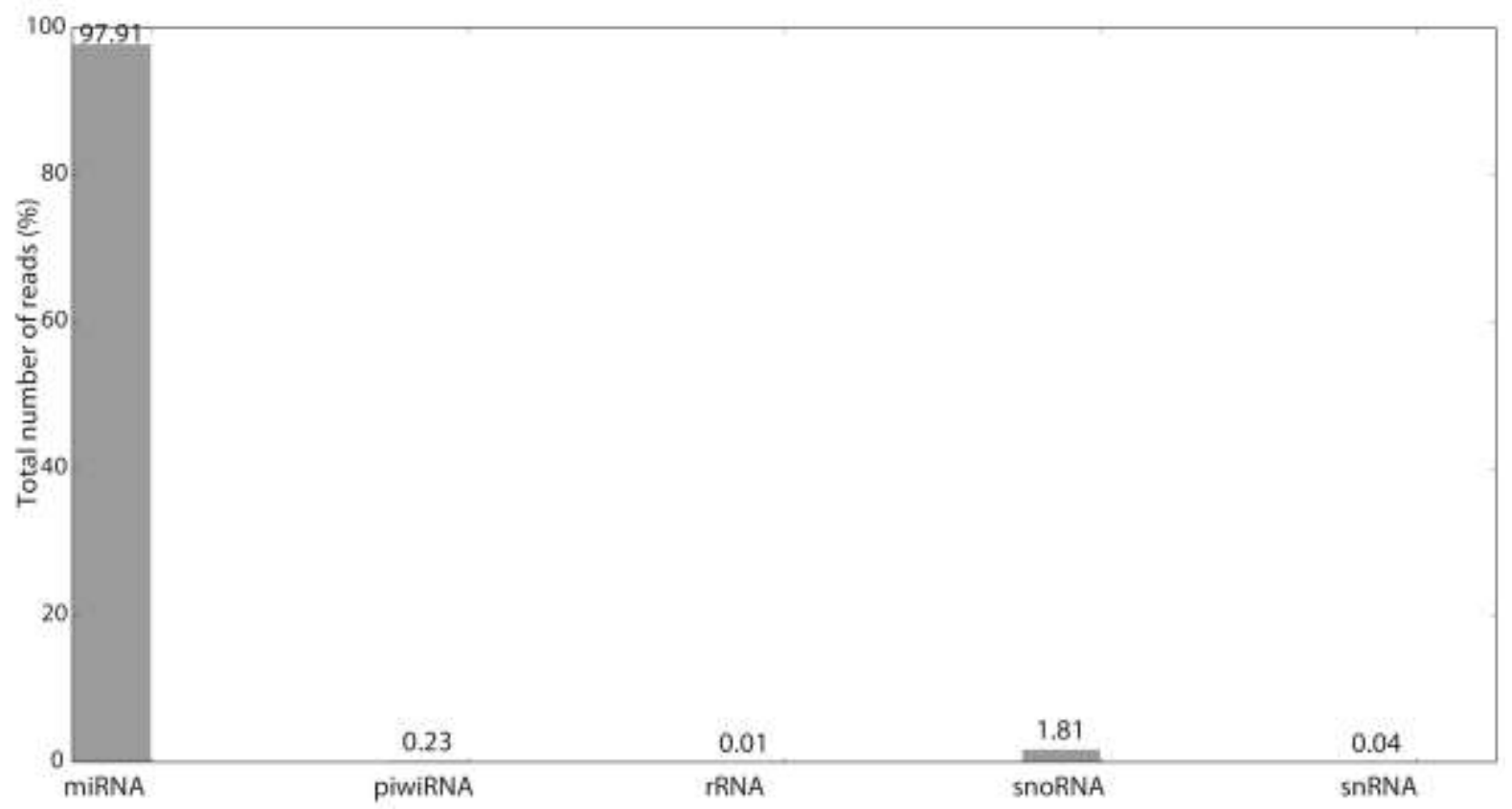

Fig. 3.1.1 Distribution frequency of mapped small RNA class reads combined for all brain regions. The bar graph shows that miRNAs are the most abundant class of small RNAs in memory subregions of young mice. SnoRNA population is the second most abundant small RNAs. 
Further analyses were concentrated on the miRNAs. We detected 205, 214, 200, 214 miRNAs in the CA1, CA3, DG and ACC of these mice respectively (Fig. 3. 1. 2A, facing page). Interestingly, 172 miRNAs are commonly expressed in all brain regions of young mice (Fig 3.1.2B facing page). Barplot in Fig 3.1.2C (facing page) displays the most frequent mapped miRNAs. MiRNAs with the expression level smaller than around $1.50 \%$ are shown as rest. As shown in Fig. 3.1.1, miR127-3p is the most frequent miRNA in brain subregions. Other highly expressed miRNAs are: 92b, 125a, 22, 92a, 99b, 128, 30d, 434, 191, 30a, 29a and 204 (Fig. 3.1.2C). In order to understand the association of these commonly expressed miRNAs with biological pathways, we used the IPA (ingenuity pathway analysis tool) for functional pathways identification taking into account only confirmed target genes.

Since ingenuity software ranks the cancer-related canonical pathways as the highest expressed canonical pathways, the top biological functions were linked to cancer mechanism, cell death and survival (Fig. 3.1. 2C). However the analyses revealed a number of highly enriched pathways that are linked to cell growth, tumor suppression, development and neurogenesis function such as cyclins cell cycle, PTEN (Phosphate and tensin homolog) signaling and Aryl hydrocarbon receptor (Fig 3.1.2D). 
A

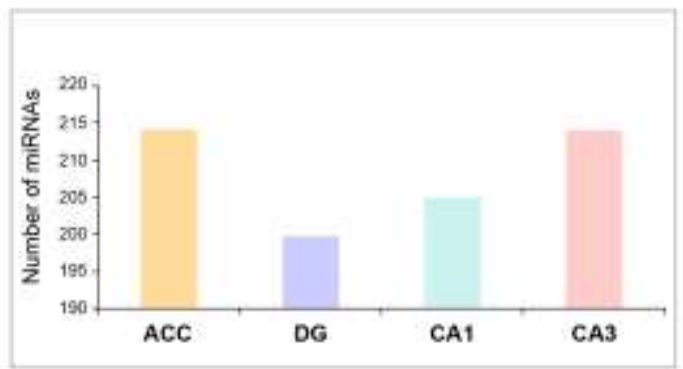

B

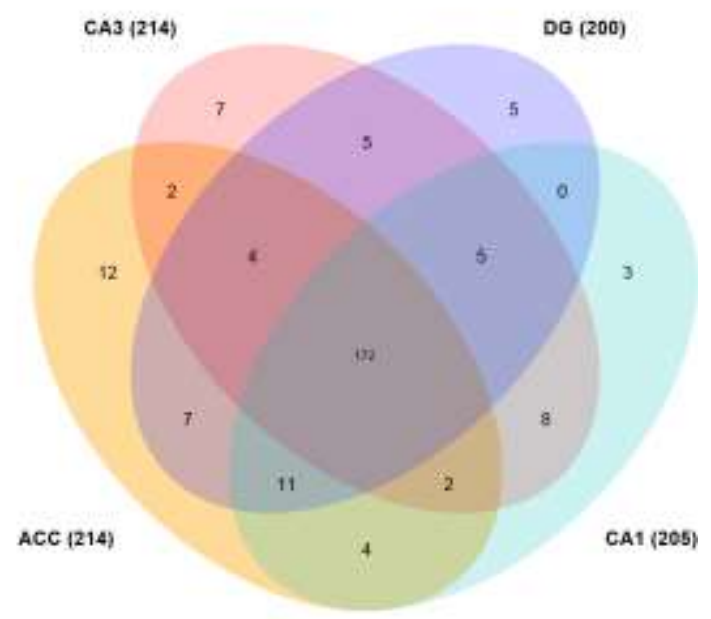

C

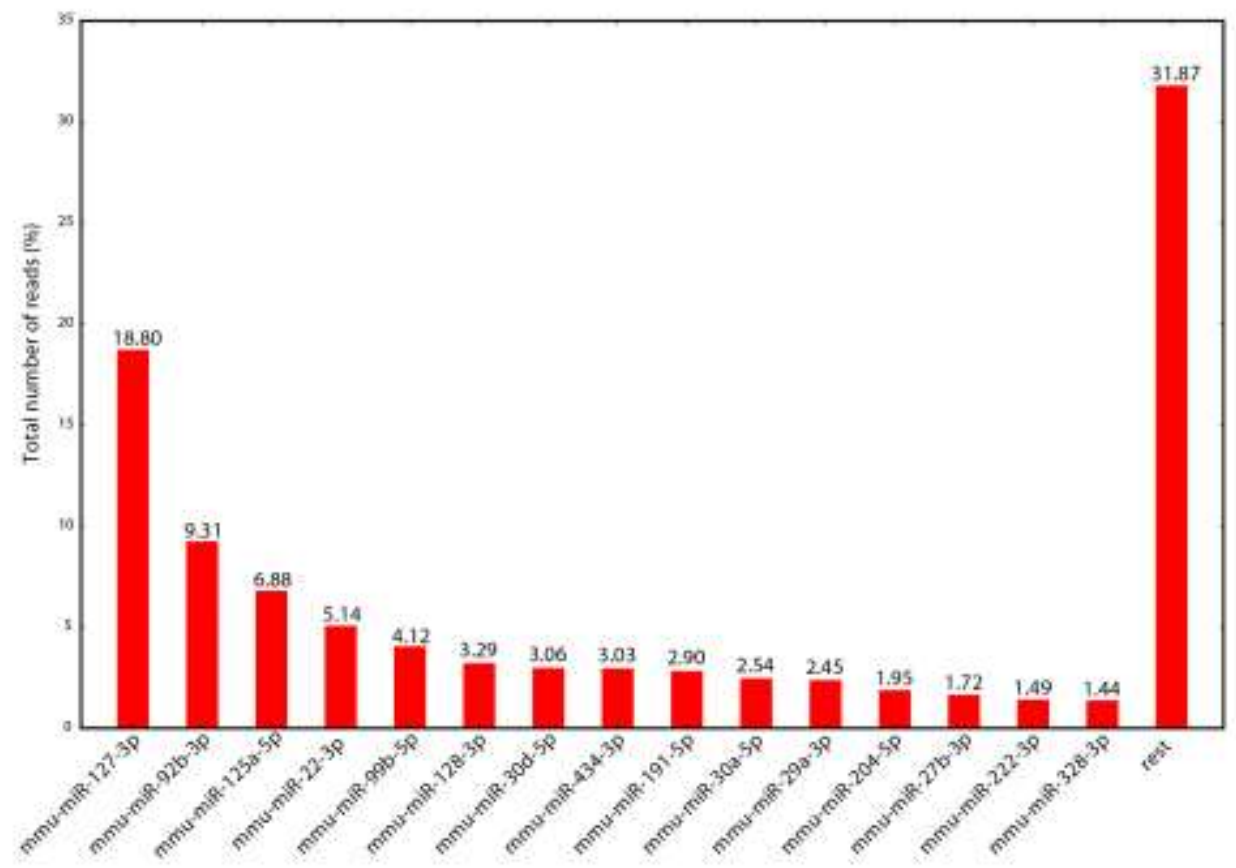

D

Aryl Hydrocarbon Receptor Signaling Cyclins and Cell Cycle Regulation Adipogenesis pathway Pancreatic Adenocarcinoma Signaling PTEN Signaling TGF- $\beta$ Signaling Role of Osteoblasts, Osteoclasts and Chondrocytes in Rheumatoid Arthritis Hepatic Fibrosis / Hepatic Stellate Cell Activation Cell Cycle: G1/S Checkpoint Regulation Molecular Mechanisms of Cancer

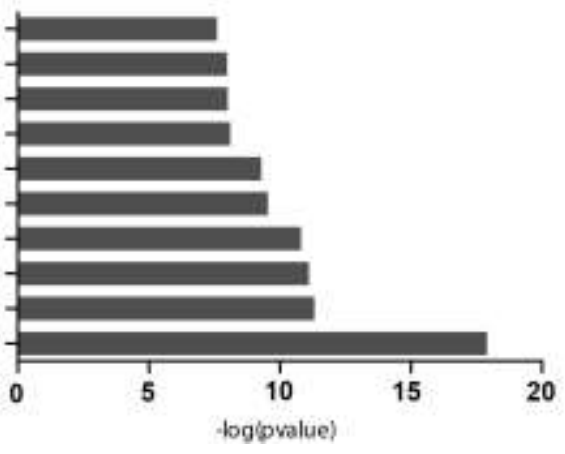

Fig. 3.1.2 Number of expressed miRNAs in different brain subregions of young mice (A) Number of unique and overlapping miRNAs in brain subregions (B) Most frequently expressed miRNAs in brain subregions of young mice (C) Top 10 canonical pathways regulated by highly expressed miRNAs (D). 
Aside from biological pathways that are correlated with neuronal function and develepoment, pathways that don't have direct correlation with the function of neurons like hepatic fibrosis, role of osteoblasts and chondrocytes in rheumatoid arthritis, pancreatic adenocarcinoma signaling and adipogenesis are also present.

Albeit the pathway analysis has to be interpreted with care, the data indicates that the four investigated brain subregions share a core miRNAome signature that controls key molecular pathways linked to brain cell development, homeostasis and plasticity.

Since our analysis was so far based on the presence or absence of a given miRNA, we decided to test if miRNAs present in the four brain subregions differ significantly regarding absolute expression level, which may point to distinct function of the investigated brain subregions. Hierarchical clustering analysis using Pearson correlation indicated that the four different brain subregions showed distinguishable expression profiles, which was particularly obvious for the DG (Fig. 3.1.3). Nevertheless, the correlation between all brain regions was still high.

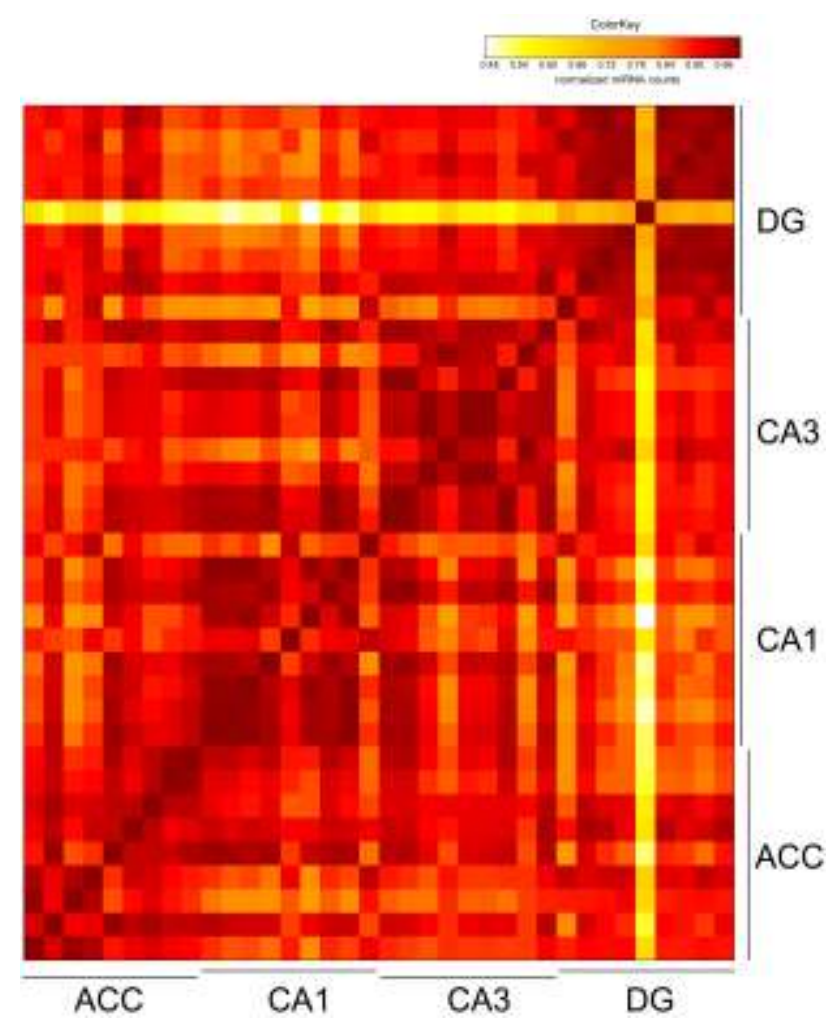

Fig. 3.1.3 Correlation (Pearson) matrix of miRNAome expression patterns between different brain subregions in young mice. It shows that DG has a most distinguishable expression profile. Samples with lower correlation are represented by the shades of yellow and samples with higher correlation are represented by the shades of orange to red. 


\subsubsection{MiRNA profile of memory subregions differs in young and old mice}

Many studies show role for selected miRNAs in neuronal plasticity, memory function and the pathogenesis of cognitive diseases such as $\mathrm{AD}$. To better understand the dynamics of the brain miRNAome during cognitive function and diseases, the small non-coding RNAome in young and old mice in ACC, DG, CA1 and CA3 (brain subregions) were compared. The laboratory of Prof. Fischer has established that 16- month old mice shown impared memory function, when compared to young 3-momth old mice (Peleg, 2010). Fig 3.1.4 shows unpublished data that was generated in the laboratory by another $\mathrm{PhD}$ student (Pooja Rao), showing impared learning in the Morris Water Maze test, a commonly used paradigm to analyze spatial memory in rodents.

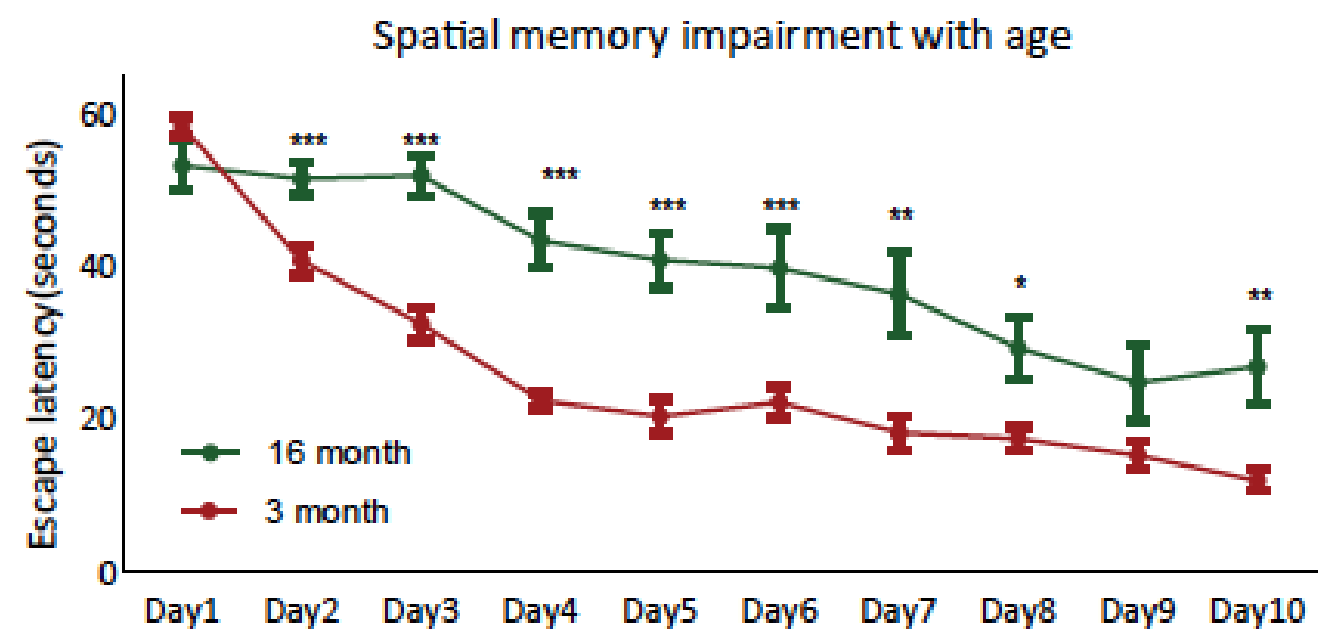

Fig. 3.1.4 Morris water maze experiment. Graphs show the escape latency of young (3-month) and old mice (16-month) throughout the water maze training. Old mice show significantly enhanced escape latency when compared to young mice, which is indicative of impaired spatial memory formation. Error bars indicate SEM. ( $\left.{ }^{*} \mathrm{P}<0.05 ; * * \mathrm{P}<0.01 ; * * * \mathrm{P}<0.001\right)$ (Courtesy Pooja Rao)

Analyses on small RNAome in old mice revealed that like young animals the major proportion of the small RNAome in the old animals are miRNAs and second most abundant small RNAs are snoRNAs (Fig. 3.1.5). In order to have an overview of the miRNA population in old animals in chosen brain subregions, we looked at number of expressed miRNA numbers in these subregions. The bar graph shows the number of miRNAs in ACC, DG, CA1 and CA3 (Fig. 3.1.6A, facing page). 191 miRNAs in ACC and 192 miRNAs in DG were detected respectively; while in CA1 and CA3 the number of detected miRNAs are 186 
and177. In total 155 commonly expressed miRNAs are detected (Fig. 3.1.6B, facing page). Bar plot in Fig. 3.1.6C (facing page) shows most abundant miRNAs. Like the young group, miR127-3p is the most abundant miRNA in brain subregions with $24.68 \%$ abundance out of all detected miRNAs in old mice. Other highly expressed miRNAs are: 92b, 125a, 191, 99b, 22, 434,27b, 128 and 204 (Fig. 3.1.6C, facing page).

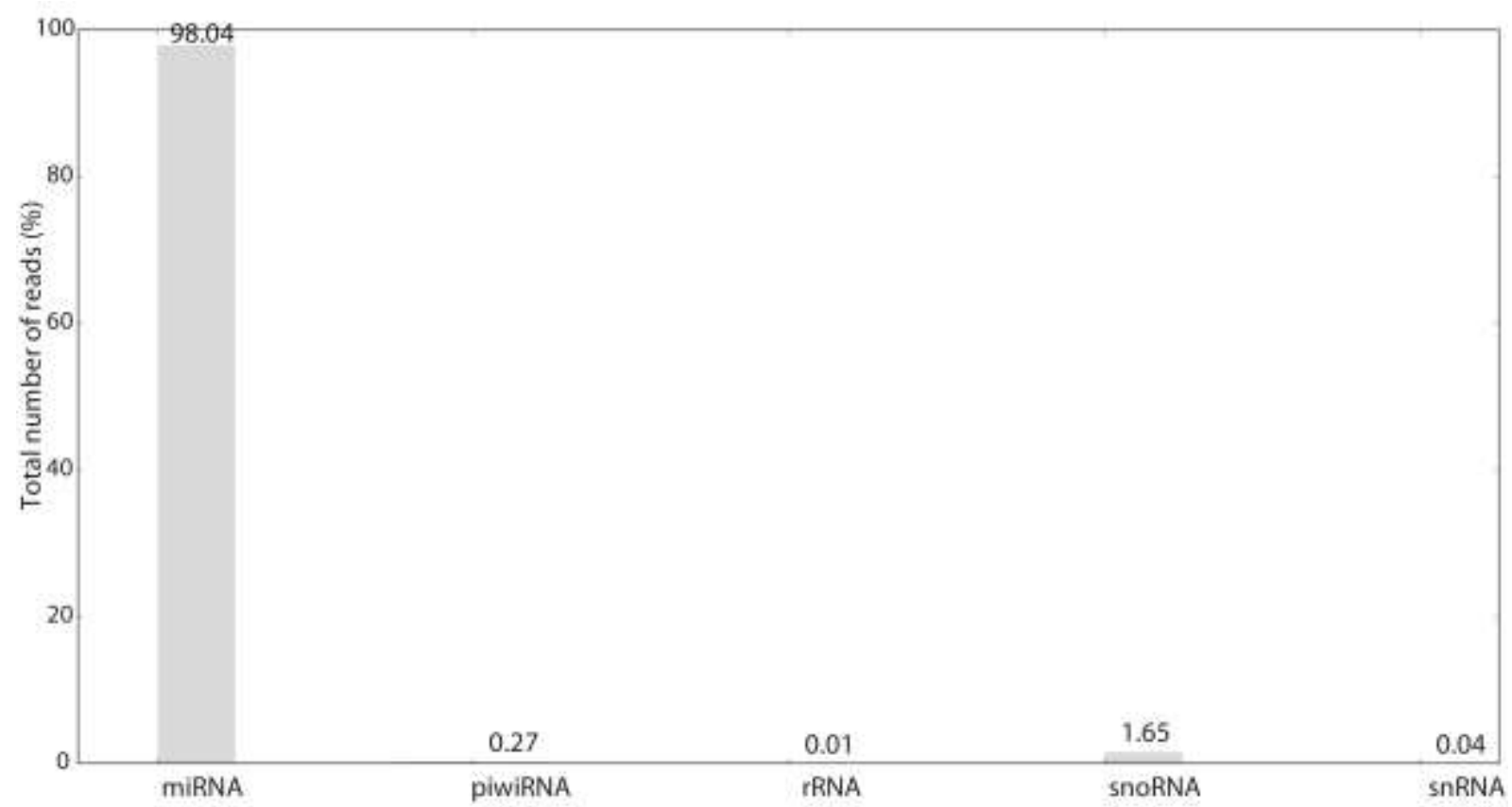

Fig. 3.1.5 Distribution frequency of mapped small RNA class reads combined for all brain regions. The bar graph shows that miRNAs are the most abundant class of small RNAs in memory subregions of aged mice. SnoRNA population is the second most abundant small RNAs. 
A

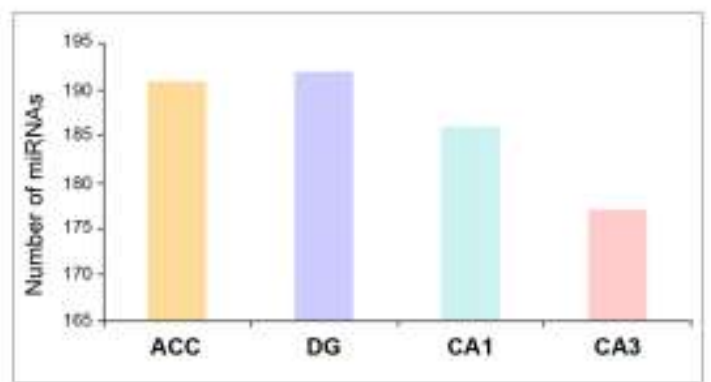

B

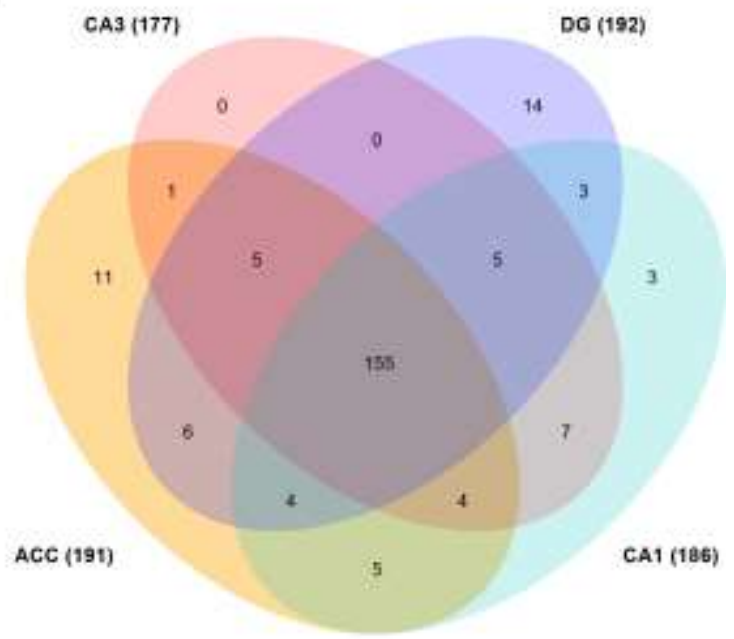

C

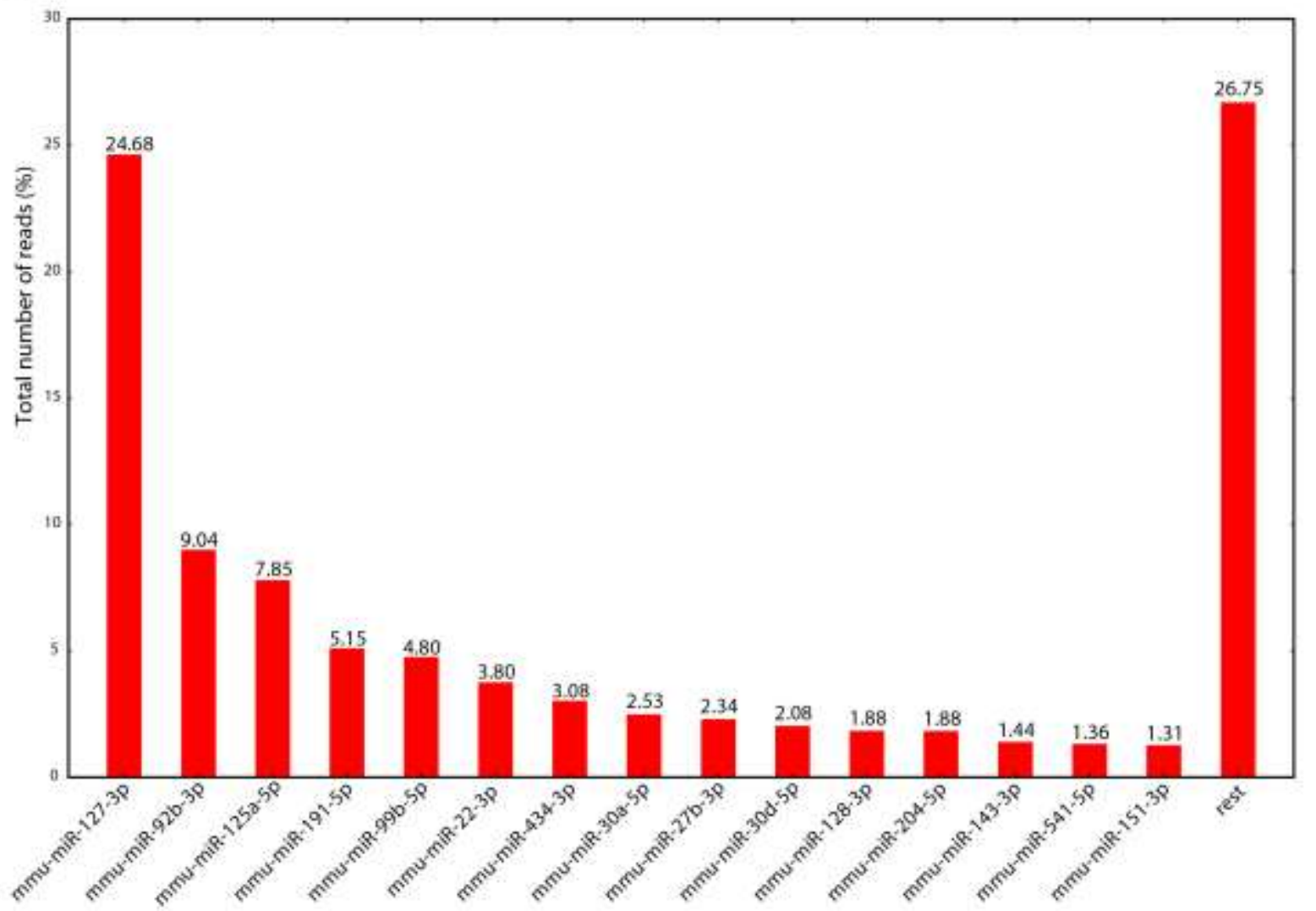

Fig.3.1.6 Number of expressed miRNAs in different brain subregions of old mice (A) Number of unique and overlapping miRNAs in brain subregions (B) Most frequently expressed miRNAs in brain subregions of old mice (C). 
The data analyses so far were based on screening the miRNAome in young and old animals according to their uniquely mapped reads. To understand the difference between miRNAome of memory subregions in young and old mice and to trace the influence of aging on the miRNA pool of the memory subregions, we performed differential expression analyses (padj $<0,05$; $\log 2$ fold change $<>0,5$; basemean $>=100$ ).

In all investigated brain subregions, we found remarkable number of miRNAs that were differentially expressed when comparing the young to old brain (Fig. 3.1.7 A-D, facing page) some of them with fold change greater than 20, which are almost exceptional for the regulation of miRNAs. We found 120 differentially expressed miRNAs (padj < 0,05; $\log 2$ fold change $<>0,5$; basemean $>=100$ ) in ACC, 86 miRNAs in CA1, 166 in CA3 and 104 in DG (Fig 3.1.8, facing page). This data suggests that while the four investigated brain subregions share a substantial miRNAome signature, the aging process affects these brain regions in a distinct manner. The number of differentially expressed miRNAs is not the same in all subregions. CA1 with 86 has the lowest amount of differentially expressed miRNAs while its adjacent subregion CA3 has the largest number of differentially expressed miRNA.

We then looked at miRNAome expression patterns in aged mice by performing a hierarchical clustering analysis on the correlation (Pearson) matrix of brain subregions, which showed a clear separation of these four subregions (Fig. 3.1.9). ACC and DG display more significant changes when comparing to CA1 and CA3. 
A
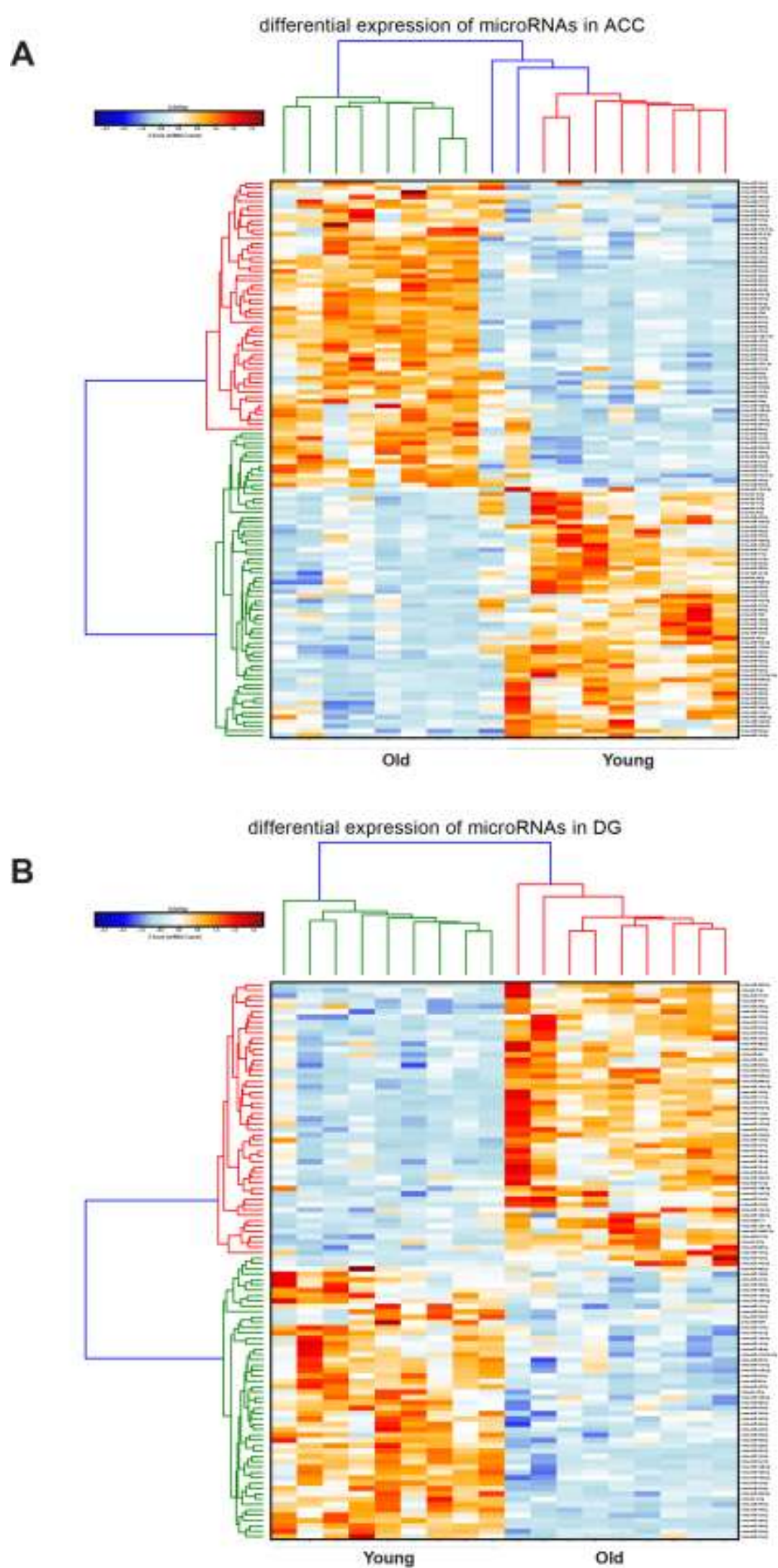

Fig. 3.1.7 (A-B) Heat maps show the Euclidean distances between the differentially expressed miRNAs in old over young animals. (A) and (B) show the clustration of the miRNAs in the ACC and DG respectively. 

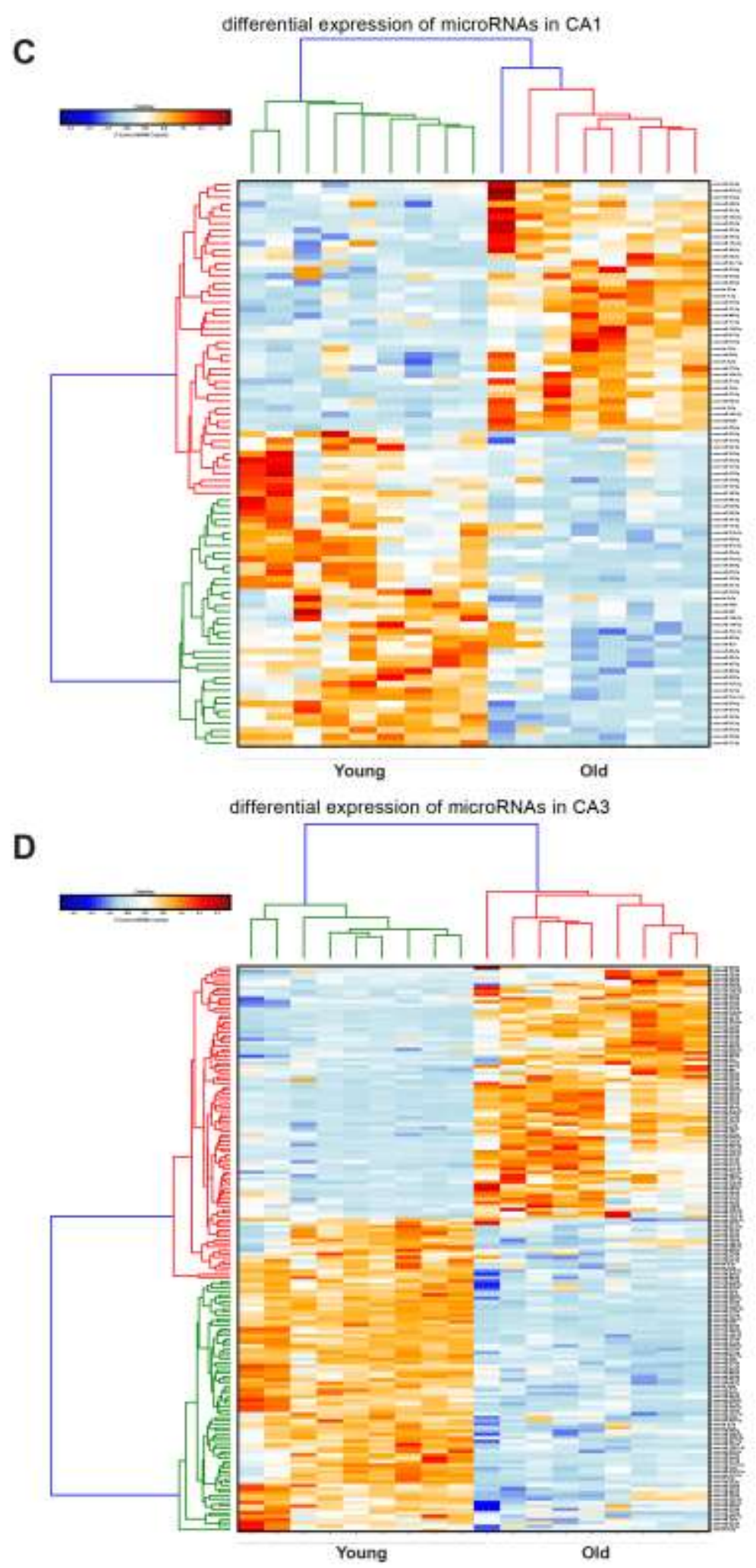

Fig. 3.1.7 (C-D) Heat maps show the Euclidean distances between the differentially expressed miRNAs in old over young animals. (C) and (D) heat maps show the clustration of the miRNAs in the CA1 and CA3 respectively. As it is pictured in the key color, colors in red region show higher and colors in blue region show lower expression. 


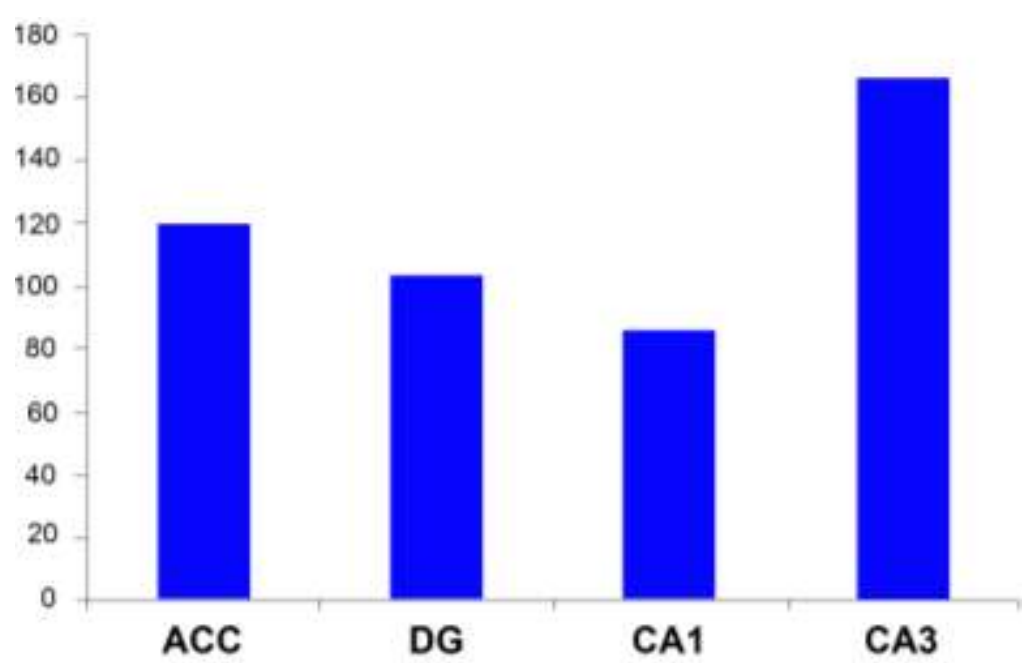

Fig. 3.1.8 Number of the differentially expressed miRNAs in the brain subregions of young and old mice.

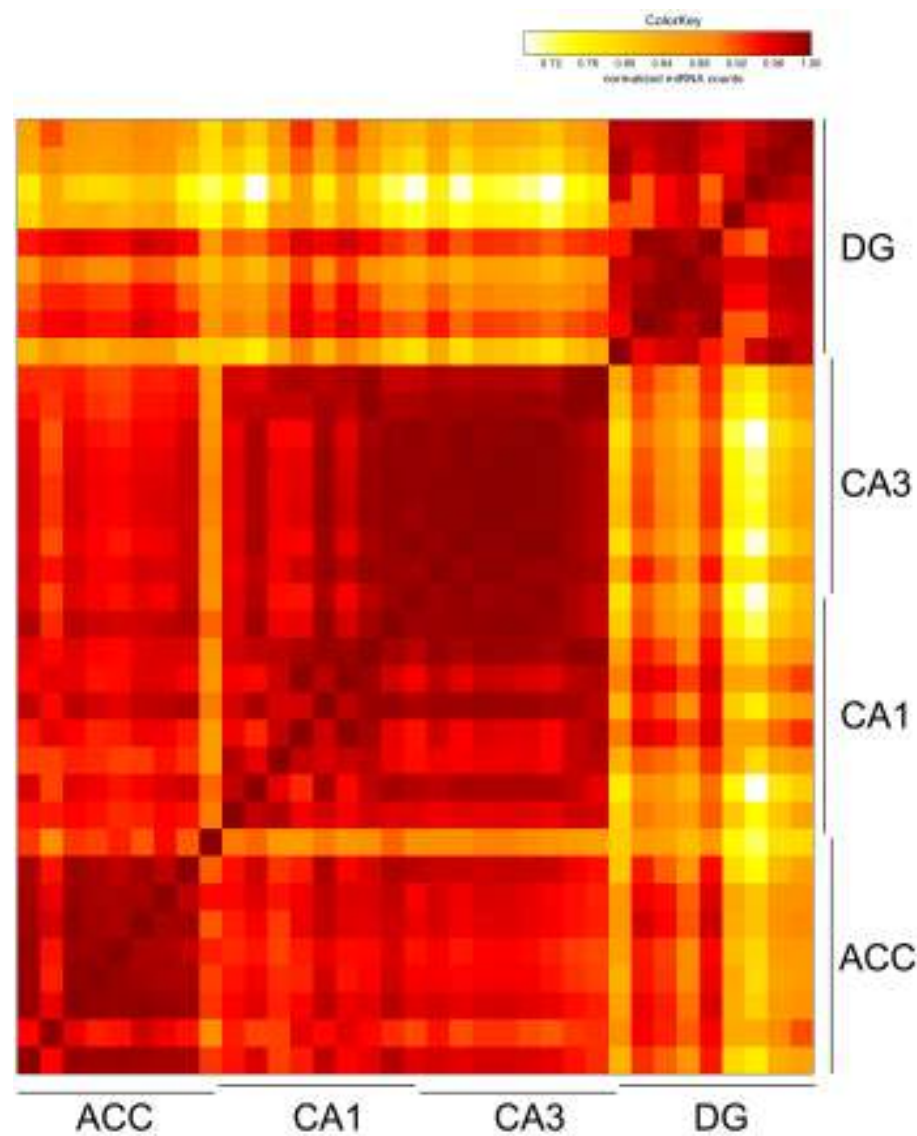

Fig. 3.1.9 Correlation (Pearson) matrix of miRNAome expression patterns between different brain subregions in aged mice. Samples with lower correlation are represented by the shades of yellow and samples with higher correlation are represented by the shades of orange to red. 
Differential expression analyses of miRNAs for each subregion gave us a closer look at miRNA deregulation along aging. Of note, deregulation pattern of the miRNAs differs from region to region, for example one miRNA that is upregulated in ACC might be downregulated in CA1 and vice versa. To have a better understanding of the effect of aging on the miRNAome of brain memory subregions, we looked at the common upregulated miRNAs in brain subregions and also the common downregulated miRNAs along aging in the brain. We found four commonly upregulated miRNAs in brain subregions upon aging. These miRNAs are: miR-10a-5p, miR-191-5p, miR-411-3p and miR-541-5p (Fig.3.1.10A, facing page). Pathway analyses for these commonly upregulated miRNAs revealed that these miRNAs are associated with immune system coordination and activation, pathways like communication between innate and adaptive immune system, TREM1 (Triggering Receptor Expressed on Myeloid cells 1) signaling which is correlated with inflammatory responses in the cell, dendritic cell maturation that is crucial in antigen processing and Interleukines production pathways (Fig.3.1.10B, facing page).

Venn diagram in (Fig.3.1.11A) shows that there are six commonly downregulated miRNAs in all investigated brain subregions. These miRNAs are: miR-137-3p, miR-298-5p, miR-29c-3p, miR-504-5p, miR-543-3p and miR-708-3p. Pathway analyses for these commonly downregulated miRNAs showed that few of these pathways are associated with inflammation and immune system activity like dendritic cell maturation and cyclin and cell cycle regulation (Fig.3.1.11B). In total, upregulated and downregulated miRNAs along aging in these subregions are correlated with cell proliferation and immune system activity.

Apart from the commonly deregulated miRNAs in these brain subregions, we were able to find miRNAs, which are specifically deregulated in each memory subregion. Table 3.1 shows the list of miRNAs that are downregulated or upregulated specifically in each memory subregion. CA1 shows the lowest number of exclusively deregulated miRNAs and CA3 has the largest number of excusively upregulated and downregulated miRNAs. 
A

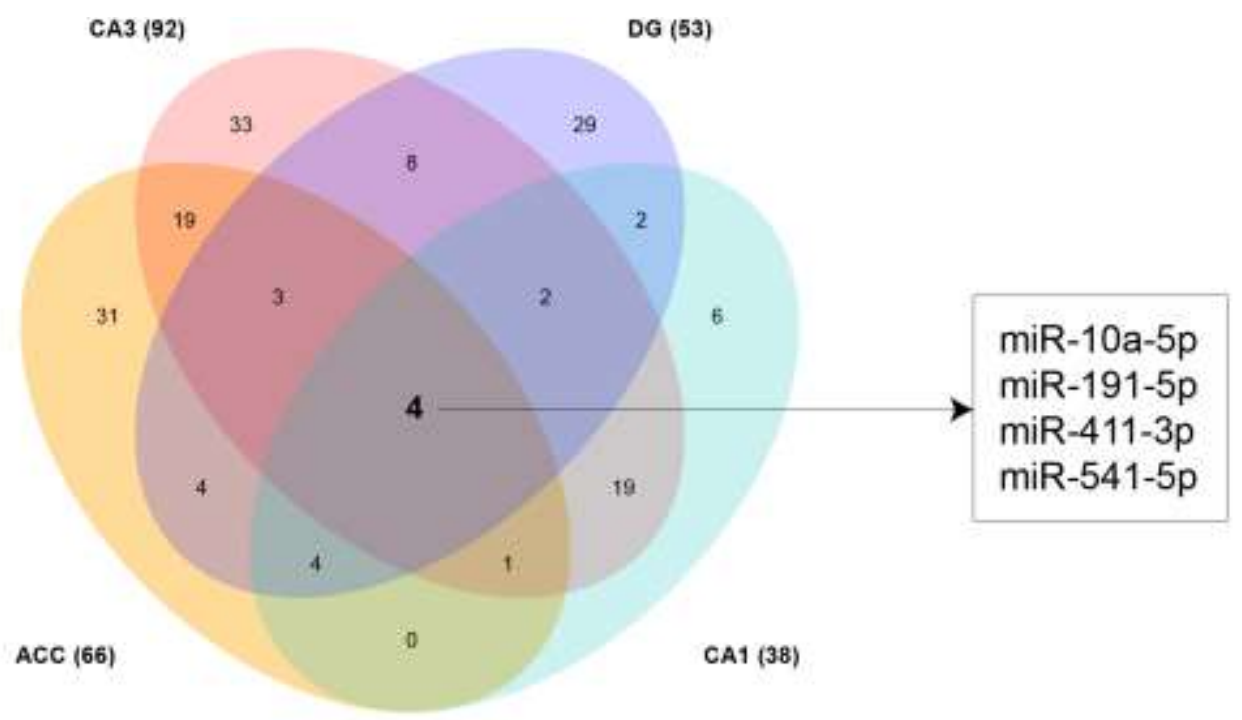

B

Differential Regulation of Cytokine Production in Macrophages and T Helper Cells by IL-17A and IL-17F Role of Macrophages, Fibroblasts and Endothelial Cells in Rheumatoid Arthritis Colorectal Cancer Metastasis Signaling
Dendritic Cell Maturation Role of Pattern Recognition Receptors in Recognition of Bacteria and Viruses LXR/RXR Activation Crosstalk between Dendritic Cells and Natural Killer Cells Altered T Cell and B Cell Signaling in Rheumatoid Arthritis TREM1 Signaling Communication between Innate and Adaptive Immune Cells

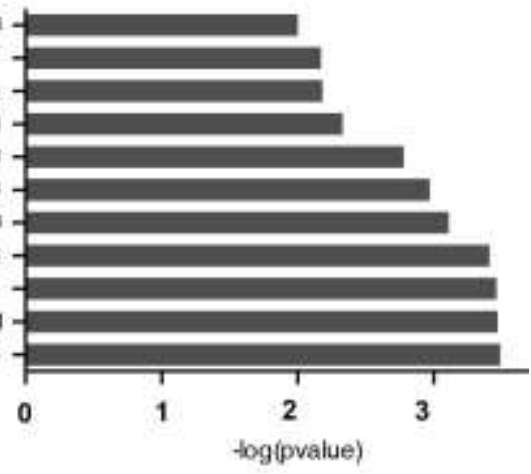

Fig. 3.1.10 Venn diagram shows commonly upregulated miRNAs in brain subregions upon aging (A) Shows top 10 canonical pathways that are associated with the four commonly upregulated miRNAs in brain subregions (B). 
A

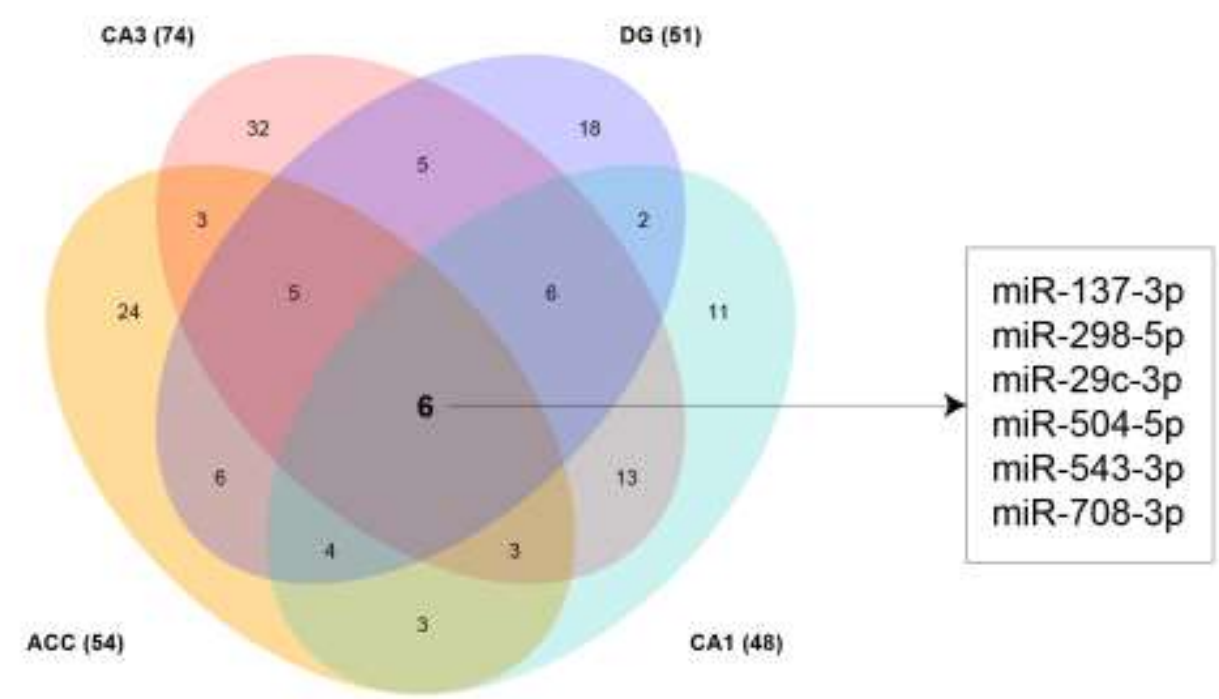

B

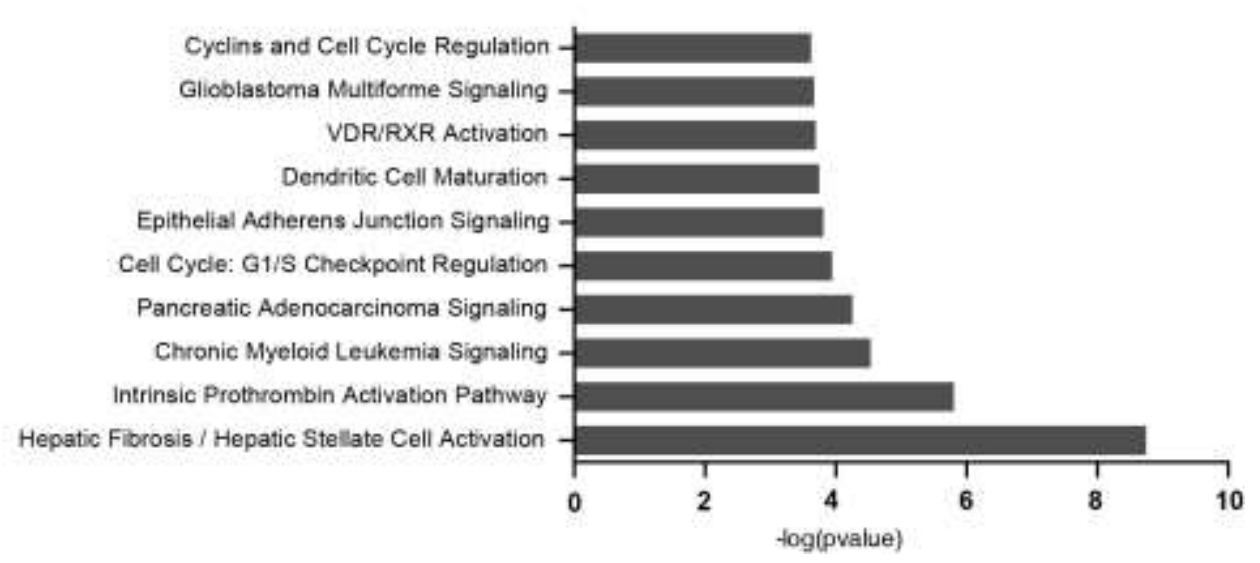

Fig. 3.1.11 Venn diagram shows the commonly downregulated miRNAs in all brain subregions upon aging (A) Top 10 canonical pathways that are associated with the 6 commonly downregulated miRNAs in all brain subregions (B). 
Table 3.1 List of miRNAs that are upregulated and downregulated along aging specifically in each memory subregion.

\begin{tabular}{|c|c|c|c|c|c|c|}
\hline & \multicolumn{3}{|c|}{ Upregulated along aging } & \multicolumn{3}{|c|}{ Downregulated along aging } \\
\hline \multirow{11}{*}{$\stackrel{8}{\Omega}$} & $\operatorname{miR}-125 b-2-3 p$ & miR-3061-3p & miR-431-3p & let- $7 a-5 p$ & miR-139-5p & $\operatorname{miR}-412-5 p$ \\
\hline & miR-125b-5p & miR-326-3p & $\operatorname{miR}-434-3 p$ & let- $7 c-5 p$ & miR-1839-5p & $\operatorname{miR}-495-3 p$ \\
\hline & miR-127-5p & miR-330-5p & $\operatorname{miR}-434-5 p$ & let-7d-5p & miR-1843a-3p & miR-598-3p \\
\hline & miR-1298-3p & miR-338-3p & $\operatorname{miR}-540-3 p$ & let- $7 e-5 p$ & miR-185-5p & $\operatorname{miR}-6540-5 p$ \\
\hline & miR-132-3p & $\operatorname{miR}-346-5 p$ & $\operatorname{miR}-582-3 p$ & let- $7 f-5 p$ & miR-221-3p & miR-673-5p \\
\hline & miR-140-3p & $\operatorname{miR}-370-3 p$ & $\operatorname{miR}-652-3 p$ & let-7g-5p & miR-3068-3p & miR-6944-3p \\
\hline & miR-149-5p & miR-381-3p & $\operatorname{miR}-666-5 p$ & miR-1224-5p & miR-320-3p & miR-7080-3p \\
\hline & $\operatorname{miR}-181 c-3 p$ & miR-383-5p & miR-676-3p & miR-128-3p & miR-322-3p & miR-7224-3p \\
\hline & miR-1981-5p & miR-410-3p & miR-7019-3p & & & \\
\hline & miR-24-2-5p & $\operatorname{miR}-423-3 p$ & miR-7046-3p & & & \\
\hline & & & $\operatorname{miR}-92 a-3 p$ & & & \\
\hline \multirow{10}{*}{ ఠ̊ } & let-7i-3p & miR-3102-3p & miR-486-5p & miR-101b-3p & miR-324-3p & \\
\hline & $\operatorname{miR}-1247-5 p$ & $\operatorname{miR}-325-3 p$ & $\operatorname{miR}-543-5 p$ & $\operatorname{miR}-126 a-5 p$ & $\operatorname{miR}-328-3 p$ & \\
\hline & miR-128-2-5p & miR-340-3p & miR-664-3p & miR-1306-5p & miR-345-3p & \\
\hline & $\operatorname{miR}-132-5 p$ & $\operatorname{miR}-344 d-3-5 p$ & miR-6948-3p & miR-148a-3p & $\operatorname{miR}-434-3 p$ & \\
\hline & $\operatorname{miR}-145 a-5 p$ & $\operatorname{miR}-345-5 p$ & miR-6989-3p & miR-148b-3p & $\operatorname{miR}-483-3 p$ & \\
\hline & miR-148a-5p & $\operatorname{miR}-3535$ & miR-7044-3p & miR-1964-3p & miR-5099 & \\
\hline & miR-1839-3p & miR-361-5p & miR-7220-5p & miR-21a-5p & miR-92a-3p & \\
\hline & $\operatorname{miR}-212-3 p$ & miR-369-5p & miR-8111 & $\operatorname{miR}-26 b-5 p$ & $\operatorname{miR}-98-3 p$ & \\
\hline & miR-212-5p & miR-376b-5p & miR-874-3p & miR-296-5p & $\operatorname{miR}-99 a-3 p$ & \\
\hline & mmiR-23b-3p & $\operatorname{miR}-484$ & & & & \\
\hline \multirow{6}{*}{$\Omega$} & let-7d-5p & & & miR-125b-5p & $\operatorname{miR}-221-5 p$ & \\
\hline & miR-185-5p & & & miR-1298-5p & $\operatorname{miR}-341-3 p$ & \\
\hline & miR-195a-5p & & & miR-140-3p & miR-377-3p & \\
\hline & miR-335-3p & & & miR-181a-1-3p & miR-381-3p & \\
\hline & miR-384-5p & & & miR-181c-5p & miR-409-5p & \\
\hline & miR-877-3p & & & & $\operatorname{miR}-758-3 p$ & \\
\hline \multirow{11}{*}{$\stackrel{\Omega}{R}$} & let- $7 b-3 p$ & miR-1843a-5p & $\operatorname{miR}-488-3 p$ & miR-129-1-3p & $\operatorname{miR}-23 b-3 p$ & miR-423-3p \\
\hline & let- $7 f-5 p$ & miR-1843b-3p & miR-598-3p & miR-130b-5p & miR-24-2-5p & $\operatorname{miR}-434-5 p$ \\
\hline & let- $7 i-5 p$ & miR-1843b-5p & miR-664-5p & miR-132-5p & $\operatorname{miR}-27 a-3 p$ & miR-487b-3p \\
\hline & miR-106b-3p & miR-1981-3p & miR-667-3p & miR-138-1-3p & miR-322-5p & miR-582-5p \\
\hline & miR-10b-5p & miR-3057-5p & miR-671-3p & miR-151-5p & miR-338-3p & miR-708-5p \\
\hline & miR-125b-1-3p & $\operatorname{miR}-3078-5 p$ & $\operatorname{miR}-673-5 p$ & miR-187-3p & miR-340-3p & $\operatorname{miR}-744-3 p$ \\
\hline & miR-139-3p & miR-3099-3p & miR-7068-3p & miR-190a-5p & $\operatorname{miR}-345-5 p$ & miR-770-5p \\
\hline & miR-148a-3p & miR-323-3p & miR-8114 & miR-212-3p & miR-34b-3p & miR-7a-1-3p \\
\hline & miR-148b-3p & miR-3475-3p & miR-873a-5p & miR-219a-5p & miR-374b-5p & miR-7a-2-3p \\
\hline & miR-152-3p & miR-369-3p & miR-877-5p & miR-222-3p & miR-376a-5p & miR-874-5p \\
\hline & miR-184-3p & miR-411-5p & miR-92b-3p & miR-23a-3p & miR-376b-3p & \\
\hline
\end{tabular}




\subsubsection{Blood small RNAome changes along aging}

An additional focus of this project so far was to find out the aging-induced changes at epigenome level in memory and learning subregions of the brain in mice. Since searching for miRNA biomarkers in the biofluids is becoming more important in neurodegenerative diseases research field, an interesting approach was to survey aging influence on blood small RNAome as a non-invasive method. Furthermore, it was also of paramount importance to seek if the aging-induced changes in brain could also be detected in blood. Blood was also taken from the same mice that their brain subregions were subjected to RNA isolation and NGS. Similar to brain subregions, the biggest population of small RNAome in blood is also miRNAs but second most abundant small RNAs are piwiRNAs (Fig. 3.1.12). Other small non-coding RNAs like snoRNA, rRNA and sRNA are extremely low.

The highly abundant miRNAs in blood samples is different from highly abundant miRNAs brain samples; miR-451a, miR-92a, and miR-191 are amongst the most expressed miRNAs in blood (Fig. 3.1.13). However there are some common miRNAs between blood and brain highly expressed miRNAs, these miRNAs are: miR-191, miR-22, miR-30a, miR-30d and miR-151. To find out the importance of these differences and similarities more detailed analyses were performed.

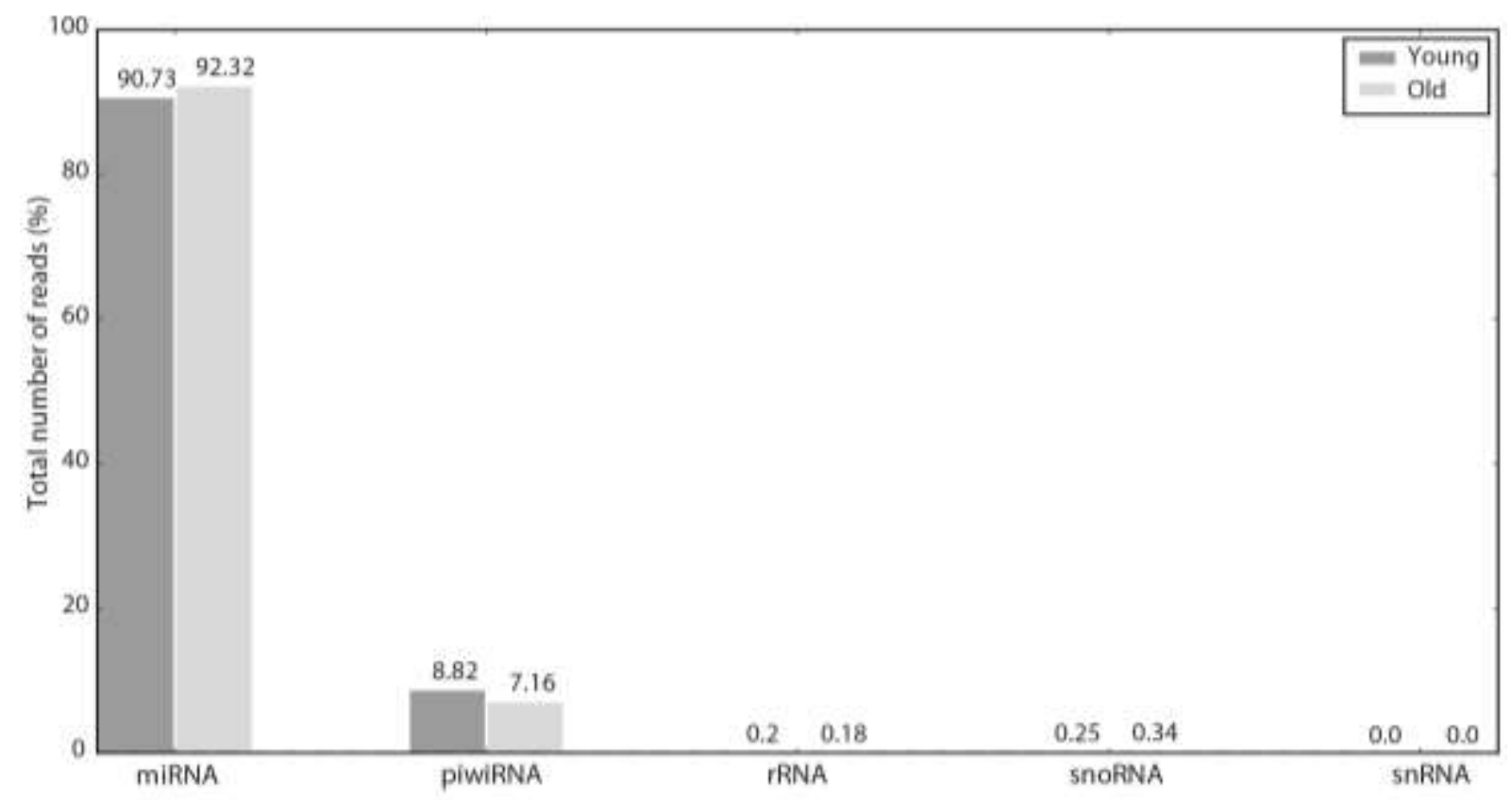

Fig. 3.1.12 The bar graph shows that miRNA are the most abundant class of small RNAs in blood of young and aged mice. PiwiRNAs with $8.82 \%$ in young and $7.16 \%$ in old animals are the second most abundant small RNA. 
A

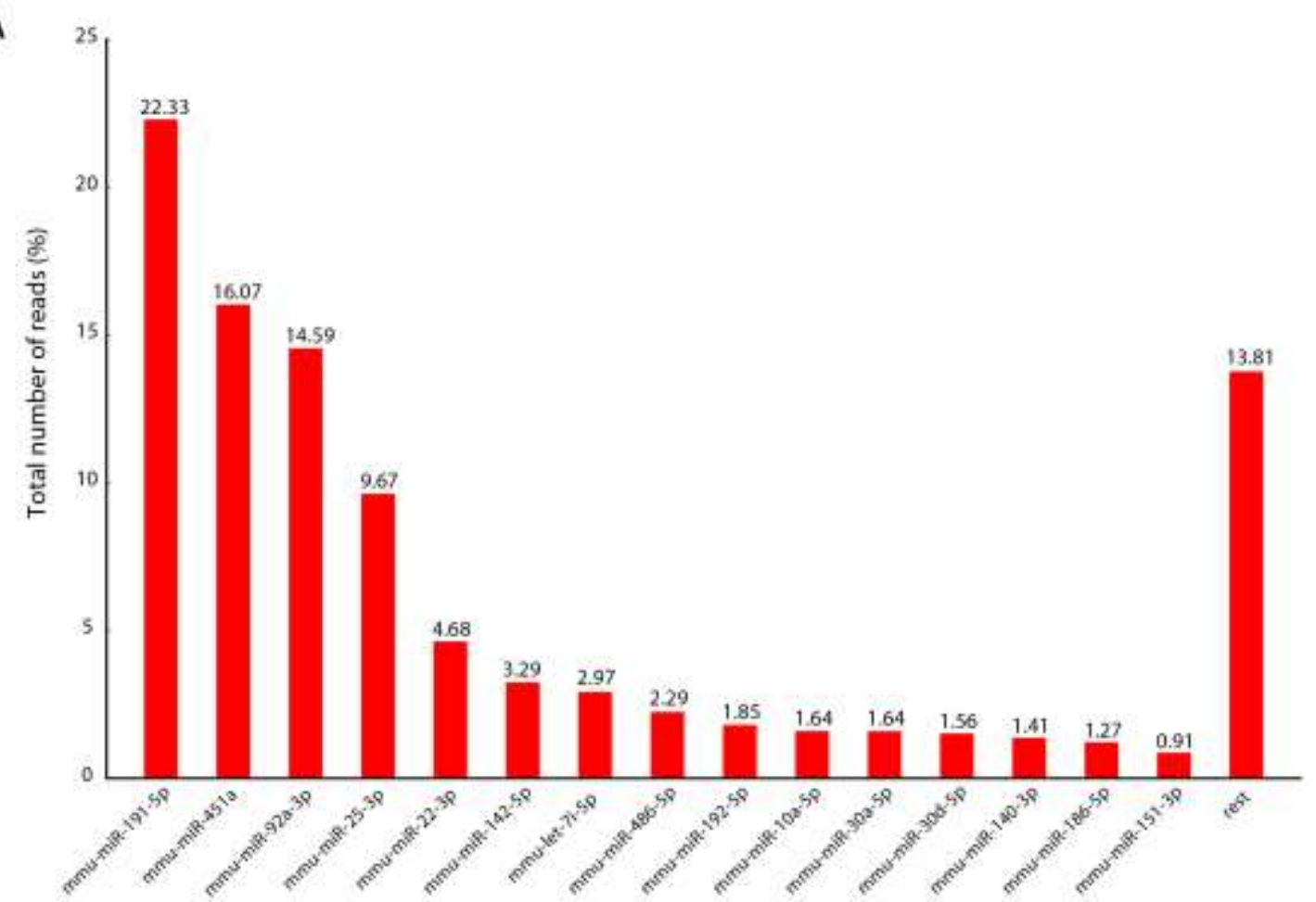

B

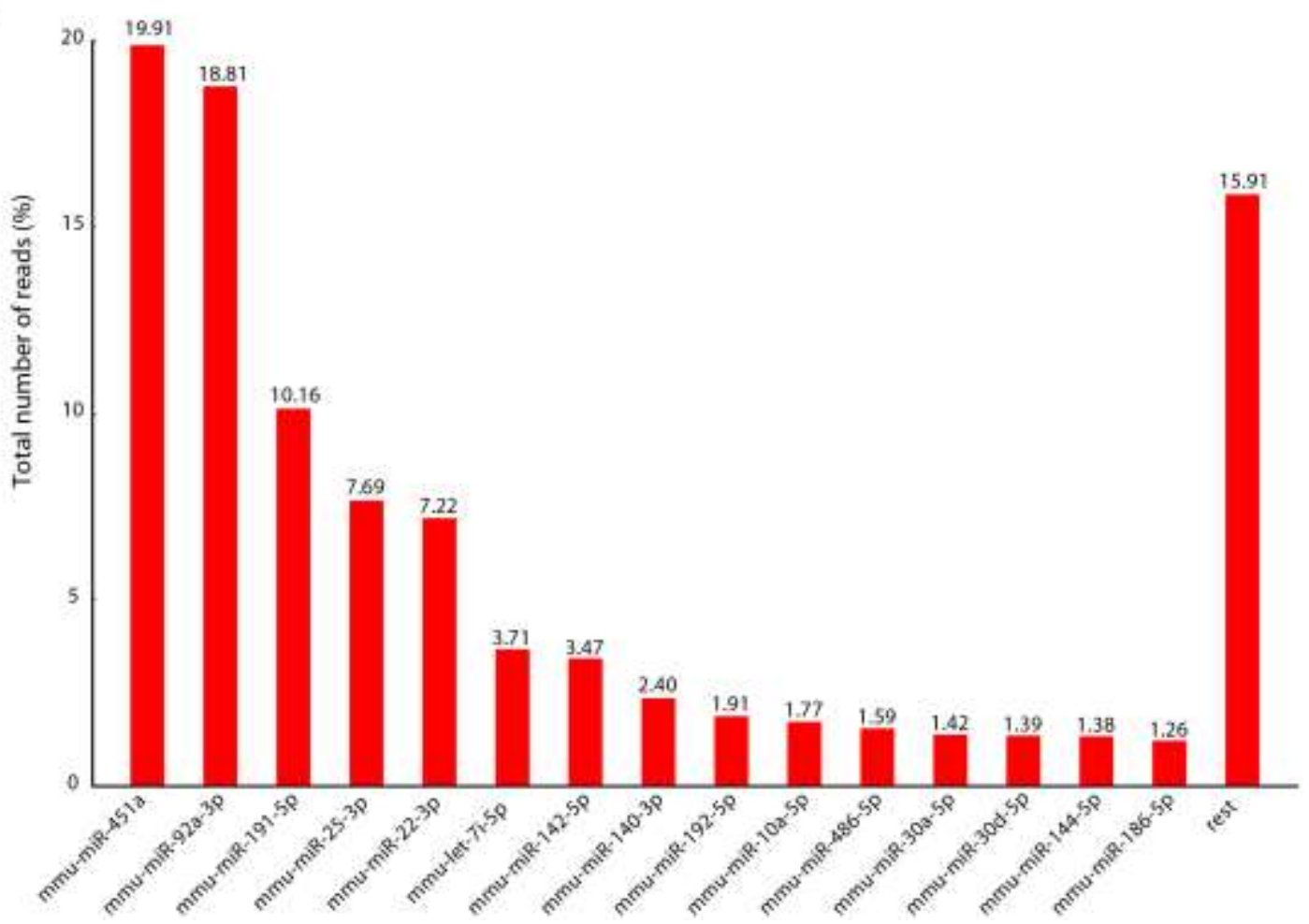

Fig. 3.1.13 Blood miRNA population by frequency of uniquely mapped reads in young (A) and in old mice (B). 


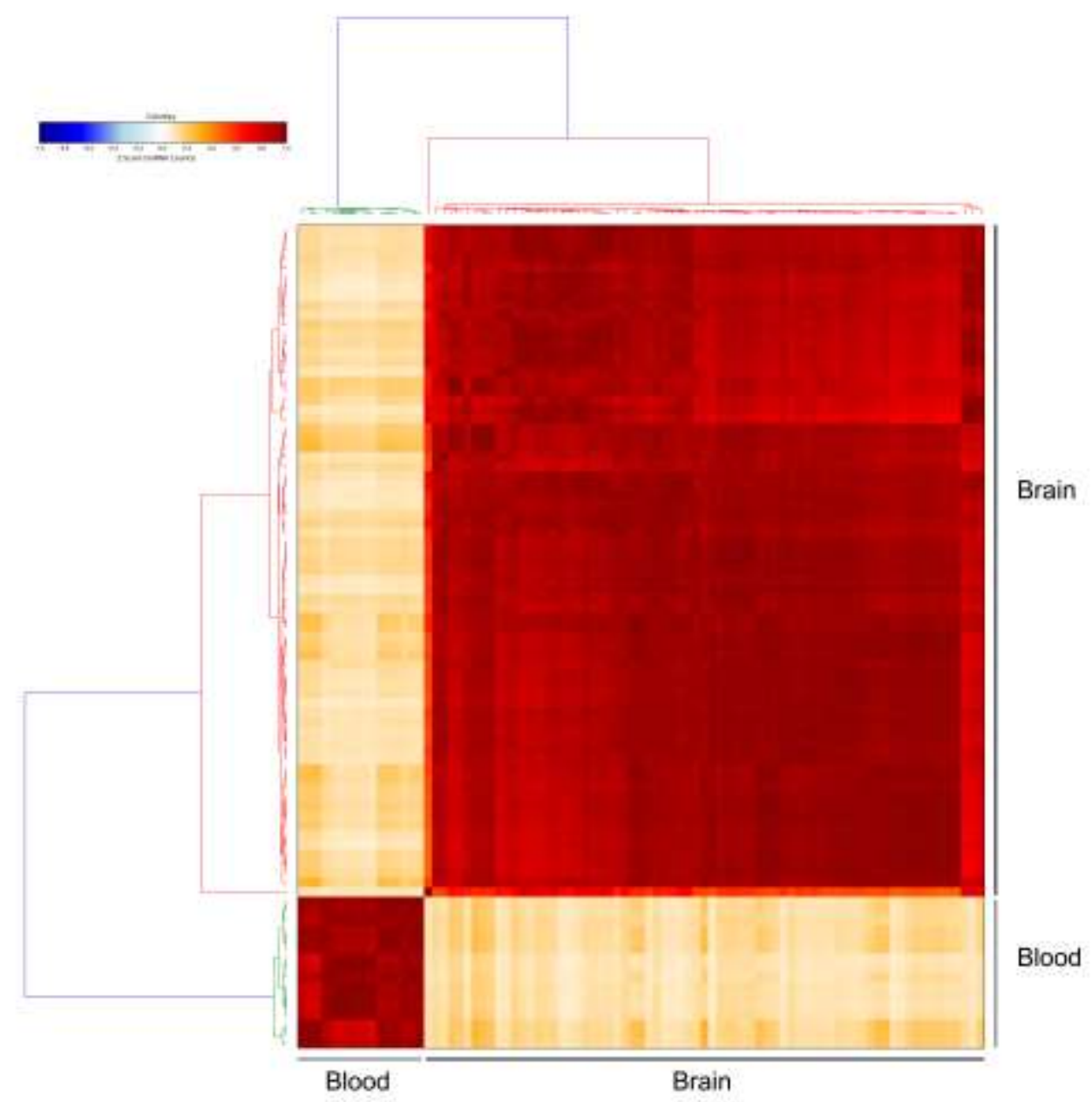

Fig. 3.1.14 Heat map shows the correlation between miRNAs in the brain and blood in both young and old group. Clustering pattern shows brain miRNAome is different from blood miRNAome.

Further clustering analysis shows that the blood miRNAome in young and old mice is substantially different from the same animals' brain miRNAome (Fig 3.1.14). While this is expected, an interesting question here is to see if there is an overlap between the aging brain and blood miRNAome. To this end we first compared the blood miRNAome in young and old mice (Fig 3.1.15). 


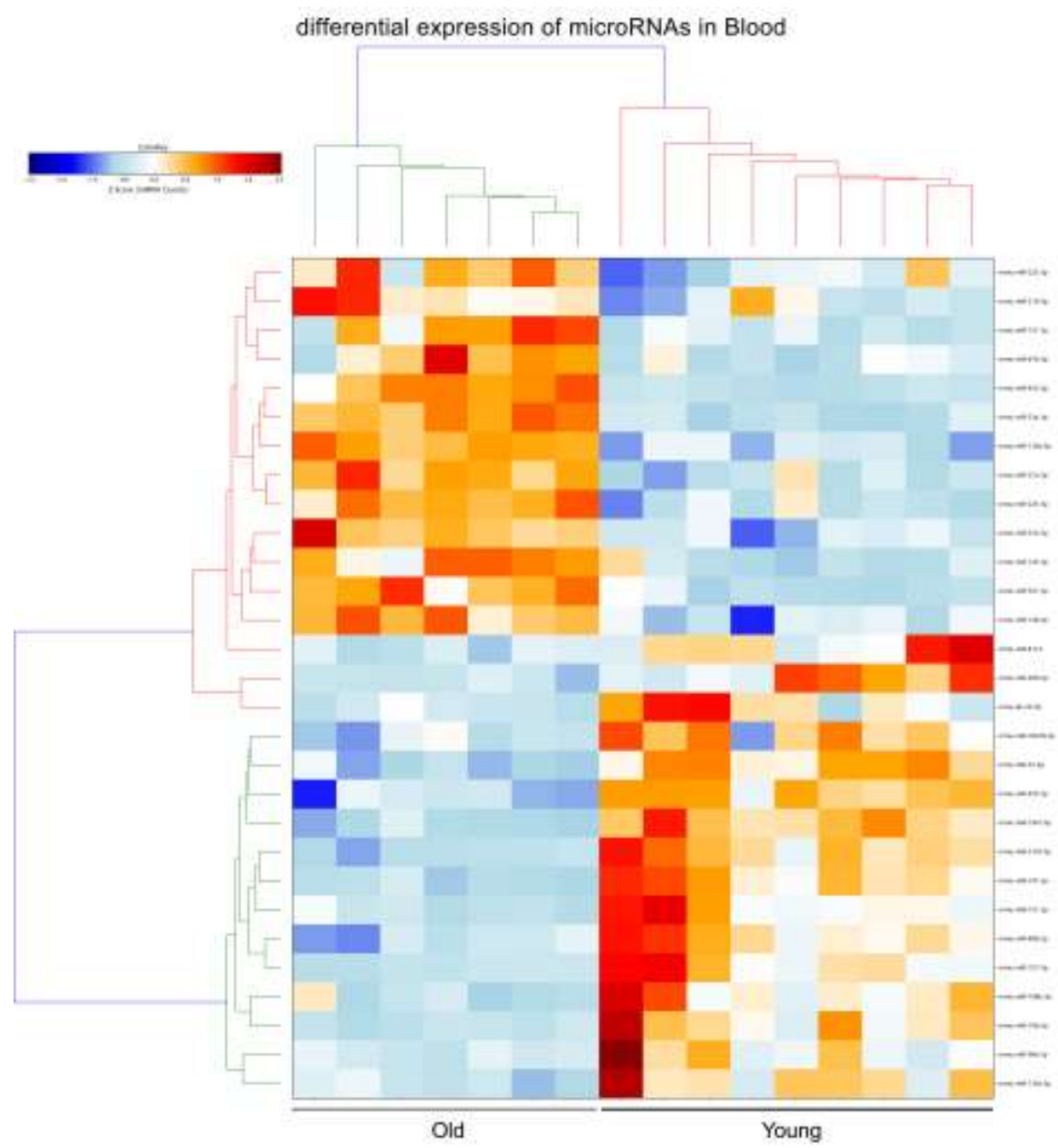

Fig. 3.1.15 Heat map shows the differential miRNA expression changes in blood of old mice.

In order to have a more precise look to blood miRNAome overlapping with memoryassociated miRNAome changes, we looked specifically to commonly upregulated and downregulated miRNAs for each brain subregion and blood. The miRNAs that were commonly upregulated in ACC and blood shows 15\% similarity (Fig. 3.1.16A) miR-143-3p, miR-151-5p, miR-351-5p, miR-423-3p, miR-676-3p are the common upregulated miRNAs in ACC and blood. The same comparison for DG shows a 15\% of similarity (Fig. 3.1.16B) miR151-5p and miR-23a-3p are the common upregulated miRNAs in DG and blood. CA1 has only one commonly upregulated miRNAs as in blood which is correspondent to $7,6 \%$ of similarity, miR-23a-3p is the common upregulated miRNA in CA1 and blood (Fig. 3.1.16C). Comparison between commonly upregulated miRNAs in CA3 and blood shows that $15 \%$ of miRNAs have overlapping, miR-143-3p and miR-351-5p are the two commonly upregulated miRNAs in blood and CA3 (Fig. 3.1.16D). 
A

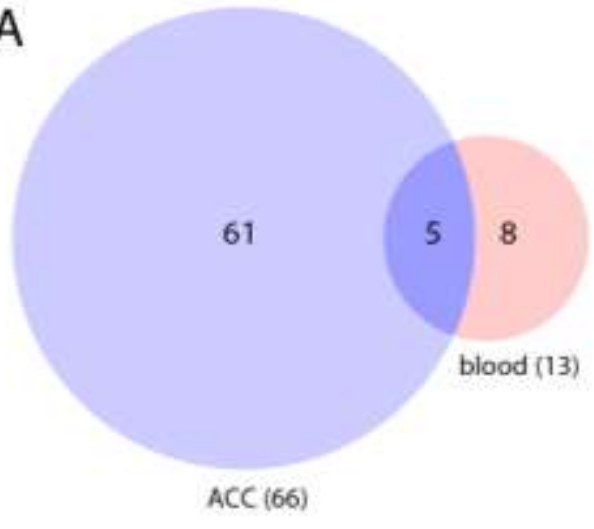

C

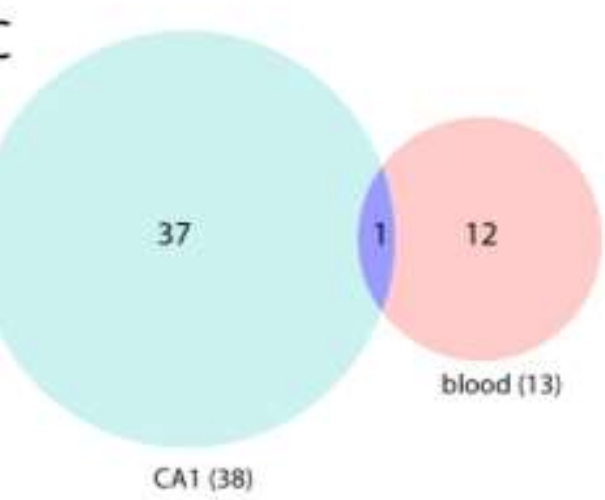

B
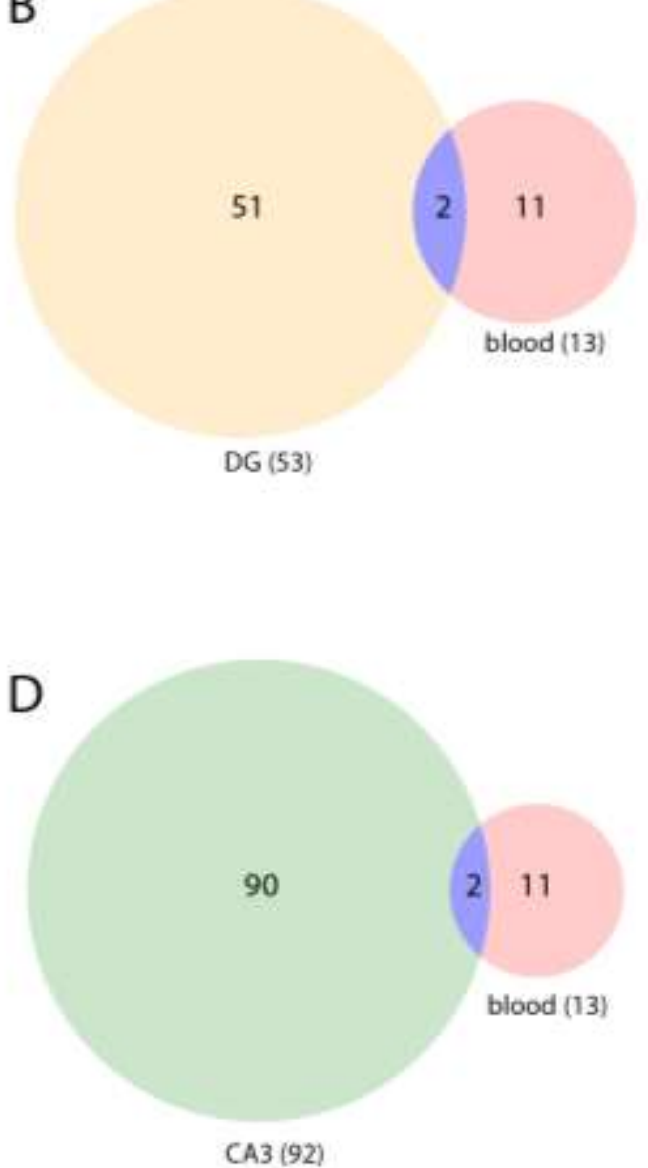

Fig. 3.1.16 Venn diagrams show the number of unique and overlapping upregulated miRNAs between the separate brain regions and blood in the old mice. 
A
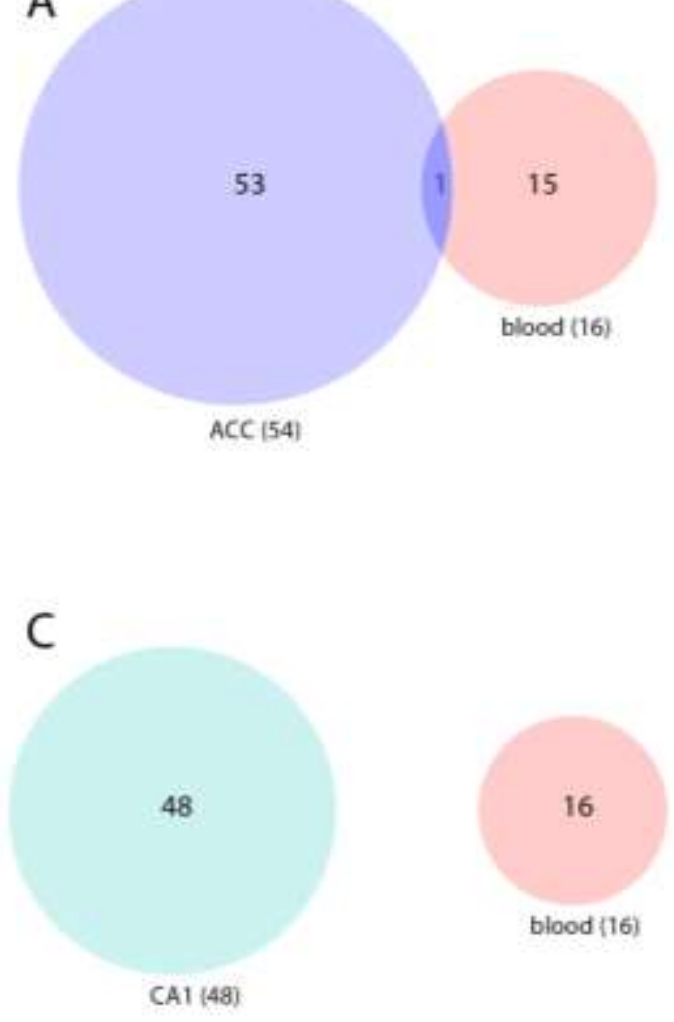

B

48

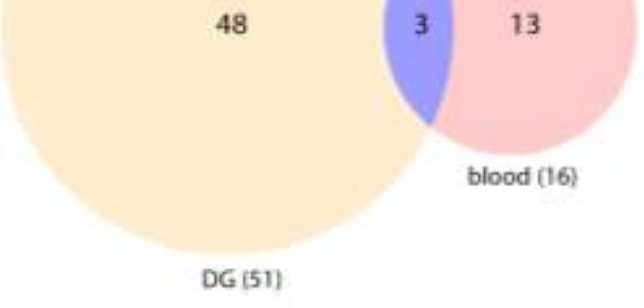

D

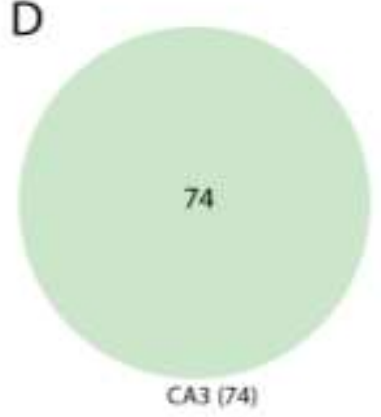

16

blood (16)

Fig. 3.1.17 Venn diagrams show the number of unique and overlapping downregulated miRNAs between the separate brain regions and blood in the old mice.

As it is pictured in Venn diagrams in Fig 3.1.17 ACC and DG have the common downregulated miRNAs with blood (Fig. 3.1.17A -B) let-7d-3p is the ACC signature in blood while let-7d-3p, miR-126a-5p, miR-26b-5p are DG signatures which can be detected in blood. CA1 and CA3 don't show any commonly downregulated miRNAs with blood.

Rather then assuming that a potential blood miRNAome signature of the aging brain reflects only selected brain subregions, it can also be hypothesized that age-associated changes across various brain regions are - at least partially - reflected in blood. Thus, we treated all miRNA changes observed in the aging brain as one signature. When comparing this signature to the blood miRNAome, nearly $83 \%$ of the changing miRNAs seen in blood are also observed in the brain. Performing a hypergeometric test indicated that this finding is highly relevant (< 7.712e-05). We detected 29 differentially expressed miRNAs (log2 fold change $>0,3$; padj 0,05 and basemean of 25 counts, excluding two samples as outliers). The below listed miRNAs are the 24 differentially expressed miRNAs in the old brain and blood: let-7d-3p, miR-106b-3p, miR-10b-5p, miR-126a-5p, miR-127-3p, miR-128-3p, miR-143-3p, miR-151- 
3p, miR-151-5p, miR-1843b-3p, miR-191-5p, miR-222-3p, miR-23a-3p, miR-25-3p, miR26b-5p, miR-27a-3p, miR-351-5p, miR-423-3p, miR-425-5p, miR-486-5p, miR-532-5p, miR676-3, miR-8114 and miR-99a-5p (Fig. 3.1.18A)

Among these 24 deregulated miRNAs 9 miRNAs have the same deregulation pattern, which is around $31 \%$ of the deregulated miRNAs in blood. The 6 common upregulated miRNAs are: miR-143-3p, miR-151-5p, miR-23a-3p, miR-351-5p, miR-423-3p, miR-676-3p (Fig. 3.1.18B). The 3 common downregulated miRNAs are: let-7d-3p, miR-126a-5p, miR-26b-5p (Fig. 3.1.18C). Pathway analyses for commonly downregulated and commonly upregulated miRNAs in brain and blood shows that these miRNAs are linked to tumor prevention pathway, cell apoptosis and cell antiproliferation mechanisms like p53, cell apoptosis signaling and TGF-beta respectively (Transforming growth factor beta) signaling (Fig.3.1.19 A and B). Although the canonical pathways that are regulated by commonly upregulated and downregulated miRNAs are different, these pathways show a high level of unity in terms of mechanisms that they regulate. 


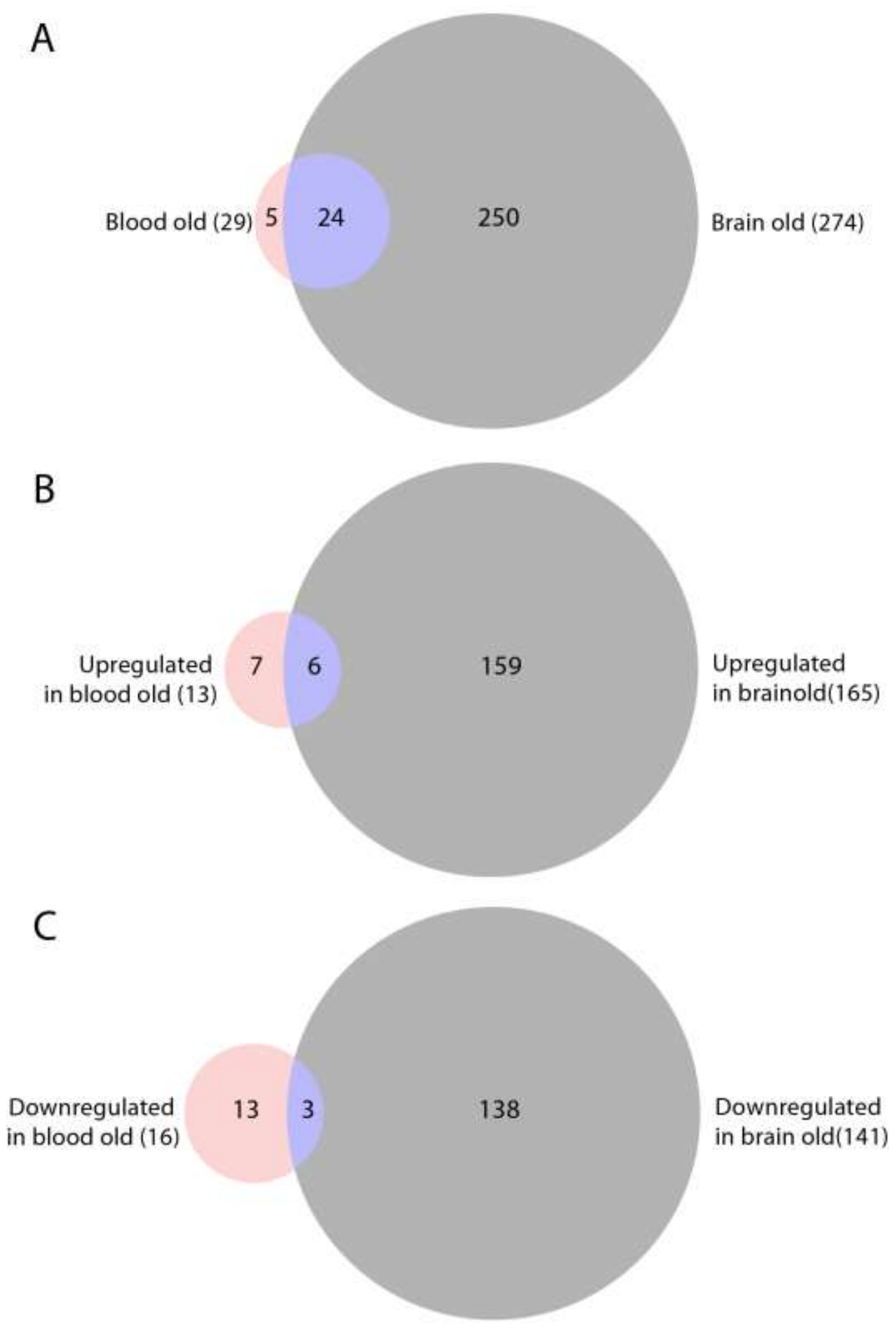

Fig. 3.1.18 Venn diagrams show the number of unique and overlapping upregulated and down regulated miRNAs between the whole brain subregions and blood in the old mice. 


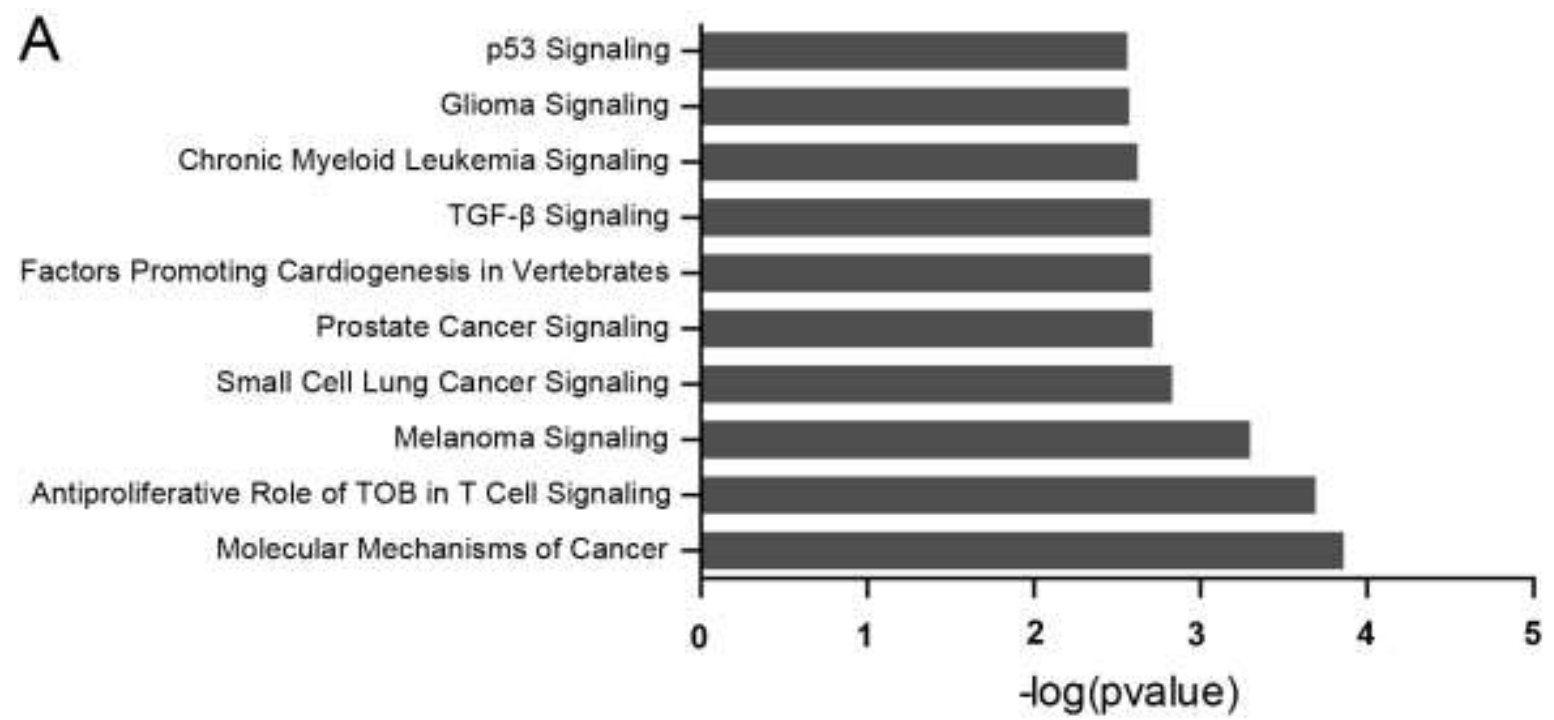

B

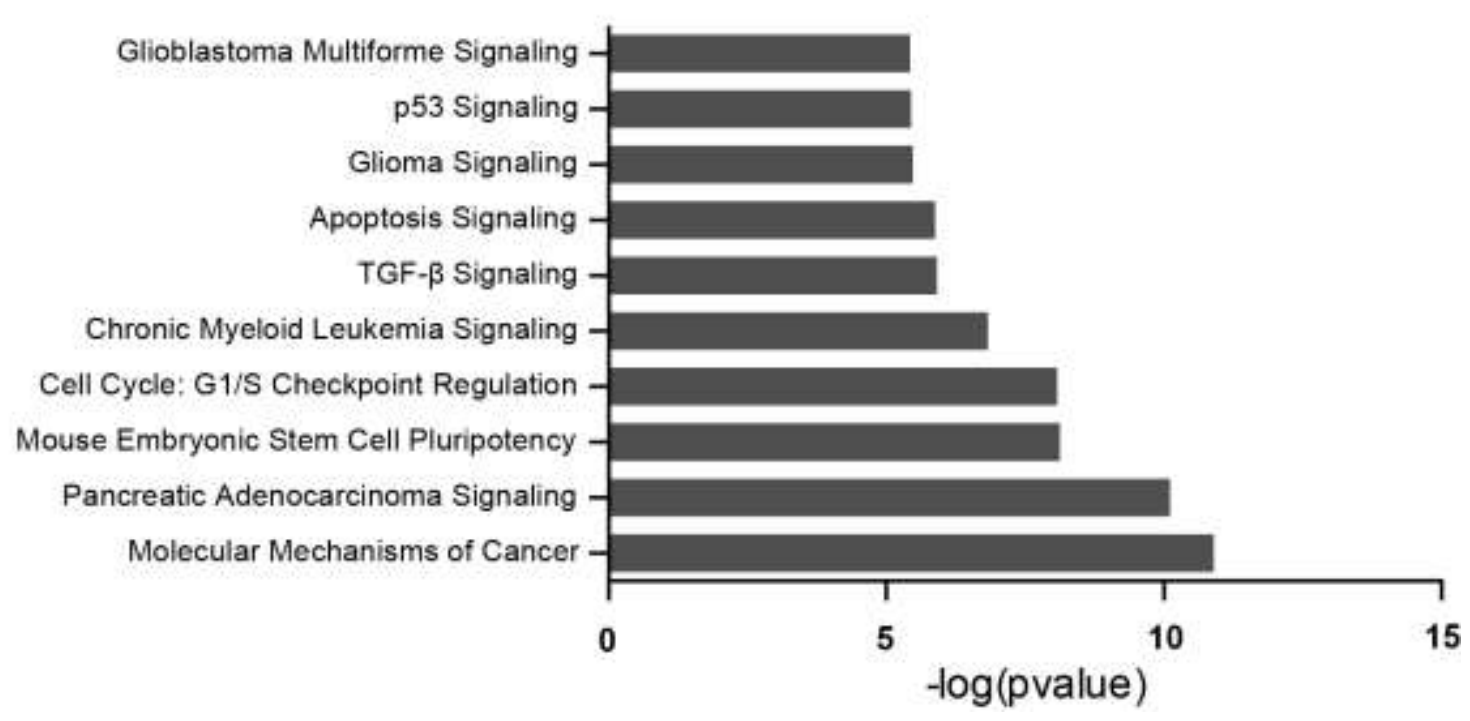

Fig. 3.1.19 Top 10 canonical pathways that are linked to commonly downregulated (A) and commonly upregulated miRNAs (B) in brain regions and blood. 


\subsubsection{Other small RNAs in brain and blood}

Data analyses show that other small RNAs are also present in the brain and blood as well. The population of these non-miRNA small RNAs is different in brain and blood. SnoRNA is found as the second most abundant small RNA in young and old brain $(1.65 \%$ and $1.81 \%$ respectively (Fig 3.1.1 and Fig. 3.1.5)). Fig (3.1.20 A-D) shows the heat map for ACC, DG, CA1 and CA3 for differentially expressed snoRNAs. As it is obvious the abundance of snoRNAs is not the same in all four brain subregions. CA1 shows the less number of differentially expressed snoRNAs. SnoRNAs that are highly abundant in all brain subregion in young and old mice are: Scarna 3a, Snord 85, Snord 99, Snord 104, Snorna 36b, Mir 1839, Snord 12, Snord 57 and Scarna 3b. Different nomenclature for snoRNAs arises from their found sites in the cells, Scarna (small Cajal-body specific RNAs) is found with cajal bodies that are subnuclear complexes in the cells. Mir 1839 has been named as a miRNA because of its similarity with miRNAs in terms of function.

In blood samples, piwiRNA is the second most abundant smallRNA class in both young and old mice with $8.82 \%$ and $7.16 \%$ respectively (Fig. 3.1.12). DQ695413 is the most abundant piwiRNA in young and old group and other piwiRNAs are expressed or detected at a very low level (Fig. 3.1.21). According to piwiRNA bank DQ695413 is the accession number for mmu-piR-016327, which is present in chromosome $\mathrm{Y}$ and 22 base pairs in size. Interestingly piwiRNA is the largest class of non-coding RNAs in eukaryotic cells and found mostley in germ line cells. Unlike snoRNAs that show some similarities with miRNAs in terms of biogenesis and function, piwiRNAs biogenesis and function is distinctive from miRNAs. 


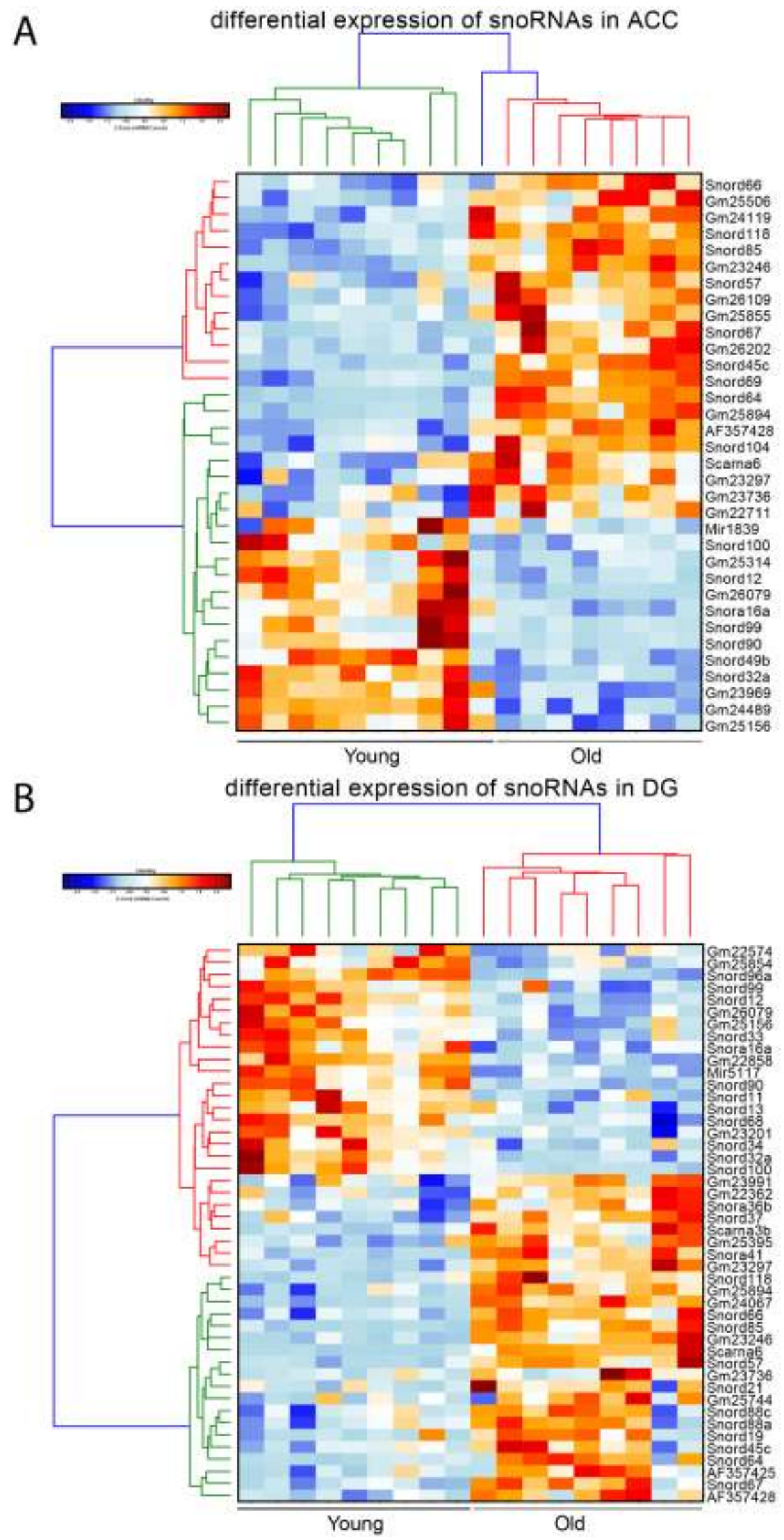

Fig. 3.1.20 (A-B) Heat map shows the Euclidean distances between the differentially expressed snoRNAs in ACC (A), DG (B) from old over young mice. 

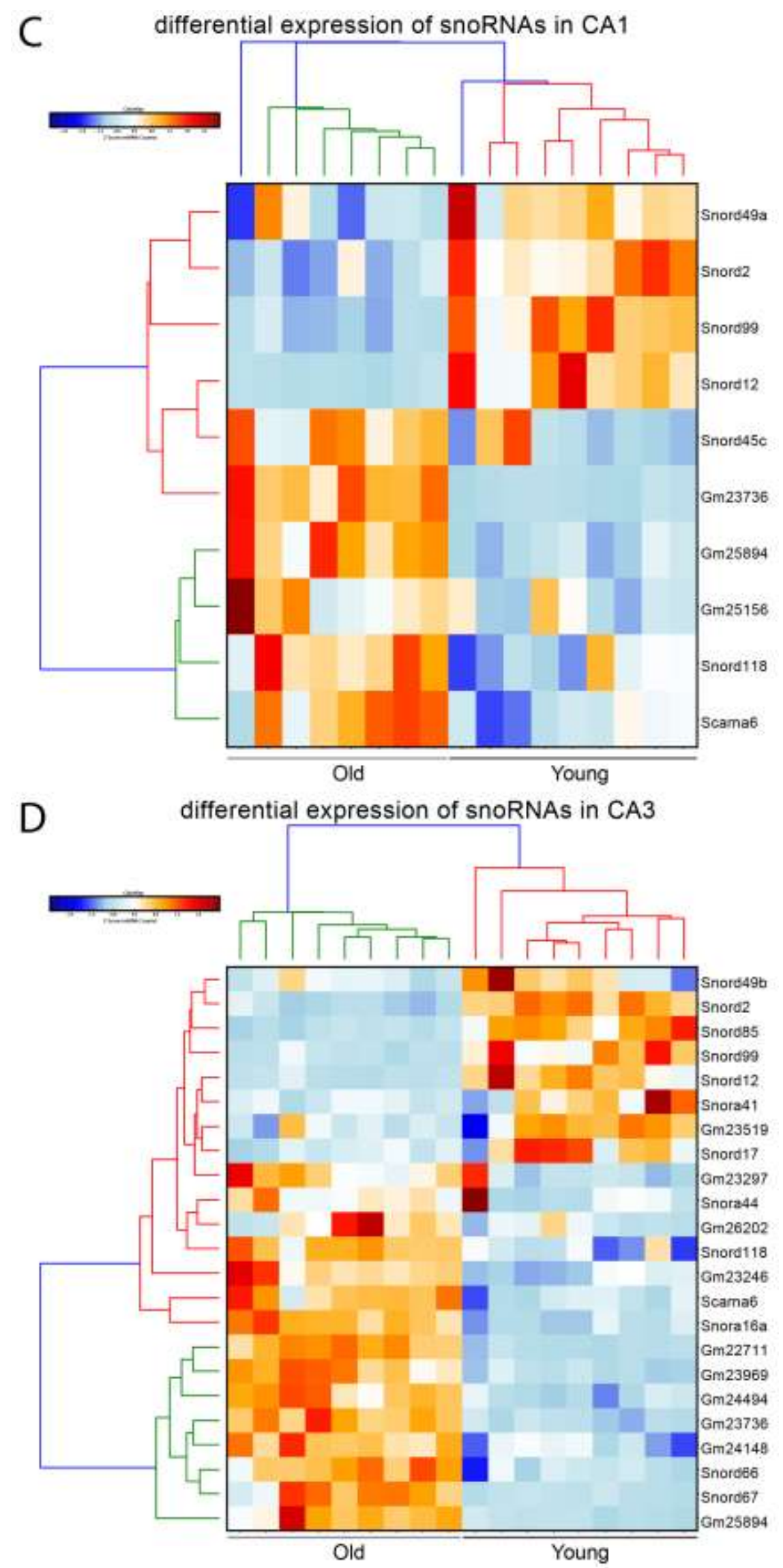

Fig. 3.1.20 (C-D) Heat map shows the Euclidean distances between the differentially expressed snoRNAs in CA1 (C) and CA3 (D) from old over young mice. 


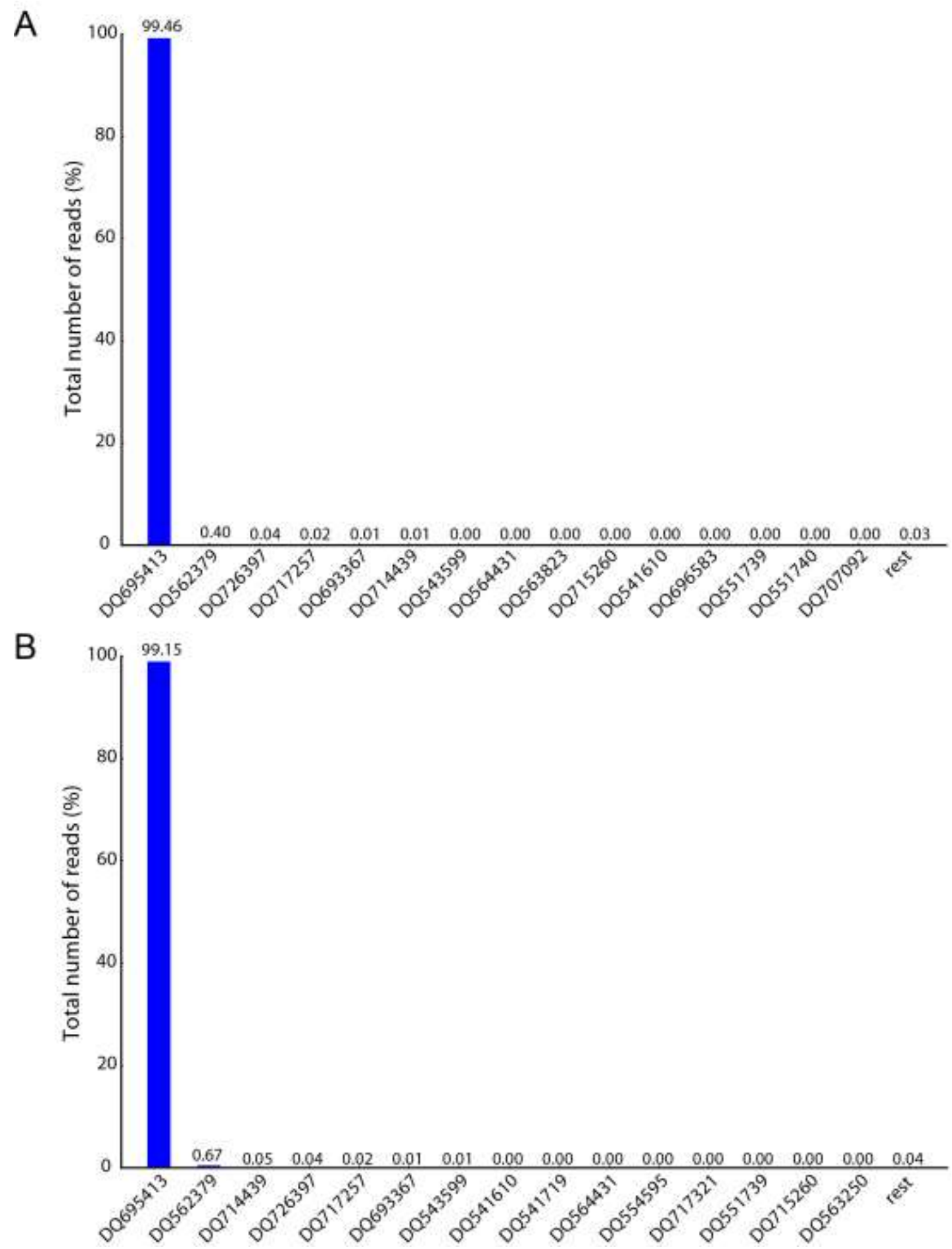

Fig. 3.1.21 PiwiRNA population by frequency of uniquely mapped reads in blood samples from young (A) and old mice (B). 


\subsection{MiRNAs as therapeutic targets in Alzheimer's disease}

Pioneering studies have shown that deregulation of miRNAs plays a significant role in pathological mechanisms. Therefore one interesting approach is to suppress the expression of disease-related miRNAs. In order to circumvent the obstacles in miRNA delivery process, different methods have been used and proposed. In the present study the main focus was to use exosomes as delivery vehicles for miRNA inhibitory molecules. To increase the efficiency of delivery by exosomes they should be modified specifically for the target cells, which in our case are neuronal cells. The following sections show the results of applying measles virus glycoprotein (MVG) pseudotyping system in order to producing specific exosomes, which target only neurons.

\subsubsection{Measles virus glycoproteins can be sorted in the exosomes}

Exosomes were prepared from the cell culture medium of the N2a cells cotransfected with plasmids encoding the wild type and mutant variants of the MVG $\mathrm{H}$ and F. As explained before the aim of plasmid transfection was to obtain modified exosome with more efficient delivery capability for neuronal cells. N2a cell lysates were used for protein extraction, which served as a positive control for plasmid transfection. All exosome preparations were positive for the exosomal marker protein Flotillin-2 (Fig. 3.2.1). Additionally, the presence of the wild and mutant forms of the glycoprotein $\mathrm{H}$ and $\mathrm{F}$ was shown in all exosome preparations, suggesting that these proteins are highly enriched in exosomes (Fig. 3.2.1). All three variants of the $\mathrm{H}$ protein differing in their size were detected with the same antibody (H 606). For the F proteins (wild type and two mutants) F431 antibody was used, according to the western blot signals Hdc18 and Fdc30 were chosen for pseudotyping the exosomes (facing page). 


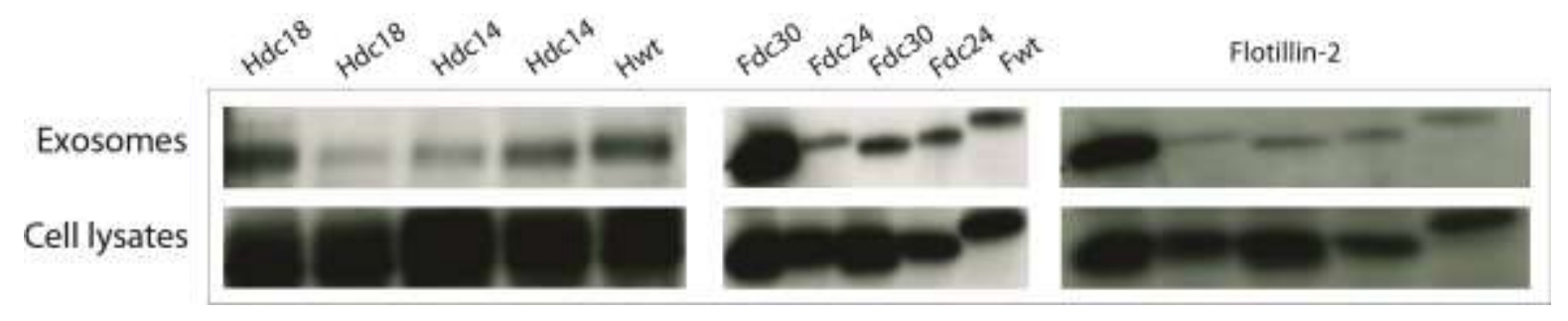

Fig. 3.2.1 Exemplary picture of the western blot analysis of the protein preparations from the exosomes from the cell culture medium and N2a cell lysates. The western blot shows the presence of measles virus $\mathrm{H}$ and $\mathrm{F}$ proteins, strong signals of Flotillin-2 serve as a quality check for the successful exosome extraction.

\subsubsection{Modification of the exosomes with the measles virus glycoproteins did not change efficiency of the cargo delivery}

Exosomes prepared from the culture medium of transfected (see section 2.3.1) and not transfected cells were first electroporated with Luciferase GL3 specific siRNA and then added to HT1080Luc cells. Standard siRNA transfection using oligofectamine reagent was performed to check specificity and efficiency of the chosen siRNA. As shown in Fig. 3.2.2 and 3.2.3, both modified and unmodified exosomes were able to deliver siRNA to cells but without any difference. This experiment was performed with two different amounts of exosomes and siRNAs (Fig. 3.2.2 and 3.2.3). The knock down effect of $3 \mu \mathrm{g}$ exosomes and $3 \mu \mathrm{g}$ siRNAs is not significant while knock down effect of $10 \mu \mathrm{g}$ exosomes and $10 \mu \mathrm{g}$ siRNAs seems to be significant. Of note, knockdown effect of siRNA from the exosomes is much milder than in complex with oligofectamine, although statistically significant compared to control (facing page). However this project was not continued since the preliminary results were not convincing and for improving the results the available technology was not efficient (see part 4.2.2 in discussion) 


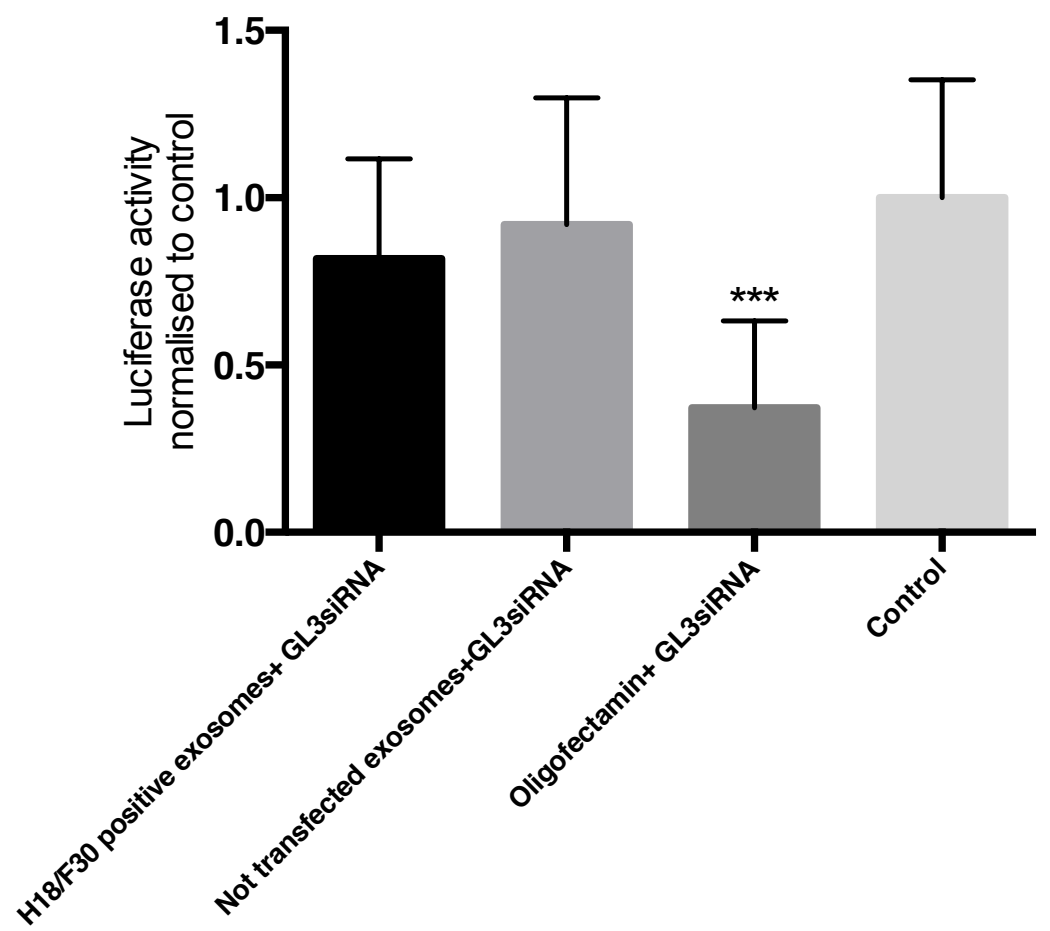

Fig.3.2.2 Results of the luminometer analyses of exosomal delivery of $3 \mu \mathrm{g}$ GL3 siRNA. $3 \mu \mathrm{g}$ exosomes carrying the measles virus glycoproteins deliver siRNA to the target cells as efficient as exosomes without modifications. Error bars show standard deviation.

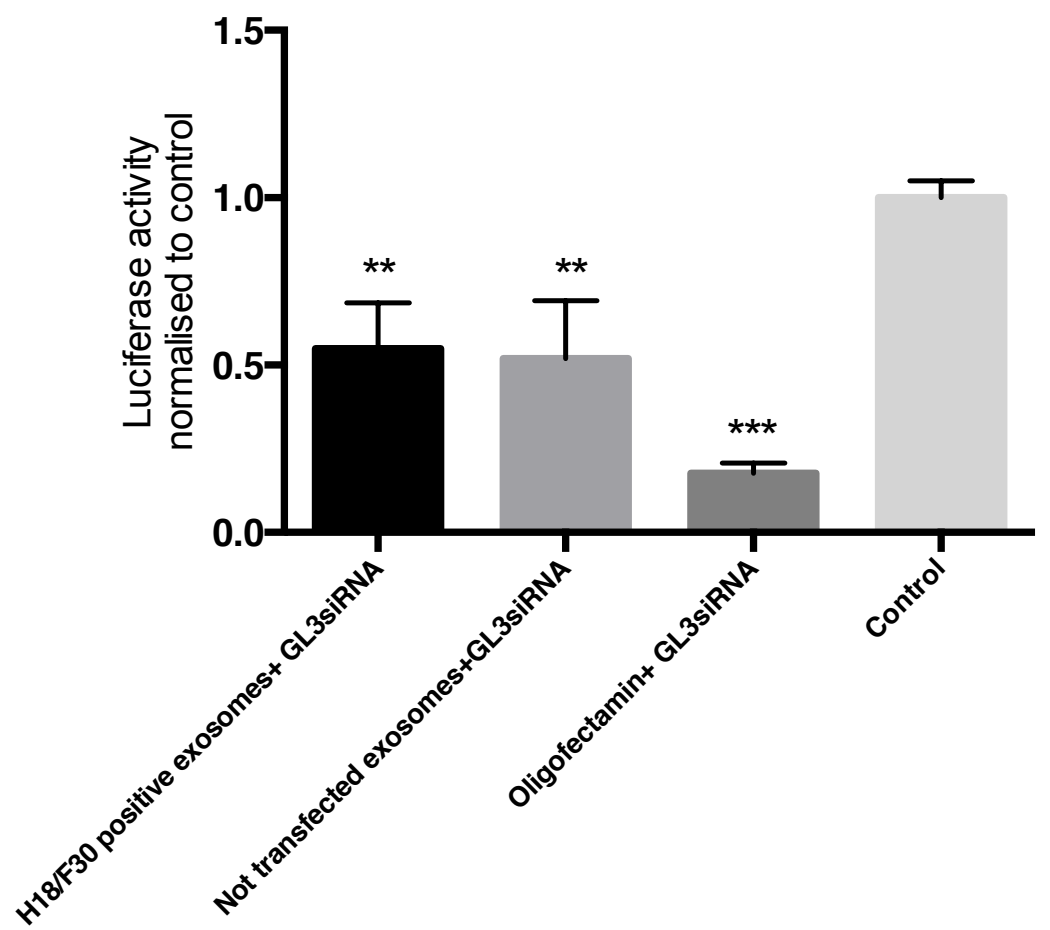

Fig.3.2.3 Results of the luminometer analyses of exosomal delivery of $10 \mu \mathrm{g}$ GL3 siRNA. 10 $\mu \mathrm{g}$ exosomes carrying the measles virus glycoproteins deliver siRNA to the target cells as efficient as exosomes without modifications. Error bars show standard deviation. 
Discussion 


\subsection{Impact of aging on the brain}

\subsubsection{Small RNA expression in memory subregions changes with aging}

Neurodegeneration manifestations are obvious at the late stages of the AD when no cure is effective. Considering aging as the major risk factor for $\mathrm{AD}$ and exploring the changes at molecular level could be a promising approach to figure out the underlying biological abnormalities that increase the chance of AD in late elderly. So far the knowledge about molecular mechanisms of human $\mathrm{AD}$ are based on the post-mortem observations. Studies that could trace the changes in the aging brain and simultaneously seek for malignancies along aging are not feasible in human. In this study we used young (4-month-old) and old mice with 18 months of age that corresponds to late middle age in human and performed high throughput next generation sequencing (NGS) to detect the changes at small RNA level along aging. The results show that aging causes a remarkable change in the small RNA profile of the brain subregions that are intimately linked to learning, memory and cognitive functions. Previous studies were performed in mice, primates and also post mortem tissues from humans to study the influence of aging on the gene expression regulation patterns and pathways in the brain (Lee et al., 2000; Jiang et al., 2001; Fraser et al., 2005; Lu et al., 2004). However these studies did not put their focus on the regulation of the affected pathways during aging in the brain. To include the role of miRNAs as a regulatory molecule of the aging-related pathways a similar study to ours elucidated the role of miRNAs in the aging-associated pathways in the mouse brain (Inukai et al., 2012). In this study using Solexa technology they could show that many miRNAs including several novel miRNAs are differentially expressed upon aging and the pathways like insulin signaling pathway that are regulated by novel miRNAs along aging have significant roles in the process of aging.

However in this study they used the whole brain and the main emphasis was to find out the novel miRNAs that are expressed during aging, while in our study we focused mainly on the expression pattern of the miRNAs and other non-coding small RNAs in each memory associated subregion of the brain along aging.

\subsubsection{MiRNAome changes along aging in memory subregions distinctly}

Along with other biological changes in the process of aging the miRNA profile and its expression pattern also goes under changes. The alteration in miRNAome can be considered as an important factor because this biomolecule has significant regulatory role in crucial 
biological pathways. Furthermore, the regulatory role of miRNAs in the aging network has been confirmed before (Chen et al., 2010)

The results in this study show that the largest proportion of the small RNAs in brain subregions is miRNA and snoRNA is the second most abundant small non-coding RNA and other small non-coding RNAs like piwiRNA and rRNA are present in a very low range (Fig.3.1.1 and Fig.3.1.5). One reasoning behind this could be Truseq small RNA kit that was used for preparing the small RNA library. Although Truseq small RNA is designed for high throughput sequencing of small RNAs it has an affinity for miRNAs that are generated by Dicer processing and it is because of the modified adaptor targeting. However there is no gold standard method for miRNA expression profiling and each method has its biases that should be taken into consideration. According to our results aging induces remarkable changes in the miRNA profile. Since the only difference between the groups of animals was age, therefore it can be claimed that aging causes this profile change in the miRNAome of the brain. A remarkable point that came out from the results of this study was that the changes in miRNA profile and expression was specific to each subregion. Aside from this specific differential expression, we could show that miR-127 and miR-128 and members of the let- 7 group are among the commonly expressed miRNAs in all of young and old brain subregions, the presence of these miRNAs in brain tissues was shown before (Bak et al., 2008, Babak et al., 2004; Barad et al., 2004). Of note the presence of region-specific miRNAs is of paramount importance as it can suggest that each region has its own specific regulatory miRNAs, which can regulate region-specific functions. MiRNAs regulate protein expression at posttranscriptional level and a tremendous number of proteins, which are regulated by miRNAs, are key players of the biological pathways. Therefore difference between miRNA species of the memory subregions would suggest the presence of different biological pathways.

According to our results after miRNA snoRNA is the most abundant small non-coding RNA in the brain subregions (Fig. 3.1.1 and Fig.3.1.5). Although the frequency of this class of small RNA in young and old mice is under $2 \%$, Euclidean distance analyses could be performed for all subregions (Fig. 3.1.20). Presence of snoRNAs in central nervous system has been shown before and the role of some specific snoRNAs in learning and memory has also been studied (Rogelj et al., 2003). In this study they could show that hippocampal snoRNAs regulate higher cognitive functions of the brain. Role of snoRNAs in diseases has been first observed in cancer. It has been shown that differentially expressed snoRNAs and snoRNAs with mutations are crucial in development of lung cancer and prostate cancer 
respectively (Liao et al., 2010; Dong et al., 2008). So far Prader-Willi syndrome is the moststudied neurological disorder that is associated with mutations in snoRNAs (Sahoo et al., 2008) and there has been no specific role for snoRNAs in AD. However the significant role of snoRNA in gene expression flexibility can suggest potentials for this class of small noncoding RNAs in neuropathological processes.

\subsubsection{Aging-associated inflammatory and immune system activation pathways}

Diverse molecular pathways and biochemical mechanisms control the process of aging. In our study the role of miRNAs in regulating aging-associated pathways were analyzed by IPA (Ingenuity software). The results show that miRNAs that are differentially expressed upon aging control the immune system activity-related pathways (Fig. 3.1.10 and Fig.3.1.11). The deregulated activation of immune system indicates the over expression of inflammation mechanisms.

However the mechanisms related to aging is not similar in all species since life span in different species is not the same, mechanisms like oxidative stress and telomerase shortening are species-specific (Kim 2007). Beside specific aging-associated pathways there are also common pathways, which are happening in all species in old ages mechanisms like inflammation (Franceschi et al., 2000). In line with this it should be taken into account that computational analyses that are used for miRNA target prediction provide helpful tool for miRNA research but it should be noted that there is no prediction algorithm that can capture all of the biological aspects of the miRNAs.

\subsubsection{MiRNA as a predictive biomarker}

A good and reliable molecular biomarker should be detectable, robust and specific. The choice of the biomarker could have different reasoning behind. One decisive factor for choosing the biomarker is the nature of the disease. There are some diseases that usually begin with no symptom like $\mathrm{AD}$ and in this case biomarkers help to identify the individuals with high risk for the disease (Craig-Schapiro et al., 2009). In our study we focused on aging as a risk factor for $\mathrm{AD}$ and sought for the differentially expressed miRNAs in aged animals to find any similarities between the miRNA profile of the aged animals and miRNA profile in AD. Our results show that miRNA expression in brain tissue is changing massively in aged mice (Fig. 3.1.7). Among deregulated miRNAs miR34c is downregulated in hippocampal subregions while in $\mathrm{AD}$ disease mouse model and patients this miRNA is upregulated 
(Zovoilis et al., 2011). This observation can suggest that in healthy aged animals in contrast to $\mathrm{AD}$ mouse model miR34c is not upregulated. According to our results there are also some miRNAs that are highly upregulated in one subregion and exactly the same miRNA is downregulated in another subregion. Among these differentially deregulated miRNAs miR212 was particularly interesting since this miRNA was only upregulated in DG of the old mice and downregulated in other memory subregions. This finding is in accordance with previous studies on DG that showed this miRNA is highly expressed in granular cells of the DG (Magill et al., 2010). One possible explanation for the upregulation of this miRNA in DG upon aging could be the compensatory role of this miRNA for producing more newborn neurons to replenish the deleterious effect of the aging-associated processes. In total our results can lead to this point that miRNA expression profile is an indicator for aging in brain memory subregions.

Anyhow using miRNAs as diagnostic, prognostic or predictive biomarkers or surrogate endpoint of a disease is still in its infancy. There is still a long way of research ahead in order to overcome the shortcomings of this field of biomarker research.

\subsubsection{Choice of biofluid for biomarker studies}

Studies in the area of neurodegenerative diseases favor CSF as the most reliable body fluid in terms of biomarker research, simply because it bathes the brain. However there are considerable complications with using CSF as the source of biomarker. CSF collection is an invasive method and different factors can cause variability in the CSF samples. However other body fluids like urine, blood serum or even tears (Weber et al., 2010) have been used as biomarker sources for diseases. Kumar et al. (2013) published a list of plasma-based miRNAs as $\mathrm{AD}$ signature. In this study we used blood as the source of circulating miRNA since among above-mentioned body fluids so far blood offers the most non-invasive analysis tool.

\subsubsection{Blood indicates changes in the aging brain}

It was previously shown that blood is sensitive to changes in the central nervous system and is contributed to gene expression patterns (Scherzer et al., 2007). Our results show that small RNAome of young and old animals are distinctive and like brain samples miRNA is the largest proportion of the small RNAome in the blood samples of young and old animals and piwiRNA is coming up as the second abundant small RNA (Fig. 3.1.12). This shows that 
small RNAome population in brain and blood are different. A previous study revealed that the piwiRNA proportion of blood in comparison to this in plasma is larger than in plasma (Spornraft et al., 2015). However we put the main focus on comparison between miRNAs of blood and brain.

Although correlation analyses between brain and blood show that there is a considerable discrepancy between miRNAome in blood and brain we could detect a convincing rate of similarity between miRNAome of blood and brain subregions that were differentially expressed along aging.

Of note the number of miRNAs in blood is very low in comparison to brain tissues. One reason for that could be the amount of blood that is subjected to RNA isolation. The amount of blood that is used for the whole RNA isolation and NGS process is on one hand a small proportion of the whole blood of the animal and on the other hand it is highly diluted in comparison to solid brain tissues. It might be that if the whole blood could be used for NGS we could observe a larger amount of miRNAs and consequently more common miRNAs between brain and blood. However numerous studies have used blood as biomarker source. Blood-based proteins have been studied as reliable biomarkers for AD (Doecke et al., 2012; Tan et al., 2012). Another study on AD biomarkers proposed a blood-based 12-miRNA signature (Leidinger et al., 2013). A novel aspect of our study in comparison to the similar studies was that we compared the miRNAome of blood with four subregion of the brain that are closely related to memory and cognition. These comparisons show that miRNA deregulation in each region is to a great extent detectable in blood (Fig. 3.1.16 and Fig. 3.1.17) and when we take all brain subregions as a whole and compare it to blood the number of similarly deregulated miRNAs is noticeable.

In this study we could detect one similar signature miRNA (miR-26b) in blood as it was reported in Leidinger et al. (2013) study for AD. Interestingly the regulation pattern of this miRNA is downregulated upon aging, which is similar to the regulation pattern of this miRNA in AD patients. However how the aging- induced miRNAs in blood can be related to AD-induced miRNAs in blood is a matter of debate.

Aside from all benefits that blood provides for biomarker research it should also be taken into consideration that blood is a heterogeneous fluid with different cellular and molecular components that can cause contamination in terms of biomarker study. 


\subsection{MiRNA as therapeutic target}

\subsubsection{Neuronal targeting of the exosomes}

Role of deregulated miRNAs in pathological processes makes this biomolecule as a proper target for therapy. In this study we were planning to apply siRNA as inhibitors for miRNAs. Since the target miRNA of our study was shown to be upregulated in neuronal cells therefore in order to delivering the inhibitory siRNA to the neuronal cells exosomes were used as cargo vehicles.

Using exosome as drug carrier is becoming more popular in neuropathological area since it can cross the blood brain barrier. Numerous studies in the field of exosomes have immense impact on our understanding of possible applications and potentials of the exosome in this regard. In this project we investigated the possibility of pseudotyping of exosomes with measles virus glycoproteins (MVG). A similar study to ours used other virus glycoproteins namely rabid virus glycoprotein (RVG) to specify the exosomes for the target cells (AlvarezErviti et al., 2011). This specification made the exosomes specific for neural cells while our approach was to target only neurons and with this approach we used MVG. Our results show that MVG variants can be sorted in the exosomes. As control we used Flotillin to confirm the accuracy of exosome preparation. Using virus glycoproteins offers a pragmatic tool for adopting exosomes for target cells but on the other hand it can function as the immune system suppressor or stimulator and consequentially have some undesired effects on the organism. However applying exosomes as drug carriers is an emerging research field in contrast liposomes that are synthetic phospholipid vesicles are in use as drug carriers since several years. Exosomes offer some benefits in comparison to liposomes and on the other hand liposomes have some properties which exosomes are lacking them. One smart strategy could be to combine beneficial features of liposomes and exosomes to develop an efficient drug delivery system (van der Meel et al., 2014)

\subsubsection{Loading the exosomes with desired cargo}

Exosomes are endogenous nanovesicles that transfer different kinds of molecules between the cells. This natural potentiality of the exosomes as carriers can be utilized in pharmaceutical research. There are different methods to load the exosomes with desired cargos. In the present study electroporation was used in order to load the exosomes with siRNAs. As it is shown in luciferase assay results by using relatively high amount of exosomes and siRNAs an adequate delivery effect can be achieved. Anyway there was no difference between the delivery efficiency of the native exosomes and neuronal specified 
exosomes. The electroporated exosomes in both cases (native and neuronal specified) showed less luciferase activity suppression in comparison to oligofectamine method.

This fact and similarity between delivery efficacies of both exosome variants raises these questions:

1) Do the exosomes after electroporation retain their shape?

2) Does electroporation load the exosomes with siRNA?

The study that was done by Kooijmans et al. (2013) revealed that electroporation doesn't load the exosomes with siRNAs. Electroporation of siRNAs and exosomes results into aggregation of siRNAs. This can be a persuasive explanation for the failure of our electroporation trails. Furthermore electroporation can cause the aggregation of the exosomes but this may be solved by optimization of the electroporation factors (Hood et al., 2013). Other methods that have been used or proposed in this regard have been mentioned before in Table 1.1 as it is obvious electroporation is ranked as the most applied method to load the exosomes with cargoes, incubation, transfection and cell activation are listed as the other methods in this regard. Although none of the above-mentioned tools offer an absolutely effective method to load the exosomes this area of research is highly promising. Further research and technological advances are required to fulfill the exosome application as a reliable and effective drug carrier. 
Conclusion 


\subsection{Aging-associated changes in miRNA expression profile}

The first part of this study was performed to identify the changes at molecular level that occur in association with aging. The aged-induced expression changes in miRNAome of blood was also observed and compared with change pattern in brain to figure out the overlapping. Based on the results we can conclude that:

- MiRNA expression level goes under profound changes along aging.

- The fold change in miRNA expression levels can be detected precisely in each subregion of the memory in the aging mouse brain.

\subsection{Exosomal delivery of miRNA inhibitory molecules}

The second part of this study was conducted to examine the exosome potential as proper delivery vehicle for targeting neurons exclusively. The results from this study can be concluded in this way:

- Non-exosomal glycoproteins can be sorted in the exosomes.

- Loading exosomes with desired cargoes requires more research and technical advances. 
Summary 


\section{Summary}

MicroRNAs (miRNA) are small non-coding RNAs that play a critical role in the regulation of gene expression programs and thus key mediators of cellular homeostasis. There is increasing evidence that deregulation of miRNAs contribute to neurodegenerative diseases and provide in turn novel opportunities to define biomarker signatures and develop novel therapeutic approaches. To develop effective methods for the delivery of therapeutic miRNA to neurons and to define miRNA changes during memory decline is this of utmost importance. In this project I addressed these important questions and could show that the use of modified exosomes might be a suitable approach to deliver miRNA into the brain. In addition I employed next-generation sequencing (NGS) to profile the miRNAome of 4 different brain regions in young and cognitively impaired old mice. I also examined aginginduced changes in blood from the same mice. My observation suggests that aging is associated with a remarkable deregulation of the brain and blood miRNA profile. Target prediction analyses revealed that the age-associated miRNA signature reflects inflammationassociated mechanisms. The data presents to most comprehensive analysis of the ageassociated brain miRNAome and forms the basis for further mechanistic studies. 
References 
1. Alvarez-Erviti L., Seow Y., Yin H., Betts C., Lakhal S. and Wood MJ. (2011) Delivery of siRNA to the mouse brain by systemic injection of targeted exosomes. Nature Biotechnology, 29 (4): 341-5.

2. Amaral D. and Lavenex P. (2006). "Ch 3. Hippocampal Neuroanatomy". In Andersen P., Morris R., Amaral D., Bliss T and O'Keefe J. The Hippocampus Book. Oxford University Press. ISBN 978-0-19-510027-3.

3. Andersson T., Rahman S., Sansom SN., Alsio JM., Kaneda M., Smith J., O'Carroll D., Tarakhovsky A. and Livesey FJ. (2010) Reversible block of mouse neural stem cell differentiation in the absence of dicer and microRNAs. PLoS One 5 (10): e13453.

4. Anliker B., Abel T., Kneissl S., Hlavaty J., Caputi A., Brynza J, Schneider IC., Münch RC., Petznek H., Kontermann RE., Koehl U., Johnston IC., Keinänen K., Müller UC., Hohenadl C., Monyer H., Cichutek K and Buchholz CJ. (2010) Specific gene transfer to neurons, endothelial cells and hematopoietic progenitors with lentiviral vectors. Nature Methods. 7 (11): 929-35.

5. Arrant AE., and Roberson ED. (2014) MicroRNA-124 modulates social behavior in frontotemporal dementia. Nature medicine. 20 (12): 1381-3.

6. Arroyo JD., Chevillet JR., Kroh EM., Ruf IK., Pritchard CC., Gibson DF., Mitchell PS., Bennett CF., Pogosova-Agadjanyan EL., Stirewalt DL., Tait JF. and Tewari M. (2011) Argonaute 2 complexes carry a population of circulating microRNAs independent of vesicles in human plasma. Proceeding National Academic Science USA, 108 (12): 5003-8.

7. Auer IA., Schmidt ML., Lee VM., Curry B., Suzuki K., Shin RW., Pentchev PG., Carstea ED. and Trojanowski JQ. (1995) Paired helical filament tau (PHFtau) in Niemann-Pick type $\mathrm{C}$ disease is similar to PHFtau in Alzheimer's disease. Acta Neuropathologica, 90 (6): 547-51.

8. Bacskai BJ., Hochner B., Mahaut-Smith, M., Adams, SR., Kaang BK., Kandel, ER. and Tsien, RY. (1993) Spatially resolved dynamics of cAMP and protein Kinase A subunit in Aplysia sensory neurons. Science, 260 (5105): 222-6.

9. Babak T., Zhang W., Morris, Q., Blencowe BJ., and Hughes, TR. (2004) Probing microRNAs with microarrays: Tissue specificity and functional inference. RNA 10 (11): 1813-9. 
10. Bak M., Silahtaroglu A., Møller M., Christensen M., Rath MF., Skryabin B., Tommerup N. and Kauppinen S. (2008) MiRNA expression in the adult mouse central nervous system. RNA 14 (3): 432-44.

11. Bakhti M., Winter C. and Simons M. (2011) Inhibition of myelin membrane sheath formation by oligodendrocyte-derived exosome-like vesicles. Journal of Biological Chemistry, 286 (1): 787-96.

12. Barad O., Meiri E., Avniel A., Aharonov R., Barzilai A., Bentwich I., Einav U., Gilad S., Hurban P., Karov Y., Lobenhofer EK, Sharon E, Shiboleth YM., Shtutman M., Bentwich Z. and Einat P. (2004). MicroRNA expression detected by oligonucleotide microarrays: System establishment and expression profiling in human tissues. Genome Research. 14 (12): 2486-94.

13. Barbato C., Ruberti F. and Cogoni C. (2009) Searching for MIND: MicroRNAs in Neurodegenerative Diseases. Journal of Biomedical Biotechnology, Doi: $10.1155 / 2009 / 871313$.

14. Bartel DP. (2004) MicroRNAs: genomics, biogenesis, mechanism, and function. Cell, 116 (2): 281-97.

15. Baylin SB. and Ohm JE. (2006) Epigenetic gene silencing in cancer-a mechanism for early oncogenic pathway addiction?. Nature Review Cancer, 6 (2): 107-16.

16. Boissonneault V., Plante I., Rivest S. and Provost P. (2009) MicroRNA- 298 and microRNA-328 regulate expression of mouse beta-amyloid precursor proteinconverting enzyme 1. Journal of Biological Chemistry 284 (4): 1971- 1981.

17. Borchert GM., Lanier W. and Davidson BL. (2006) RNA polymerase III transcribes human microRNAs. Nature Structural Molecular Biology, 13 (12): 1097-101.

18. Brunelli M., Castellucci V. and Kandel ER. (1976) Synaptic facilitation and behavioral sensitization in Aplysia: possible role of serotonin and cyclic AMP. Science, 194 (4270): 1178-81.

19. Bryniarski K., Ptak W., Jayakumar A., Püllmann K., Caplan MJ., Chairoungdua A., Lu J., Adams BD., Sikora E., Nazimek K., Marquez S., Kleinstein SH., Sangwung P., Wakiri Y., Delgato E., Redegeld F., Blokhuis BR., Wojcikowski J., Daniel AW., Groot Kormelink T. and Askenase PW. (2013) Antigen-specific, antibody-coated, exosomelike nanovesicles deliver suppressor T-cell microRNA-150 to effector T cells to inhibit contact sensitivity. Journal of Allergy and Clinical Immunology, 132 (1): 170-81. 
20. Burger C. (2010) Region-specific genetic alterations in the aging hippocampus: implications for cognitive aging. Frontiers in aging neuroscience doi: 10.3389/fnagi.2010.00140.

21. Bush G., Luu Ph. and Posner M. (2000) Cognitive and Emotional Influences in anterior cingulate cortex. Trends in Cognitive Sciences, 4 (6): 215-222.

22. Cai X., Hagedorn CH. and Cullen BR. (2004) Human microRNAs are processed from capped, polyadenylated transcripts that can also function as mRNAs. RNA, 10 (12): 1957-66.

23. Calin GA., Dumitru CD., Shimizu M., Bichi R., Zupo S., Noch E., Aldler H., Rattan S., Keating M., Rai K., Rassenti L., Kipps T., Negrini M., Bullrich F. and Croce CM. (2002) Frequent deletions and down-regulation of micro- RNA genes miR15 and miR16 at 13 q14 in chronic lymphocytic leukemia. Proceeding National Academic Science USA, 99 (24): 15524-15529.

24. Capece V., Vizcaino JC., Vidal R., Rahman RU., Centeno TP., Shomroni O., Suberviola I., Fischer A and Bonn S. (2015) Oasis: online analysis of small RNA deep sequencing data. Bioinformatics, 19. pii: btv113.

25. Chen K. and Rajewsky N. (2007) The evolution of gene regulation by transcription factors and microRNAs. Nature Reviews Genetics, 8 (2): 93103.

26. Chen L., Charrier A., Zhou Y., Chen R., Yu B., Agarwal K., Tsukamoto H., Lee LJ., Paulaitis ME. and Brigstock DR. (2014) Epigenetic regulation of connective tissue growth factor by microRNA-214 delivery in exosomes from mouse or human hepatic stellate cells. Hepatology, 59 (3): 1118-29.

27. Chen LH., Chiou GY., Chen YW., Li HY and Chiou SH. (2010) MicroRNA and aging: a novel modulator in regulating the aging network. Anging Research Reviews. 9 Suppl 1: S59-66.

28. Cocucci E., Racchetti G. and Meldolesi J. (2009) Shedding microvesicles: artefacts no more. Trends in Cell Biology, 19 (2): 43-51.

29. Cogswell JP., Ward J., Taylor IA., Waters M., Shi Y., Cannon B., Kelnar K., Kemppainen J., Brown D., Chen C., Prinjha RK., Richardson JC., Saunders AM., Roses AD. and Richards CA. (2008) Identification of miRNA changes in Alzheimer's disease brain and CSF yields putative biomarkers and insights into disease pathways. Journal of Alzheimer's Disease, 14 (1): 27-41.

30. Conde-Vancells J., Rodriguez-Suarez E., Embade N., Gil D., Matthiesen R., Valle M., Elortza F., Lu SC., Mato JM. and Falcon-Perez JM. (2008) Characterization and 
comprehensive proteome profiling of exosomes secreted by hepatocytes. Journal of Proteome Research, 7 (12): 5157-66.

31. Craig-Schapiro R., Fagan AM. and Holtzman DM. (2009) Biomarkers of Alzheimer's disease. Neurobiology of disease, 35 (2): 128-40.

32. De Felice B., Annunziata A., Fiorentino G., Borra M., Biffali E., Coppola C., Cotrufo R., Brettschneider J., Giordana ML., Dalmay T., Wheeler G. and D’Alessandro R. (2014) miR-338-3p is over-expressed in blood, CFS, serum and spinal cord from sporadic amyotrophic lateral sclerosis patients. Neurogenetics, 15 (4): 243-53.

33. Dobin A., Davis CA., Schlesinger F., Drenkow J., Zaleski C., Jha S., Batut P., Chaisson M. and Gingeras TR. (2013) STAR: ultrafast universal RNA-seq aligner. Bioinformatics, 29 (1): 15-21.

34. Doecke JD., Laws SM., Faux NG., Wilson W., Burnham SC., Lam CP., Mondal A., Bedo J., Bush AI., Brown B., De Ruyck K., Ellis KA., Fowler C., Gupta VB., Head R., Macaulay SL., Pertile K., Rowe CC., Rembach A., Rodrigues M., Rumble R., Szoeke C., Taddei K., Taddei T., Trounson B., Ames D., Masters CL. and Martins RN. (2012) Blood-based protein biomarkers for diagnosis of Alzheimer disease. Archive of Neurology, 69 (10): 1318-25.

35. Dong XY., Rodriguez C., Guo P., Sun X., Talbot JT., Zhou W., Petros J., Li Q., Vessella RL., Kibel AS., Stevens VL., Calle EE. and Dong JT. (2008) snoRNA U50 is a candidate tumorsuppressor gene at $6 \mathrm{q} 14.3$ with a mutation associated with clinically significant prostate cancer. (2008) Human Molecular Genetic, 17 (7): 1031-42.

36. Doxakis E. (2010) Post-transcriptional regulation of alpha-synuclein expression by mir7 and mir-153. Journal of Biological Chemistry, 285 (17): 12726-12734.

37. Duijvesz D., Burnum-Johnson KE., Gritsenko MA., Hoogland AM., Vredenbregt-van den Berg MS., Willemsen R., Luider T., Paša-Tolić L. and, Jenster G. (2013) Proteomic profiling of exosomes leads to the identification of novel biomarkers for prostate cancer. Plos One, 8 (12): e82589.

38. Emmanouilidou E., Melachroinou K., Roumeliotis T., Garbis SD., Ntzouni M., Margaritis LH., Stefanis L. and Vekrellis K. (2010) Cell-produced alpha-synuclein is secreted in a calcium-dependent manner by exosomes and impacts neuronal survival. Journal of Neuroscience, 30 (20): 6838-51.

39. Etheridge A., Lee I., Hood L., Galas D and Wang K. (2011) Extracellular microRNA: A new source of biomarkers. Mutation Research, 717 (1-2): 85-90. 
40. Femminella GD., Ferrara N. and Rengo G. (2015) The emerging role of microRNAs in Alzheimer's disease. Frontiers in Physiology, doi: 10.3389/fphys.2015.00040.

41. Franceschi C., Bonafe M., Valensin S., Olivieri F., De Luca M., Ottaviani E. and De Benedictis, G. (2000) Inflamm-aging. An evolutionary perspective on immunosenescence. Annals of the New York Academy of Science, 908, 244-254.

42. Fraser HB., Khaitovich P., Plotkin JB., Paabo S. and Eisen MB. (2005) Aging and gene expression in the primate brain. PLoS Biology, 3 (9): e274.

43. Friedländer MR., Mackowiak SD., Li N., Chen W. and Rajewsky N. (2012) miRDeep2 accurately identifies known and hundreds of novel microRNA genes in seven animal clades. Nucleic Acid Research, 40 (1): 37-52.

44. Funke S., Maisner A., Mühlebach MD., Koehl U., Grez M., Cattaneo R., Cichutek K. and Buchholz CJ. (2008) Targeted cell entry of lentiviral vectors Molecular Therapy. 16 (8): $1427-36$.

45. Funke S, Schneider IC., Glaser S., Mühlebach MD., Moritz T., Cattaneo R., Cichutek K. and Buchholz CJ. (2009) Pseudotyping lentiviral vectors with the wild-type measles virus glycoproteins improves titer and selectivity. Gene Therapy. 16 (5): 700-5.

46. Guzowski JF. (2002) Insights into immediate-early gene function in hippocampal memory consolidation using antisense oligonucleotide and fluorescent imaging approaches. Hippocampus, 2 (1): 86-104.

47. György B., Szabó TG., Pásztói M., Pál Z., Misják P., Aradi B., László V., Pállinger E., Pap E., Kittel A., Nagy G., Falus A. and Buzás EI. (2011) Membrane vesicles, current state-of-the-art: emerging role of extracellular vesicles. Cellular Molecular Life Science, 68 (16): 2667-88.

48. Hagihara H., Toyama K., Yamasaki N. and Miyakawa T. (2009) Dissection of hippocampal dentate gyrus from adult mouse. Journal of visualized experiments: JoVE, (33). doi: 10.3791/1543.

49. Hebert SS., Horre K., Nicolai L., Papadopoulou AS., Mandemakers W., Silahtaroglu AN., Kauppinen S., Delacourte A. and De Strooper B. (2008) Loss of microRNA cluster miR-29a/b-1 in sporadic Alzheimer's disease correlates with increased BACE1/beta-secretase expression. Proceeding National Academic Science USA, 105 (17): $6415-20$.

50. Hess C., Sadallah S., Hefti A., Landmann R. and Schifferli JA. (1999) Ectosomes released by human neutrophils are specialized functional units. Journal of Immunology, 163 (8): 4564-73. 
51. Holley CL. and Topkara VK. (2011) An introduction to small non-coding RNAs: miRNA and snoRNA. Cardiovascular Drugs and Therapy, 25 (2): 151-159.

52. Holme PA., Solum NO., Brosstad F., Røger M. and Abdelnoor M. (1994) Demonstration of platelet-derived microvesicles in blood from patients with activated coagulation and fibrinolysis using a filtration technique and western blotting. Thrombosis and Haemostasis, 72 (5): 666-71.

53. Hood L., Scott MJ., Wickline SA. (2013) Maximizing exosome colloidal stability following electroporation, Analytical Biochemistry, doi: 10.1016/j.ab.2013.12.001.

54. Hurley JH. (2008) ESCRT complexes and the biogenesis of multivesicular bodies. Current Opinion in Cell Biology, 20 (1): 4-11.

55. Inukai S., de Lencastre A., Turner M. and Slack F. (2012) Novel microRNAs differentially expressed during aging in the mouse brain Plose One, 7 (7): e40028.

56. Jang SC., Kim OY., Yoon CM., Choi DS., Roh TY. and Park J. (2013) Bioinspired exosome-mimetic nanovesicles for targeted delivery of chemotherapeutics to malignant tumors. ACS Nano, 7 (9): 7698-710.

57. Jiang CH., Tsien JZ., Schultz PG. and Hu Y. (2001) The effects of aging on gene expression in the hypothalamus and cortex of mice. Proceeding of National Academic Science USA, 98 (4): 1930-1934.

58. Jones PA. and Baylin SB. (2002) The fundamental role of epigenetic events in cancer. Nature Review Genetics, 3 (6): 415-28.

59. Katakowski M., Buller B., Zheng X., Lu Y., Rogers T., Osobamiro O., Shu W., Jiang F. and Chopp M. (2013) Exosomes from marrow stromal cells expressing miR-146b inhibit glioma growth. Cancer Letters, 335 (1): 201-4.

60. Kawaji H. and Hayashizaki Y. (2008) Exploration of small RNAs. PLoS Genetics. 4 (1): e22.

61. Kawase-Koga Y., Otaegi G. and Sun T. (2009) Different timings of Dicer deletion affect neurogenesis and gliogenesis in the developing mouse central nervous system. Development Dynamics, 238 (11): 2800-2812.

62. Kim SK. (2007) Common aging pathways in worms, flies, mice and humans. Journal of Experimental Biology, 210 (Pt 9): 1607-12.

63. Klose RJ. and Bird AP. (2006) Genomic DNA methylation: the mark and its mediators. Trends Biochemistry Science, 31 (2): 89-97.

64. Kooijmans SA., Stremersch S., Braeckmans K., de Smedt SC., Hendrix A., Wood MJ., Schiffelers RM., Raemdonck K. and Vader P. (2013) Electroporation-induced 
siRNA precipitation obscures the efficiency of siRNA loading into extracellular vesicles. Journal of controlled release, 172 (1): 229-38.

65. Kosaka N., Iguchi H., Yoshioka Y., Hagiwara K., Takeshita F. and Ochiya T. (2012) Competitive interactions of cancer cells and normal cells via secretory microRNAs. Journal of Biological Chemistry, 287 (2): 1397-405.

66. Kosaka N., Iguchi H., Yoshioka Y., Takeshita F., Matsuki Y. and Ochiya T. (2010) Secretory mechanisms and intercellular transfer of microRNAs in living cells. Journal of Biological Chemistry, 285 (23): 17442-52.

67. Krutzfeldt J. and Stoffel M. (2006) MicroRNAs: a new class of regulatory genes affecting metabolism. Cell. Metabolism, 4 (1): 9-12.

68. Kumar P., Dezso Z., MacKenzie C., Oestreicher J., Agoulnik S., Byrne M., Bernier F., Yanagimachi M., Aoshima K. and Oda Y. (2013) Circulating miRNA biomarkers for Alzheimer's disease. Plose One, 8 (7): e69807.

69. Lagos-Quintana M., Rauhut R., Lendeckel W. and Tuschl T. (2001) Identification of novel genes coding for small expressed RNAs. Science, 294 (5543): 853-8.

70. Lagos-Quintana M., Rauhut R., Yalcin A., Meyer J., Lendeckel W. and Tuschl T. (2002) Identification of tissue-specific microRNAs from mouse. Current Biology, 12 (9): 735-739.

71. Landry CD., Kandel ER. and Rajasethupathy P. (2013) New mechanisms in memory storage: piRNAs and epigenetics. Trends in Neuroscience. 36 (9): 535-42.

72. Lee CK., Weindruch R. and Prolla TA. (2000) Gene-expression profile of the ageing brain in mice. Nature Genetics, 25 (3): 294-297

73. Lee RC., Feinbaum RL. and Ambros V. (1993) The C. elegans heterochronic gene lin-4 encodes small RNAs with antisense complementarity to lin-14. Cell, 75 (5): 843-54.

74. Lee Y., Kim M., Han J., Yeom KH., Lee S., Baek SH. and Kim VN. (2004) MicroRNA genes are transcribed by RNA polymerase II. EMBO Journal, 23 (20): 4051-60.

75. Leidinger P., Backes C., Deutscher S., Schmitt K., Mueller SC., Frese K., Haas J., Ruprecht K., Friedemann P., Stähler C., Lang CJG., Meder B., Bartfai T., Meese E. and Keller A. (2013) A blood based 12-miRNA signature of Alzheimer disease patients. Genome Biology, doi: 10.1186/gb-2013-14-7-r78.

76. Liao J., Yu L., Mei Y., Guarnera M. and Shen J. (2010) Small nucleolar RNA signatures as biomarkers for non-small-cell lung cancer. Molecular Cancer, doi: 10.1186/1476-4598-9-198.

77. Lin H. (2007) piRNAs in the germ line. Science, 316 (5823): 397. 
78. Liu C., Teng ZQ., Santistevan NJ., Szulwach KE., Guo W., Jin P. and Zhao X. (2010) Epigenetic regulation of miR-184 by MBD1 governs neural stem cell proliferation and differentiation. Cell Stem Cell, 6 (5): 433-444.

79. Love MI., Huber W. and Anders S. (2014) Moderated estimation of fold change and dispersion for RNA-seq data with DESeq2. Genome Biology, 15 (12): 550.

80. Lukiw WJ., Zhao Y. and Cui JG. (2008) An NF-kappaB-sensitive micro RNA-146amediated inflammatory circuit in Alzheimer disease and in stressed human brain cells. Journal of Biological Chemistry, 283 (46): 31315-31322.

81. Lu T, Pan Y, Kao SY, Li C, Kohane I, Chan J. and Yankner BA. (2004) Gene regulation and DNA damage in the ageing human brain. Nature, 429 (6994): 883-891.

82. Mackenzie IR. and Rademakers R. (2007) The molecular genetics and neuropathology of frontotemporal lobar degeneration: recent developments. Neurogenetics, 8 (4): 23748.

83. Magill ST., Cambronne XA., Luikart BW., Lioy DT., Leighton BH., Westbrook GL., Mandel G. and Goodman RH. (2010) microRNA-132 regulates dendritic growth and arborization of newborn neurons in the adult hippocampus. Proceeding of the National Academic Science USA, 107 (47): 20382-7.

84. Malecova B. and Morris KV. (2010) Transcriptional gene silencing through epigenetic changes mediated by non-coding RNAs. Current Opinion in Molecular Therapy, 12 (2): 214-22.

85. Mercer TR., Dinger ME. and Mattick JS. (2009) Long noncoding RNAs: insights into functions. Nature Reviews Genetics, 10 (3): 155-159.

86. Miyoshi K., Miyoshi T. and Siomi H. (2010) Many ways to generate microRNA-like small RNAs: non-canonical pathways for microRNA production. Molecular Genetic Genomics, 284 (2): 95-103.

87. Motti D., Bixby JL. and Lemmon VP. (2012) MicroRNAs and neuronal development. Seminars Fetal Neonatal Medicine, 17 (6): 347-52.

88. Munoz JL., Bliss SA., Greco SJ., Ramkissoon SH., Ligon KL. and Rameshwar P. (2013) Delivery of functional anti-miR-9 by mesenchymal stem cell-derived exosomes to glioblastoma multiforme cells conferred chemosensitivity. Molecular Therapy Nucleic Acids, doi: 10.1038/mtna.2013.60.

89. Nelson PT. and Keller JN. (2007) RNA in brain disease: no longer just the messenger in the middle. Journal of Neuropathology and Experimental Neurology, 66 (6): 461-8. 
90. Ohno SI., Takanashi M., Sudo K., Ueda S., Ishikawa A. and Matsuyama N. (2012) Systemically injected exosomes targeted to EGFR deliver antitumor microRNA to breast cancer cells. Molecular Therapy, 21 (1): 185-91.

91. Pan BT. and Johnstone RM. (1983) Fate of the transferrin receptor during maturation of sheep reticulocytes in vitro: selective externalization of the receptor. Cell, 33 (3): 96778.

92. Pan Q., Ramakrishnaiah V., Henry S., Fouraschen S., de Ruiter PE., Kwekkeboom J., Tilanus HW., Janssen HL. And van der Laan LJ. (2012) Hepatic cell-to-cell transmission of small silencing RNA can extend the therapeutic reach of RNA interference (RNAi). Gut, 61 (9): 1330-9.

93. Peleg S., Sananbenesi F., Zovoilis A., Burkhardt S., Bahari-Javan S., Agis-Balboa RC., Cota P., Wittnam JL., Gogol-Doering A., Opitz L., Salinas-Riester G,Dettenhofer M., Kang H., Farinelli L., Chen W. and Fischer A. (2010) Altered histone acetylation is associated with age-dependent memory impairment in mice. Science, 328 (5979): 7536.

94. Phizicky EM. and Hopper AK. (2010) tRNA biology charges to the front. Genes and Development, 24 (17):1832-1860.

95. Pritchard CC., Cheng HH. and Tewari M. (2012) MiRNA profiling: approaches and considerations. Nature Review Genetics, 13 (5): 358-69.

96. Qian Z., Gilbert M.E., Colicos M.A., Kandel E.R. and Kuhl D. (1993) Tissueplasminogen activator is induced as an immediate-early gene during seizure, kindling and long-term potentiation. Nature, 361 (6411): 453- 45.

97. Qureshi IA. and Mehler MF. (2013) Epigenetic mechanisms governing the process of neurodegeneration. Molecular Aspects of Medicine, 34 (4): 875-82.

98. Raiborg C. and Stenmark H. (2009) The ESCRT machinery in endosomal sorting of ubiquitylated membrane proteins. Nature, 458 (7237): 445-52.

99. Rajendran L., Honsho M., Zahn TR., Keller P., Geiger KD., Verkade P. and Simons K. (2006) Alzheimer's disease beta-amyloid peptides are released in association with exosomes. Proceeding National Academic Science USA, 103 (30): 11172-7.

100. Raposo G., Nijman HW., Stoorvogel W., Liejendekker R., Harding CV., Melief CJ. and Geuze HJ. (1996) B lymphocytes secrete antigen-presenting vesicles. Journal of Experimental Medicine, 183 (3): 1161-72.

101. Raposo G. and Stoorvogel W. (2013) Extracellular vesicles: exosomes, microvesicles, and friends. Journal of Cellular Biology, 200 (4): 373-83. 
102. Reinhart BJ., Slack FJ., Basson M., Pasquinelli AE., Bettinger JC., Rougvie AE., Horvitz HR. and Ruvkun G. (2000) The 21-nucleotide let-7 RNA regulates developmental timing in Caenorhabditis elegans. Nature, 403 (6772): 901-6.

103. Rogelj B., Hartmann CE., Yeo CH., Hunt SP. and Giese KP. (2003) Contextual fear conditioningregulates the expression of brain- specific small nucleolar RNAs in hippocampus. European Journal of Neuroscience, 18 (11): 3089-96.

104. Sahoo T., del Gaudio D., German JR., Shinawi M., Peters SU., Person RE., Garnica A., Cheung SW. and Beaudet AL. (2008) Prader-Willi phenotype caused by paternal deficiency for the HBII- $85 \mathrm{C} / \mathrm{D}$ box small nucleolar RNA cluster. Nature Genetics, 40 (6): 719-21.

105. Satoh J. (2010) MicroRNAs and their therapeutic potential for human diseases: aberrant microRNA expression in Alzheimer's disease brains. Journal of Pharmacological Science, 114 (3): 269-75.

106. Scheff SW. and Price DA. (2001) Alzheimer's disease-related synapse loss in the cingulate cortex. Journal of Alzheimer's disease, 3 (5): 495-505.

107. Scherzer CR., Eklund AC., Morse LJ., Liao Z., Locascio JJ., Fefer D., Schwarzschild MA., Schlossmacher MG., Hauser MA., Vance JM., Sudarsky LR., Standaert DG., Growdon JH., Jensen RV. and Gullans SR. (2007) Molecular markers of early Parkinson's disease based on gene expression in blood. Proceeding National Academic Science USA, 104 (3): 955-60.

108. Schonrock N., Ke YD., Humphreys D., Staufenbiel M., Ittner LM., Preiss T. and Gotz J. (2010) Neuronal microRNA deregulation in response to Alzheimer's disease amyloidbeta. PLoS One, 5 (6): e11070.

109. Scoville WB. and Milner B. (1957) Loss of recent memory after bilateral hippocampal lesions. Journal of neurology, neurosurgery and psychiatry, 20 (1): 11-21.

110. Shioya M., Obayashi S., Tabunoki H., Arima K., Saito Y., Ishida T. and Satoh J. (2010) Aberrant microRNA expression in the brains of neurodegenerative diseases: miR-29a decreased in Alzheimer disease brains targets neurone navigator 3. Neuropathology applied Neurobiology, 36 (4): 320-30.

111. Shtam TA., Kovalev RA., Varfolomeeva EY., Makarov EM., Kil YV. and Filatov MV. (2013) Exosomes are natural carriers of exogenous siRNA to human cells in vitro. Cell Communication and Signaling, Doi: 10.1186/1478-811X-11-88.

112. Simons M. and Raposo G. (2009) Exosomes - vesicular carriers for intercellular communication. Current Opinion in Cell Bioliogy, 21 (4): 575-81. 
113. Smith PA., Hashimi Al., Girard J., Delay C., and Hebert SS. (2011) In vivo regulation of amyloid precursor protein neuronal splicing by microRNAs. Journal of Neurochemistry, 116 (2): 240-7.

114. Spornraft M., Kirchner B., Pfaffl MW. and Riedmaier I. (2015) Comparison of the miRNome and piRNome of bovine blood and plasma by small RNA sequencing. Biotechnology letters Epub ahead of print.

115. Squire LR., Knowlton B. and Musen G. (1993) The structure and organization of memory. Annual Review in Psychology, 44: 453-95.

116. Stroop JR. (1935) Studies of interference in serial verbal reactions. Journal of Experimental Psychology, 18 (6): 643-662.

117. Stults DM., Killen MW., Pierce HH and Pierce AJ. (2008) Genomic architecture and inheritance of human ribosomal RNA gene clusters. Genome Research, 18 (1): 13-18.

118. Subra C., Laulagnier K., Perret B. and Record M. (2007) Exosome lipidomics unravels lipid sorting at the level of multivesicular bodies. Biochimie, 89 (2): 205-12.

119. Sun D., Zhuang X., Xiang X., Liu Y., Zhang S. and Liu C. (2010) A novel nanoparticle drug delivery system: the anti-inflammatory activity of curcumin is enhanced when encapsulated in exosomes. Molecular Therapy, 18 (9): 1606-14.

120. Szulwach KE., Li X., Smrt RD., Li Y., Luo Y., Lin L., Santistevan NJ., Li W., Zhao X and Jin P. (2010) Cross talk between microRNA and epigenetic regulation in adult neurogenesis. Journal of Cell Biology 189 (1): 127-141.

121.Tan M., Wang S., Song J. and Jia J. (2012) Combination of p53 (ser15) and p21/p21 (thr145) in peripheral blood lymphocytes as potential Alzheimer's disease biomarkers. Neuroscience Letter, 516 (2): 226-31.

122. Thery C., Amigorena S., Raposo G. and Clayton A. (2006) Isolation and characterization of exosomes from cell culture supernatants and biological fluids. Current Protocol in Cell Biology, Doi: 10.1002/0471143030.cb0322s30.

123. Tian Y., Li S., Song J., Ji T., Zhu M., Anderson GJ., Wei J. and Nie G. (2013) A doxorubicin delivery platform using engineered natural membrane vesicle exosomes for targeted tumor therapy. Biomaterials, 35 (7): 2383-90.

124. Trajkovic K., Hsu C., Chiantia S., Rajendran L., Wenzel D., Wieland F., Schwille P., Brugger B. and Simons M. (2008) Ceramide triggers budding of exosome vesicles into multivesicular endosomes. Science, 319 (5867): 1244-7.

125. Tulvig E. (1983) Elements of episodic memory. Cambridge Oxford Univ. Press, UK, $364 \mathrm{Pp}$. 
126. Turchinovich A., Weiz L., Langheinz A. and Burwinkel B. (2011) Characterization of extracellular circulating microRNA. Nucleic Acids Research, 39 (16): 7223-33.

127. Valadi H., Ekstrom K., Bossios A., Sjostrand M., Lee JJ. and Lotvall JO. (2007) Exosome mediated transfer of mrnas and micrornas is a novel mechanism of genetic exchange between cells. Nature cell biology, 9 (6): 654-659.

128. Valadkhan S. (2005) snRNAs as the catalysts of pre-mRNA splicing. Current Opinion in Chemical Biology, 9 (6): 603-608.

129. van der Meel R., Fens MH., Vader P., van Solinge WW., Eniola-Adefeso O. and Schiffelers RM. Extracellular vesicles as drug delivery systems: lessons from the liposome field. Journal of Controlled Release, 10 (195): 72-85.

130. van Niel G., Porto-Carreiro I., Simoes S. and Raposo G. (2006) Exosomes: a common pathway for a specialized function. Journal of Biochemistry, 140 (1): 13-21.

131. Veyrac A., Besnard A., Caboche J., Davis S. and Laroche S. (2014). The transcription factor zif268/egr1, brain plasticity, and memory. Progress in Molecular Biology and Translational Science, 122: 89-129.

132. Vilardo E., Barbato C., Ciotti M., Cogoni C. and Ruberti F. (2010) MicroRNA-101 regulates amyloid precursor protein expression in hippocampal neurons. Journal of Biological Chemistry, 285 (24): 18344-18351.

133. Vlassov AV., Magdaleno S., Setterquist R. and Conrad R. (2012) Exosomes: current knowledge of their composition, biological functions, and diagnostic and therapeutic potentials. Biochemistry and Biophysics Acta., 1820 (7): 940-8.

134. Wahlgren J., Karlson TDL., Brisslert M., Vaziri Sani F., Telemo E. and Sunnerhagen P. (2012) Plasma exosomes can deliver exogenous short interfering RNA to monocytes and lymphocytes. Nucleic Acids Research, 40 (17): e130.

135.Wang G., van der Walt JM., Mayhew G., Li YJ., Züchner S., Scott WK., Martin ER. and Vance JM. (2008) Variation in the miRNA-433 binding site of FGF20 confers risk for Parkinson disease by overexpression of alpha-Synuclein. American Journal of Human Genetics, 82 (2): 283-9.

136. Wang K., Zhang S., Weber J., Baxter D. and Galas DJ. (2010) Export of microRNAs and microRNA-protective protein by mammalian cells. Nucleic Acids Research, 38 (20): 7248-59.

137. Wang WX., Rajeev BW., Stromberg AJ., Ren N., Tang G., Huang Q., Rigoutsos I. and Nelson PT. (2008) The expression of microRNA miR-107 decreases early in Alzheimer's disease and may accelerate disease progression through regulation of beta- 
site amyloid precursor protein-cleaving enzyme 1. Journal of Neuroscience, 28 (5): $1213-1223$.

138. Weber JA., Baxter DH., Zhang S., Huang DY., Huang KH., Lee MJ., Galas DJ. and Wang K. (2010) The microRNA spectrum in 12 body fluids. Clinical Chemistry, 56 (11): 1733-41.

139. Weible AP., Rowland DC., Monaghan CK., Wolfgang NT. and Kentros CG. (2012) Neural correlates of long-term object memory in the mouse anterior cingulate cortex. The Journal of Neuroscience, 32 (16): 5598-5608.

140. Wiemer EA. (2007) The role of microRNAs in cancer: no small matter. European Journal of Cancer, 43 (10): 1529-44.

141. Williams RL. and Urbe S. (2007) The emerging shape of the ESCRT machinery. Nature Review Molecular Cell Biology, 8 (5): 355-68.

142. Winter J, Jung S., Keller S., Gregory RI. and Diederichs S. (2009) Many roads to maturity: microRNA biogenesis pathways and their regulation. Nature Cell Biology., 11 (3): $228-34$.

143.Xin H., Li Y., Buller B., Katakowski M., Zhang Y., Wang X., Shang X., Zhang ZG. And Chopp M. (2012) Exosome-mediated transfer of miR-133b from multipotent mesenchymal stromal cells to neural cells contributes to neurite outgrowth. Stem Cells, 30 (7): 1556-64.

144. Yamada M. (2003) Senile dementia of the neurofibrillary tangle type (tangle-only dementia): neuropathological criteria and clinical guidelines for diagnosis. Neuropathology, 23 (4): 311-17.

145. Yamashita T, Kamada H, Kanasaki S, Maeda Y, Nagano K., Abe Y., Inoue M., Yoshioka Y., Tsutsumi Y., Katayama S., Inoue M. and Tsunoda S. (2013) Epidermal growth factor receptor localized to exosome membranes as a possible biomarker for lung cancer diagnosis. Pharmazie, 68 (12): 969-73.

146.Zhang Y., Liu D., Chen X., Li J., Li L., Bian Z., Sun F., Lu J., Yin Y., Cai X., Sun Q., Wang K., Ba Y., Wang Q., Wang D., Yang J., Liu P., Xu T., Yan Q., Zhang J., Zen K. and Zhang CY. (2010) Secreted monocytic miR-150 enhances targeted endothelial cell migration. Molecular Cell Journal, 39 (1): 133-44.

147.Zhao C., Sun G., Li S. and Shi Y. (2009) A feedback regulatory loop involving microRNA-9 and nuclear receptor TLX in neural stem cell fate determination. Nature Structural Molecular Biology, 16 (4): 365-371. 
148.Zhou H., Pisitkun T., Aponte A., Yuen PS., Hoffert JD., Yasuda H., Hu X., Chawla L., Shen RF., Knepper MA. and Star RA. (2006) Exosomal Fetuin-A identified by proteomics: a novel urinary biomarker for detecting acute kidney injury. Kidney International, 70 (10): 1847-57.

149.Zhuang X., Xiang X., Grizzle W., Sun D., Zhang S., Axtell RC., Ju S., Mu J., Zhang L., Steinman L., Miller D. and Zhang HG. (2011) Treatment of brain inflammatory diseases by delivering exosome encapsulated anti-inflammatory drugs from the nasal region to the brain. Molecular Therapy, 19 (10): 1769-79.

150.Zovoilis A., Agbemenyah HY., Agis-Balboa RC., Stilling RM., Edbauer D., Rao P., Farinelli L., Delalle I., Schmitt A., Falkai P., Bahari-Javan S., Burkhardt S., Sananbenesi F. and Fischer A. (2011) microRNA-34c is a novel target to treat dementias. EMBO Journal, 30 (20): 4299-308. 
Acknowledgements 


\section{Acknowledgements}

I would like to thank my thesis committee members Prof. André Fischer, Prof. Mikael Simons and Prof. Anja Schneider. I thank Anja for supervising the first part of my PhD thesis and giving me the chance to widen my knowledge in the area of microvesicles biology. I would like to thank André for mentoring me during the whole time of my $\mathrm{PhD}$. For their great helps and companionship I would like to thank all the members of Fischer lab and Schneider lab. I thank Gaurav deeply for his help with analyzing my thesis data. I would like to express my sincere appreciation to Susanne not only for help with experiments, but also for her great mental supports. I acknowledge Pooja, Eva and Tea for very helpful advices. I am also grateful to Omid Faridani from Karloniska Institute, Stockholm, Sweden for all fruitful discussions and marvelous scientific guidance through my project. I thank Hendrik, Micha, Magda and Ashish for happy and joyful moments in the office. I would like to extend my gratitude to Stefan Bonn and his lab members especially Vincenzo and Juilo for bioinformatic analyses supports. Kasra Hassani is cordially appreciated for the proofreading of the manuscript of this dissertation. I thank and appreciate my family, my mother and father, my brothers Mohsen and Ramin and friends for all inspiring supports. I also thank CMPB and GGNB programs for making it all possible. I specially acknowledge Prof. Michael Hörner for organizing CMPB PhD seminars and helps.

Last but not least, I would like to thank my best friend and love, Hossein for his companionship and supports during every moment of my life and $\mathrm{PhD}$.

This work was financed by Inge und Fritz Kleekam Alzheimer Forschung Doktorandenstipendium and bridging fund from GGNB and herewith I would like to thank and appreciate them. 
Appendices 
Appendix 1. pCG-H plasmid map

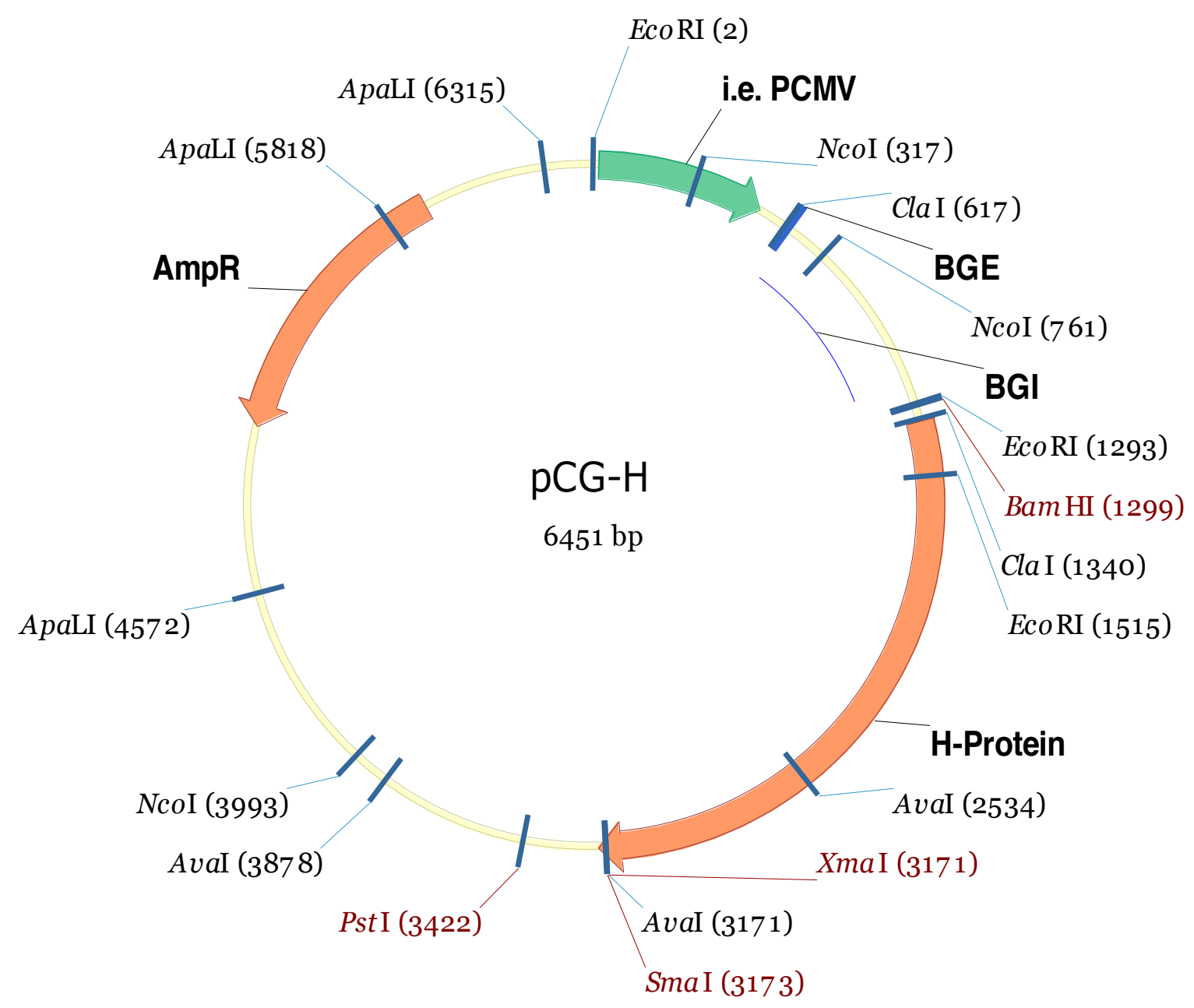


Appendix 2. pCG-F plasmid map

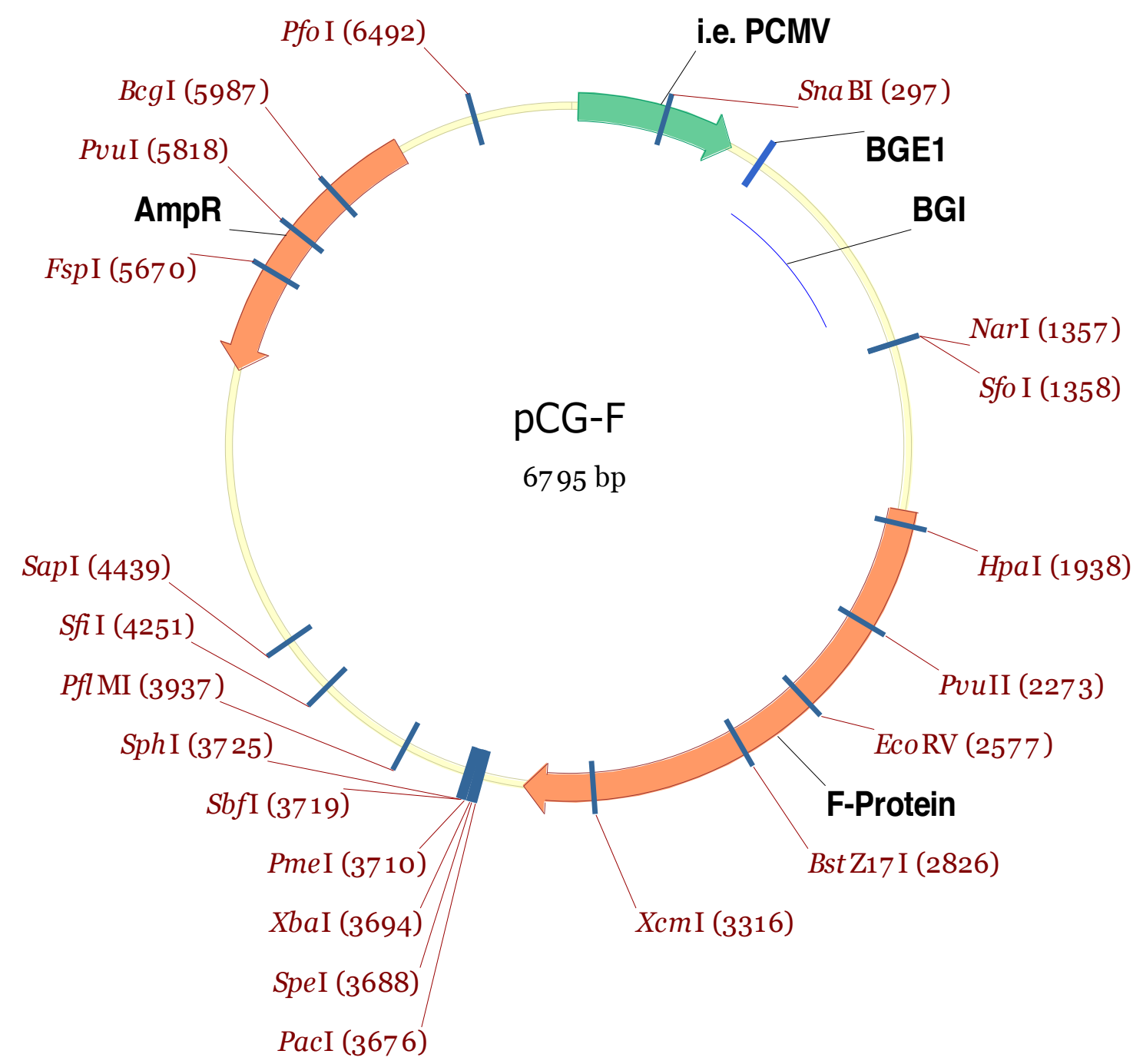


Appendix 3. pCG-Hcd18 plasmid map

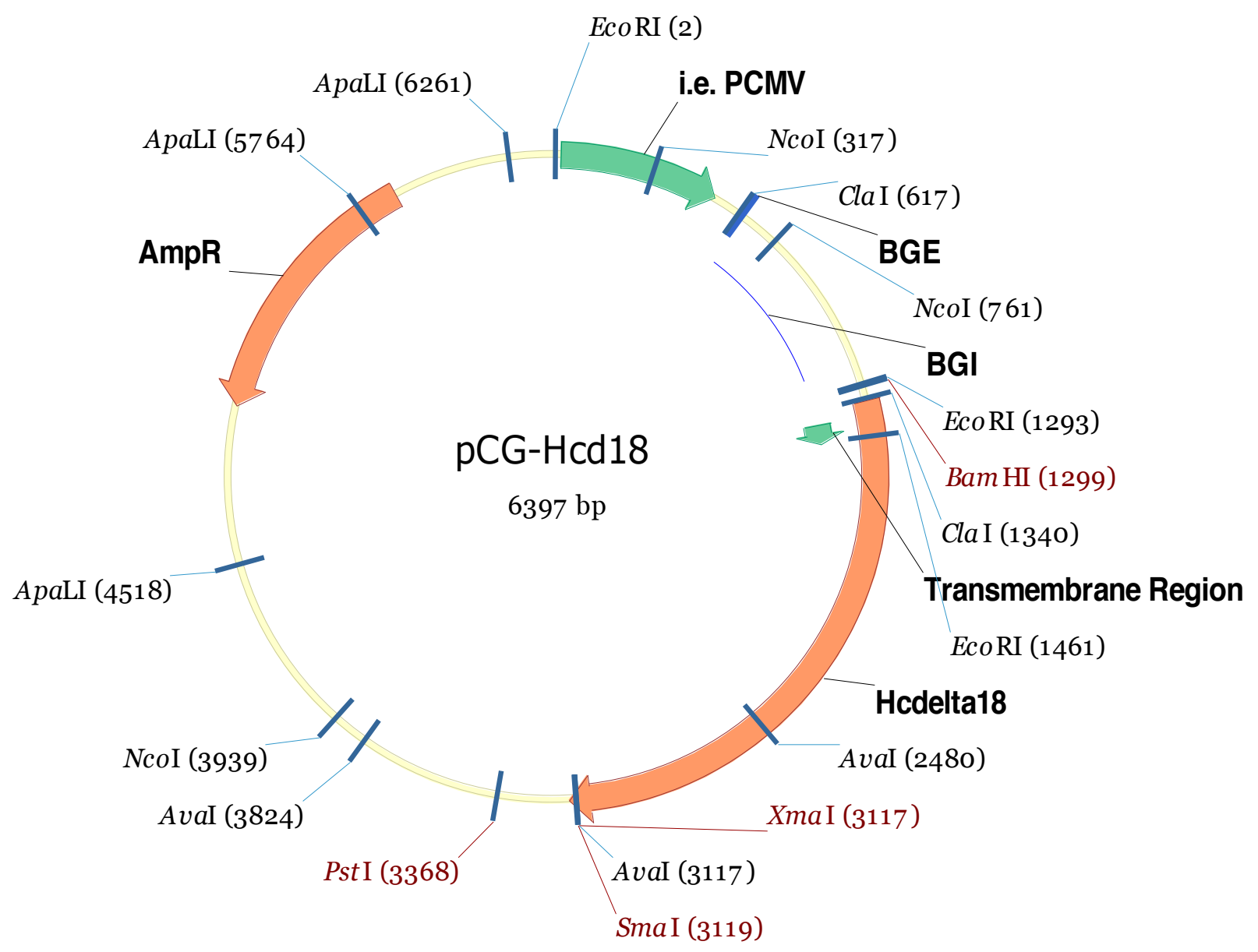


Appendix 4. pCG-Fcd30 plasmid map

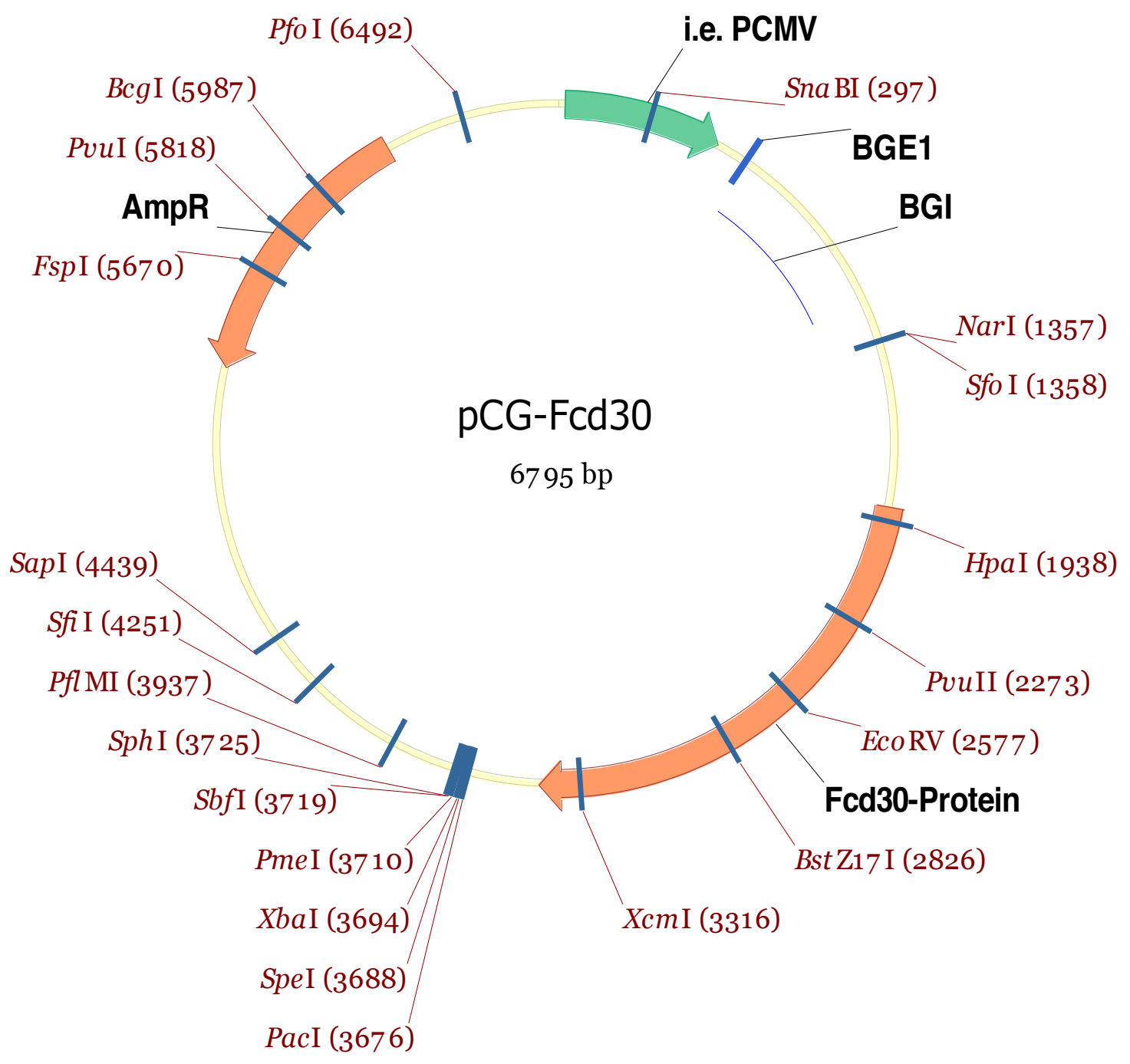




\section{Curriculum Vitae}

\section{Maryam Boroomandi}

Born: 4.8.1984, Marvdasht, Iran

\section{EDUCATIONS}

- $\mathrm{PhD}$ student in program CMPB (Center for Molecular Physiology of the Brain). University of Göttingen, DZNE Institute. Title of $\mathrm{PhD}$ thesis: "Epigenetic modulation in Alzheimer's disease: function of hippocampal miRNAs", supervisor: Prof. Dr. Andre Fischer. Since 1.12.2011.

- $\quad$ MSc student in OEP Biology, University of Bonn. (October 2009-August 2011)

- Title of M.Sc. thesis: "Comparative neuroanatomy of teleostean fish using histochemistry of endogenous enzymes (NADPH-diaphorase, Acetylcholinesterase)", supervisor: Prof. Michael Hofman, Department of Comparative Neuroanatomy. January 2011-August 2011.

- B.Sc. in Biology, Alzahra University, Tehran, Iran, 2002-2006.

\section{AWARDS \& SCHOLARSHIPS}

- Travel award from comparative neuroanatomy department, Bonn University for taking part in $8^{\text {th }}$ World Congress of IBRO, Florence, Italy, July 2011.

- Full PhD scholarship from "Inge und Fritz Kleekam Alzheimer Stiftung", December 2011-February 2015.

- Three months PhD stipend from "Göttingen Graduate School for Neurosciences, Biophysics, and Molecular Biosciences. (GGNB)” March-May 2015.

\section{PUBLICATIONS-PRESENTATIONS}

- Boroomandi, M. et al. A small-non-coding RNAome database of the aging brain. (in preparation, to be submitted in Neuroepigenetics).

- Boroomandi, M \& Fischer, A. 2014 miRNA profiles in the brain and blood as biomarker for aging-related cognitive disorders. Poster presentation in The Aging Brain summer school, Göttingen, Germany, September 2014

- Boroomandi, M. \& Hofmann, M. H. 2011. A comparative neuroanatomical study of hypothalamus in Cichlids and other teleosts. Poster presentation in $8^{\text {th }}$ World Congress of IBRO, Florence, Italy, July 2011.

- Boroomandi, M. \& Hofmann, M.H. 2011. Regional distribution of NADPH-diaphorase and acetylcholine-esterase activity in the hypothalamus of the Cichlid Thorichthys meeki. Poster presentation in $22^{\text {nd }}$ Neurobiologischer Doktoranden Workshop (Neuro-dowo), Bonn, Germany, 2011. 